UNIVERSIDADE DE SÃO PAULO

FACULDADE DE MEDICINA DE RIBEIRÃO PRETO

\author{
GABRIELA MARQUES
}

Impacto do aleitamento materno exclusivo no sobrepeso e obesidade em filhos de mães com excesso de peso 


\section{GABRIELA MARQUES}

Impacto do aleitamento materno exclusivo no sobrepeso e obesidade em filhos de mães com excesso de peso

\section{Versão Original}

Dissertação de Mestrado apresentada à Faculdade de Medicina de Ribeirão Preto da Universidade de São Paulo para obtenção do título de Mestre em Ciências.

Área de concentração: Saúde da Criança e do Adolescente.

Orientador: Prof. Dr. Ivan Savioli Ferraz.

Ribeirão Preto 
Autorizo a reprodução e divulgação total ou parcial deste trabalho, por qualquer meio convencional ou eletrônico, para fins de estudo e pesquisa, desde que citada a fonte.

Marques, Gabriela

Impacto do aleitamento materno exclusivo no sobrepeso e obesidade em filhos de mães com excesso de peso, 2020.

116p. : il. ; $30 \mathrm{~cm}$.

Dissertação de Mestrado, apresentada à Faculdade de Medicina de Ribeirão Preto/USP. Área de concentração: Saúde da Criança e do Adolescente.

Orientador: Savioli Ferraz, Ivan.

1. Aleitamento materno exclusivo. 2. Relações mãe-filho. 3. Nutrição do lactente. 4. Nutrição materna. 
Nome: MARQUES, Gabriela

Título: Impacto do aleitamento materno exclusivo no sobrepeso e obesidade em filhos de mães com excesso de peso

Dissertação apresentada à Faculdade de Medicina de Ribeirão Preto da Universidade de São Paulo para obtenção do título de Mestre em Ciências.

Aprovado em:

Banca Examinadora

Prof. Dr.

Instituição:

Julgamento:

Prof. Dr.

Instituição:

Julgamento:

Prof. Dr.

Instituição:

Julgamento: 


\section{AGRADECIMENTOS}

Agradeço ao meu orientador, Prof. Dr. Ivan Savioli Ferraz, pelos ensinamentos, paciência e apoio ao longo dessa jornada.

À Profa. Dra. Viviane Cunha Cardoso e Profa. Dra. Maria Conceição Pereira Saraiva por todo auxílio prestado para a realização deste trabalho.

A todos os professores, funcionários e colegas do Núcleo de Estudos da Saúde da Criança e Adolescente (NESCA), por se envolveram no desenvolvimento de um projeto tão majestoso como o BRISA (Coorte Brasileira de Nascimentos de Ribeirão Preto e São Luís).

Ao Dr. Davi Casale Aragon, pelas análises estatísticas.

Agradeço também aos meus pais, pelo inestimável cuidado e dedicação de sempre.

À minha irmã, pela amizade e proteção.

Por fim, agradeço à Deus, por ser o grande responsável por tudo.

A todos vocês, meus sinceros agradecimentos.

O presente trabalho foi realizado com apoio da Coordenação de Aperfeiçoamento de Pessoal de Nível Superior - Brasil (CAPES) - Código de Financiamento 001. 


\section{RESUMO}

\section{MARQUES, Gabriela. Impacto do aleitamento materno exclusivo no sobrepeso e obesidade}

em filhos de mães com excesso de peso. 2020. 116 f. Dissertação de Mestrado - Faculdade de Medicina de Ribeirão Preto, Universidade de São Paulo, Ribeirão Preto, 2020.

As taxas de sobrepeso e obesidade vêm crescendo em todo mundo. A amamentação diminui o risco de desenvolvimento de excesso de peso na infância e adolescência; entretanto, a obesidade materna é associada com um menor tempo de aleitamento materno, intenção de amamentação por períodos mais curtos, menor propensão em seu início e desmame precoce. O principal objetivo deste estudo foi de verificar o risco para o desenvolvimento de excesso de peso em filhos de mães com sobrepeso e obesidade entre o primeiro e terceiro ano de vida segundo a duração do aleitamento materno exclusivo (AME). O presente estudo está inserido numa coorte de nascimentos, composto de três etapas de avaliação: pré-natal $\left(20^{\mathrm{a}}\right.$ a $25^{\mathrm{a}}$ semanas de gestação), nascimento e seguimento (entre o primeiro e terceiro ano de vida). Finalizaram as três etapas do estudo, 1.069 pares mães-filhos. Obteve-se informações sobre características socioeconômicas, dados antropométricos das mães e dos lactentes, tipo de parto, peso ao nascer, tempo de exposição a outros alimentos que não o leite materno e duração do AME. 58,1\% das mães e 7,5\% dos lactentes apresentaram excesso de peso no seguimento. A média na duração do AME foi de 3,7 meses e a mediana, em 4,0 meses ( $D P=2,25)$. Entre os filhos de mães com excesso de peso, não se observaram diferenças entre o RR das variáveis selecionadas para o excesso de peso entre os lactentes que estiveram em AME por um período mais prolongado $(\geq$ 4,0 meses) quando comparados aos que foram amamentados por menor tempo. $\mathrm{Na}$ análise global, sem o ajuste para o excesso de peso materno, mães com sobrepeso e obesidade apresentaram risco relativo (RR) de 1,54 (IC95\%:1,22-1,94) de terem filhos com excesso de peso; após ajuste do IMC materno e demais variáveis não se observaram diferenças entre o RR para o excesso de peso entre lactentes que estiveram em $\mathrm{AME} \geq 4,0$ meses e naquelas que estiveram por um período inferior. Neste estudo, não foram observadas diferenças entre o risco de desenvolvimento de excesso de peso em filhos de mães com sobrepeso e obesidade segundo a duração do AME.

Palavras-chave: Aleitamento materno. Relações mãe-filho. Nutrição do lactente. Nutrição materna. 


\begin{abstract}
MARQUES, Gabriela. Impact of exclusive breastfeeding on overweight and obesity in children of overweight mothers. 2020.116 p. Master's thesis - Ribeirão Preto Medical School, University of São Paulo, Ribeirão Preto, 2020.

Rates of overweight and obesity have been increasing worldwide. Breastfeeding reduces the risk of developing overweight in childhood and adolescence; however, maternal obesity is associated with shorter breastfeeding time, intention to breastfeed for shorter periods, less propensity to start and early weaning. The main objective of this study was to verify the risk for the development of overweight in children of mothers with overweight and obesity between the first and third year of life according to the duration of exclusive breastfeeding (EBF). The present study is part of a birth cohort, composed of three stages of assessment: prenatal care (20 to 25 weeks of gestation), birth and follow-up (between the first and third years of life). The three stages of the study were completed by 1.069 mother-child pairs. Information on socioeconomic characteristics, anthropometric data of mothers and infants, type of delivery, birth weight, time of exposure to foods other than breast milk and duration of EBF were obtained. $58,1 \%$ of mothers and 7,5\% of infants were overweight in the follow-up. The average duration of $\mathrm{EBF}$ was 3,7 months and the median was 4,0 months ( $\mathrm{SD}=2,25)$. Among the children of overweight mothers, there were no differences between the RR of the variables selected for overweight among infants who were in EBF for a longer period ( $\geq 4.0$ months) when compared to those who were in EBF for shorter time. In the global analysis, without adjusting for maternal overweight, overweight and obese mothers had a relative risk (RR) of 1,54 (95\% CI: 1,22-1,94) of having overweight children; after adjusting the maternal BMI and other variables, there were no differences between the RR for excess weight between children who were in $\mathrm{EBF} \geq 4,0$ months and those who were for a shorter period. In this study, there were no differences between the risk of developing overweight in children of mothers with overweight and obesity according to the duration of EBF.
\end{abstract}

Keywords: Breastfeeding. Mother-child relations. Childhood nutrition. Maternal nutrition. 


\section{LISTA DE TABELAS E FIGURAS}

Figura 1 - Organograma da coorte do pré-natal do projeto BRISA de Ribeiro Preto (SP) em seus três momentos de avaliação

Tabela 1 - Classificação do estado nutricional definido pelo SISVAN para o indicador antropométrico de IMC/Idade segundo as curvas da OMS (2006) para menores de 5 anos

Tabela 2 - Classificação do estado nutricional segundo IMC para adultos 43

Figura 2 - Gráfico acíclico direcionado (DAG) proposto para identificação e seleção das variáveis integrantes do modelo de análise do estudo "Impacto do aleitamento materno exclusivo no sobrepeso e obesidade em filhos de mães com excesso de peso".

Tabela 3 - Situação socioeconômica das mães pertencentes ao estudo "Impacto do aleitamento materno exclusivo no sobrepeso e obesidade em filhos de mães com excesso de peso" (Ribeirão Preto, 20102013)

Tabela 4 - Fatores relacionados à gestação de mães pertencentes ao estudo "Impacto do aleitamento materno exclusivo no sobrepeso e obesidade em filhos de mães com excesso de peso" (Ribeirão Preto, 2010-2013) 48

Tabela 5 - Características antropométricas de mães pertencentes ao estudo "Impacto do aleitamento materno exclusivo no sobrepeso e obesidade em filhos de mães com excesso de peso" (Ribeirão Preto, 2010-2013)

Tabela 6 - Ganho de peso durante a gestação de acordo com o IMC pré-gestacional e recomendação da IOM antropométricas de mães pertencentes ao estudo "Impacto do aleitamento materno exclusivo no sobrepeso e obesidade em filhos de mães com excesso de peso" (Ribeirão Preto, 2010-2013)

Tabela 7 - Estado nutricional pelo IMC no período entre um e três anos após o parto de mães pertencentes ao estudo "Impacto do aleitamento materno exclusivo no sobrepeso e obesidade em filhos de mães com excesso de peso" (Ribeirão Preto, 2010-2013)

Tabela 8 - Evolução do estado materno pelo IMC entre o período pré-gestacional e um e três anos após o parto de mães pertencentes ao estudo "Impacto do aleitamento materno exclusivo no sobrepeso e obesidade em filhos de mães com excesso de peso” (Ribeirão Preto, 2010-2013)

Tabela 9 - Evolução do estado materno pelo IMC do final da gestação ao seguimento das mulheres pertencentes ao estudo "Impacto do aleitamento materno exclusivo no sobrepeso e obesidade em filhos de mães com excesso de peso" (Ribeirão Preto, 2010-2013)

Tabela 10 - Características relacionados à residência familiar de mães pertencentes ao estudo "Impacto do aleitamento materno exclusivo no sobrepeso e obesidade em filhos de mães com excesso de peso" (Ribeirão Preto, 2010-2013)

Tabela 11 - Características das crianças entre um e três anos de idade pertencentes ao estudo "Impacto do aleitamento materno exclusivo no sobrepeso e obesidade em filhos de mães com excesso de peso" (Ribeirão Preto, 2010-2013) 
Tabela 12 - Características antropométricas das crianças entre um e três anos de idade pertencentes ao estudo "Impacto do aleitamento materno exclusivo no sobrepeso e obesidade em filhos de mães com excesso de peso" (Ribeirão Preto, 2010-2013)

Tabela 13 - Estado nutricional no seguimento das crianças entre um e três anos de idade pertencentes ao estudo "Impacto do aleitamento materno exclusivo no sobrepeso e obesidade em filhos de mães com excesso de peso" (Ribeirão Preto, 2010-2013)

Tabela 14 - Rotina alimentar das crianças entre um e três anos de idade pertencentes ao estudo "Impacto do aleitamento materno exclusivo no sobrepeso e obesidade em filhos de mães com excesso de peso" (Ribeirão Preto, 2010-2013)

Tabela 15 - Duração da amamentação de acordo com o estado nutricional de mães pertencentes ao estudo "Impacto do aleitamento materno exclusivo no sobrepeso e obesidade em filhos de mães com excesso de peso" no período entre um e três anos após o parto (Ribeirão Preto, 2010-2013)

Tabela 16 - Riscos relativos brutos e seus respectivos intervalos de confiança para as variáveis de interesse em relação ao estado nutricional das crianças entre um e três anos de idade pertencentes ao estudo "Impacto do aleitamento materno exclusivo no sobrepeso e obesidade em filhos de mães com excesso de peso" (Ribeirão Preto, 2010-2013)

Tabela 17 - Riscos relativos ajustados e seus respectivos intervalos de confiança para as variáveis de interesse em relação ao estado nutricional das crianças entre um e três anos de idade pertencentes ao estudo "Impacto do aleitamento materno exclusivo no sobrepeso e obesidade em filhos de mães com excesso de peso" (Ribeirão Preto, 2010-2013)

Tabela 18 - Riscos relativos brutos e seus respectivos intervalos de confiança para as variáveis de interesse em relação ao estado nutricional das crianças entre um e três anos de idade pertencentes ao estudo "Impacto do aleitamento materno exclusivo no sobrepeso e obesidade em filhos de mães com excesso de peso" (Ribeirão Preto, 2010-2013).

Tabela 19 - Riscos relativos ajustados e seus respectivos intervalos de confiança para as variáveis de interesse em relação ao estado nutricional das crianças entre um e três anos de idade pertencentes ao estudo "Impacto do aleitamento materno exclusivo no sobrepeso e obesidade em filhos de mães com excesso de peso" (Ribeirão Preto, 2010-2013).

Tabela 20 - Modelo global dos riscos relativos brutos e seus respectivos intervalos de confiança para as variáveis de interesse em relação ao estado nutricional das crianças entre um e três anos de idade pertencentes ao estudo "Impacto do aleitamento materno exclusivo no sobrepeso e obesidade em filhos de mães com excesso de peso” (Ribeirão Preto, 2010-2013) 61

Tabela 21 - Modelo global dos riscos relativos brutos e seus respectivos intervalos de confiança para as variáveis de interesse em relação ao estado nutricional das crianças entre um e três anos de idade pertencentes ao estudo "Impacto do aleitamento materno exclusivo no sobrepeso e obesidade em filhos de mães com excesso de peso" (Ribeirão Preto, 2010-2013)

Tabela 22 - Modelo global dos riscos relativos brutos e seus respectivos intervalos de confiança para as variáveis de interesse em relação ao estado nutricional das crianças entre um e três anos de idade pertencentes ao estudo "Impacto do aleitamento materno exclusivo no sobrepeso e obesidade em filhos de mães com excesso de peso" (Ribeirão Preto, 2010-2013) 
Tabela 23 - Modelo global dos riscos relativos ajustados e seus respectivos intervalos de confiança para as variáveis de interesse em relação ao estado nutricional das crianças entre um e três anos de idade pertencentes ao estudo "Impacto do aleitamento materno exclusivo no sobrepeso e obesidade em filhos de mães com excesso de peso" (Ribeirão Preto, 2010-2013) 


\section{LISTA ABREVIATURAS E SIGLAS}

AM

AME

OMS

SBP

IIPPAM

PNDS

PNS

SISVAN

IMC

$\mathrm{P} / \mathrm{I}$

$\mathrm{E} / \mathrm{I}$

$\mathrm{C} / \mathrm{I}$

$\mathrm{P} / \mathrm{C}$

$\mathrm{P} / \mathrm{E}$

$\mathrm{IMC} / \mathrm{I}$

FAO

EAN

$\mathrm{DOHaD}$

DCNT

ESF

TCLE

CEP

CAPES

HCFMRP-USP
Aleitamento materno

Aleitamento materno exclusivo

Organização Mundial de Saúde

Sociedade Brasileira de Pediatria

II Pesquisa de Prevalência de Aleitamento Materno nas Capitais

Brasileiras e Distrito Federal

Pesquisa Nacional de Demografia e Saúde da Mulher e da Criança

Pesquisa Nacional de Saúde

Sistema de Vigilância Alimentar e Nutricional

Índice de Massa Corporal

Peso por idade

Estatura por idade

Comprimento por idade

Peso por comprimento

Peso por estatura

Índice de Massa Corporal por idade

Organização das Nações Unidas para Alimentação e Agricultura

Educação alimentar e nutricional

Origem Desenvolvimentista das Doenças e da Saúde

Doenças crônicas não transmissíveis

Estratégias de Saúde da Família

Termo de Consentimento Livre e Esclarecido

Comitê de Ética em Pesquisa

Coordenação de Aperfeiçoamento de Pessoal de Nível Superior

Hospital das Clínicas da Faculdade de Medicina de Ribeirão Preto da

Universidade de São Paulo 


\section{SUMÁRIO}

I INTRODUÇÃ

I.1 - O aleitamento materno e suas dimensões: do social ao biológico ........................ 12

I.1.1 Definições sobre o tema .................................................................. 12

I.1.2 - Contexto histórico: o social e o cultural ............................................. 12

I.1.2.1 - A evolução da amamentação pelo mundo ............................... 12

I.1.2.2 - A amamentação no Brasil ....................................................... 16

I.1.3 - A importância da amamentação para a criança e o seu núcleo social .... 20

I.1.3.1 - Aspectos nutricionais ......................................................... 20

I.1.3.2 - Vantagens do aleitamento materno à saúde materno-infantil .. 20

I.1.3.3 - Vantagens socioeconômicas do aleitamento materno ............. 22

I.1.3.4 - Prevalências do aleitamento materno no Brasil ....................... 23

I. 2 - O estado nutricional da criança na primeira infância .......................................... 24

I. 2.1 - Avaliação antropométrica do estado nutricional da criança .................. 24

I. 2.2 - Panoramas do excesso de peso na infância no Brasil e no mundo ........ 26

I. 2.3 - Fatores de risco: o impacto do ambiente obesogênico ......................... 27

I. 3 - Estado nutricional materno, aleitamento materno e excesso de peso na infância 29

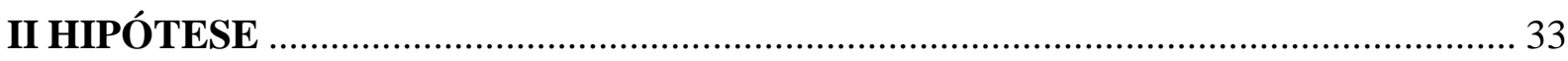

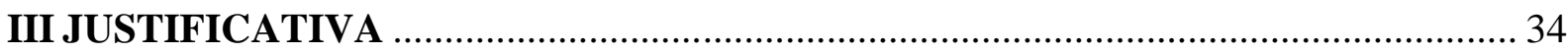

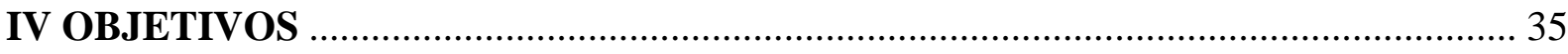

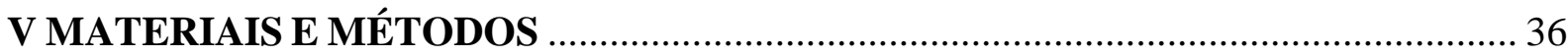

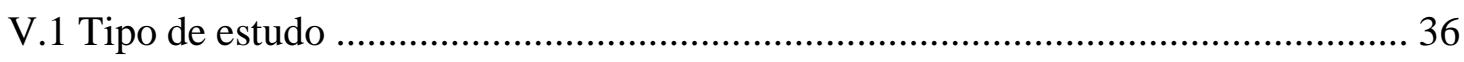

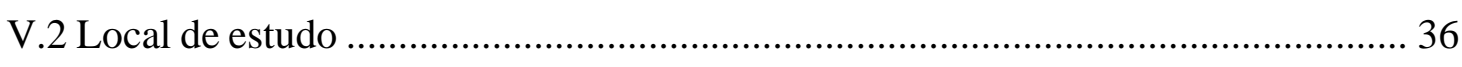

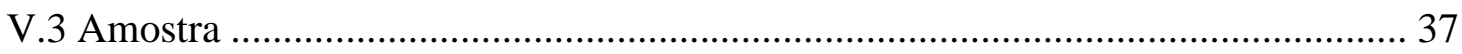

V.4 Processo de obtenção da amostra ................................................................... 38

V.5 Critérios de inclusão ........................................................................................... 39

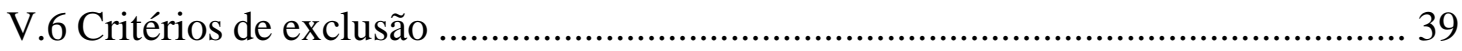

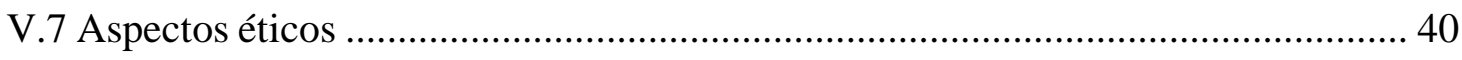

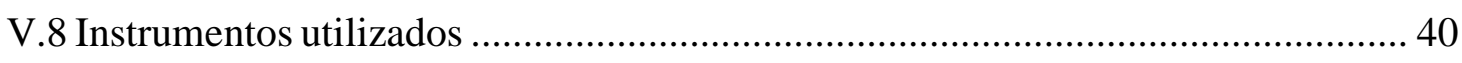

V.9 Organização do banco de dados ..................................................................... 41

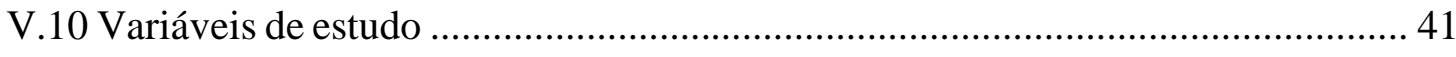

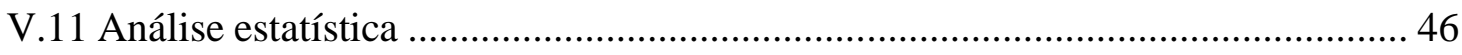

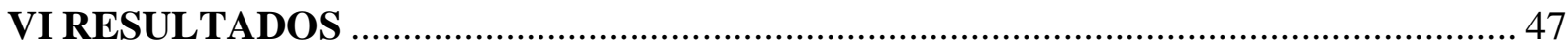


VII DISCUSSÃO

65

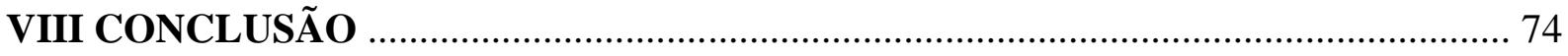

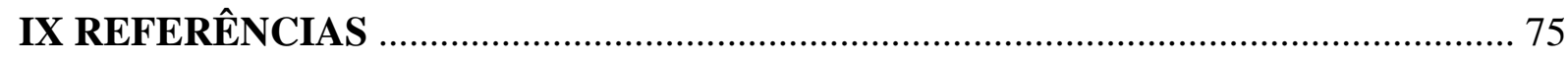

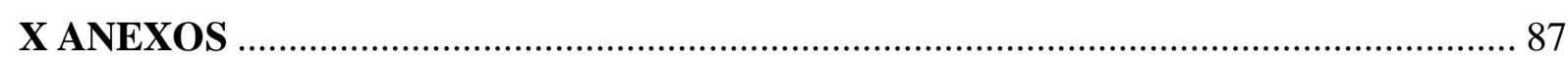




\section{I - INTRODUÇÃO}

\section{1 - O aleitamento materno e suas dimensões: do social ao biológico}

\section{1.1 - Definições sobre o tema}

De acordo com os conceitos adotadas pela Organização Mundial da Saúde (OMS), o aleitamento materno (AM) pode ser classificado de quatro formas distintas. Na primeira delas, conhecida como aleitamento materno exclusivo (AME), as necessidades nutricionais do lactente são atendidas completamente apenas com a ingestão do leite materno até os seis meses de idade (BRASIL, 2015). Ao final do sexto mês de vida, a maioria das crianças atinge um estágio de desenvolvimento motor e neurológico que possibilitam a mastigação, deglutição, digestão e excreção, habilitando-os a receber alimentos de consistência sólida e semissólida com o objetivo de complementar o leite materno (MONTE; GIUGLIANI, 2004). Assim, a criança deve iniciar a introdução da alimentação complementar que, juntamente com o leite materno, irá atender e garantir as suas novas demandas nutricionais (aleitamento materno complementado).

O AM também pode ser classificado em aleitamento materno predominante, ou seja, há predominância do leite materno na rotina alimentar da criança, porém com o consumo concomitante de água e/ou outras bebidas (como os sucos e chás, por exemplo). Já o termo aleitamento materno misto ou parcial é definido quando o lactente recebe tanto o leite materno quanto outros tipos de leite (como as fórmulas infantis industrializadas e o leite de vaca, entre outros) (BRASIL, 2015).

Mostra-se bastante reconhecida na literatura científica e difundida pela OMS, Ministério da Saúde e Sociedade Brasileira de Pediatria (SBP), a importância da continuidade da amamentação. Esses órgãos endossam que o aleitamento materno deve seguir até, pelo menos, os dois anos de idade (BRASIL, 2015; SPB, 2012).

\section{I.1.2 - Contexto histórico: o social e o cultural}

\section{I.1.2.1 - A evolução da amamentação pelo mundo}

Desde os primórdios, o ser humano sempre se mostrou dependente do leite materno para a garantia de sua sobrevivência no início da vida. Embora não se saiba com clareza sobre os 
hábitos relacionados à amamentação na Era Pré-Histórica, os primeiros delineamentos sobre o ato de amamentar são frequentemente baseados em suposições abrangendo outros primatas. Assim como eles, acredita-se que as crianças fossem amamentadas sob demanda por vários anos, geralmente em torno dos três aos cinco anos, isto é, idade em que ela adquiria capacidade de buscar o seu próprio alimento (PAPASTAVROU et al., 2015).

Com o estilo de vida envolvendo a caça e a sobrevivência, muitas vezes a mãe não conseguia amamentar e, consequentemente, a criança vinha a falecer a menos que outra mulher a substituísse. No período Neolítico, com o desenvolvimento da agricultura e a domesticação dos animais, houve uma maior oferta de alimentos e muitas crianças, na incapacidade de receber o leite humano, passaram a se alimentar com o leite animal que era ofertado através de recipientes ou mamados diretamente dos mesmos (CASTILHO; BARROS FILHO, 2010).

Nas civilizações da Antiguidade - babilônicos, egípcios, gregos e romanos -, o leite materno era tido como um alimento sagrado e vital para a saúde e sobrevivência da criança. A mãe deveria assumir o papel de amamentar, porém, na impossibilidade de atender às necessidades do filho ou por escolha daquelas pertencentes à alta sociedade da época (outorgando, inclusive, um símbolo de status para a família contratante), tais povos empregavam mulheres destinadas ao ato: as intituladas amas de leite; dentre estas geralmente se encontravam as escravas ou àquelas que adotavam a prática como profissão (BITAR, 1995).

As nutrizes obtinham privilégios com o seu novo papel social; todavia, deveriam assumir condutas de comportamentos ditadas pelos seus empregadores, como a adoção de dietas alimentares específicas, determinadas condições de higiene, cuidado pessoal e de relacionamento sexual, por exemplo (DAVIES; O’HARE, 2004). Cabe destacar que, dentro dessa cultura, pensava-se que a mulher não conseguiria cumprir, de forma concomitante, o seu dever como mulher e de mãe (DAMASCENO, 2011).

O exercício das amas de leite pode ser encontrado no Código de Hamurabi, famoso conjunto de leis oriundos da antiga Mesopotâmia. Escrito entre 1800 e 1700 a.C., há registro de regulamentações sobre a atividade das amas de leite, bem como sobre a sua execução através de contrato de trabalho e o pagamento em dinheiro (BARBIERI; COUTO, 2012; ARANTES, 1995). Com o estabelecimento de acordos entre a família e essas mulheres, muitas crianças eram levadas para as casas das nutrizes e só retornavam tempos depois para os seus lares originais (CASTILHO; BARROS FILHO, 2009).

A atividade e a existência das amas de leite tornaram-se cada vez mais popular entre a classe aristocrática da Antiguidade; suas implicações podem ser observadas nas passagens de Aristóteles (entre 384 e 322 a.C) e Plutarco (por volta de 46 e 120 d.C) que argumentavam, em 
seus discursos morais em favor da amamentação, ser o aleitamento um dever materno, além de também estimular o fortalecimento dos laços afetivos entre a díade.

Sobre os vínculos construídos através da amamentação, a relação entre a criança e a ama era muito valorizada culturalmente. A mulher era, de fato, a grande protagonista para o crescimento forte e saudável da criança, características imprescindíveis nas questões ideológicas dos povos gregos (GAMBOA, 2008). Já para os romanos, embora houvesse o estímulo da amamentação materna, este era relacionado à precocidade do envelhecimento da mulher, uma justificativa considerada plausível para a mãe da alta sociedade na contratação das amas. De acordo com os registros, as crianças eram amamentadas na época até os dois ou três anos de idade (CASTILHO; BARROS FILHO, 2009; VINAGRE et al., 2001).

O leite materno foi, durante certo tempo, relacionado com as características da nutriz. Acreditava-se que a mulher que estava amamentando pudesse transmitir suas qualidades à criança através do próprio leite. Com base nessa crença, a recomendação era de cautela na escolha da ama de leite, observando-se ainda outras características da mulher, como a idade, saúde e temperamento (CASTILHO; BARROS FILHO, 2009). Na Grécia antiga, por exemplo, tais relatos podem ser encontrados em contos mitológicos, como a do filho de Zeus, Héracles, com a mortal Alcmena, amamentado no seio de sua esposa, a deusa Hera, visando a transmissão da imortalidade e das demais qualidades divinas ao bebê (RIBEIRO, 2012).

No Império Romano e nas colônias gregas, o costume envolvendo as amas de leite foi cada vez mais sendo espalhado e introduzido na Europa. Muitos acordos foram realizados entre os nobres e as nutrizes para que elas amamentassem os bebês indesejados que eram abandonados pelas suas mães, uma maneira muito mais econômica de adquirir escravos. Com a expansão dessa cultura de amamentação, surgem publicações com orientações sobre os atributos ideais de uma ama de leite, suas regulamentações e os critérios para avaliação da qualidade do leite humano. Nesse contexto, a criança deveria ser amamentada exclusivamente até os 6 meses de idade, com desmame gradual a partir do terceiro semestre (ALMEIDA, 1999).

$\mathrm{Na}$ ausência da possibilidade da criança em ser amamentada por uma mulher, esta era colocada para mamar diretamente no animal ou recebia o leite através de utensílios específicos utilizados para armazenamento. Muitas crianças eram alimentadas por leite animal e ovos antes do desmame, já as frutas e os legumes eram introduzidos logo depois. Sobre os substitutos do leite materno na história da civilização romana, a lenda mitológica de Rômulo e Remo, fundadores de Roma e que foram amamentados por uma loba, tornou-se uma das principais referências históricas até hoje sobre o assunto (KOUTSOUKOS, 2009; JUREMA; MALFATTI, 2009). 
Entre os povos palestinos, desde 2.000 a.C, a amamentação era vista como uma obrigação religiosa que proporcionava proteção contra várias doenças no lactente. A duração mínima era de seis meses, com consecutiva introdução de alimentos sólidos e seguimento até uma nova gravidez materna. Defendia-se na cultura islâmica a continuidade da alimentação do ambiente intrauterino para o extrauterino, ou seja, da placenta da gestante e, logo depois, através do seu próprio leite que deveria ser oferecido até os dois anos de idade (ALMEIDA, 1999).

Na Idade Média, surgem contestações relativas às amas de leite particularmente pela crença envolvendo a passagem das características de quem amamentava para quem era amamentado. Nesse período, por volta do século XII, o pensamento vigente era de indiferença em relação à criança, sendo elas retratadas como adultos em tamanho reduzido; tal concepção só foi modificada ao final do século XIII com o reconhecimento da criança pela sua própria morfologia infantil (BASI; MACHADO, 2005).

O Renascimento, centrado numa visão muito mais humanística, refletiu na invenção da imprensa e no impulsionamento da indústria editorial, trazendo importantes produções na área pediátrica e repercutindo no questionamento sobre o papel real da amamentação (CASTILHO; BARROS FILHO, 2009). A descoberta da infância tornou-se notável no atual momento, sobretudo ao final do século XVI; registros históricos da época demonstravam o hábito da amamentação por grande parte das mães burguesas, entretanto, com o advento do século XVII, o emprego das amas de leite foi se alastrando entre a elite europeia (VINAGRE et al., 2001).

Na França, entre os séculos XIII e XIX, houve a propagação do aleitamento mercenário; nutrizes de baixo nível social, além de amamentar os seus próprios filhos, também eram contratadas para amamentar os filhos de mães das classes média e alta. Apesar de muitas mulheres possuírem uma prole grande, a mortalidade infantil era bastante alta (DIXON, 1988).

Além de se constituir em um meio de sobrevivência da família de baixos recursos econômicos, o aleitamento também representava uma forma de fortalecimento do poder masculino na época. Os maridos, apesar de serem considerados como os maiores prejudicados pelo desgaste físico do cônjuge com os seus afazeres, recebiam os pagamentos pelos serviços da esposa e, muitas vezes, eles próprios estabeleciam os contratos delas como amas de leite (GAMBOA, 2008). O exercício da profissão se alastrou no país no século XVII, culminando com a criação de leis para a proteção dos bebês e pela garantia das remunerações pelo trabalho realizado (DIXON, 1988).

Entre os séculos XVII e XVIII, a cultura envolvendo as amas de leite ainda era bastante presente. A principal mudança deu-se na aquisição de privilégios, como, por exemplo, a da estadia na casa da família da criança a ser amamentada, sobretudo devido ao aumento das taxas 
de mortalidade observadas quando os lactentes viviam nas casas das amas. A mortalidade infantil atingia valores muito significantes na época, tanto entre as crianças que não tinham a opção de uma ama e que, consequentemente, eram desmamadas, como daquelas que eram amamentadas por essas mulheres. Assim, foram instaurados na Inglaterra alguns cuidados sobre a alimentação infantil, como a proibição do consumo de misturas consideradas não naturais até o surgimento das primeiras dentições e a recomendação sobre a necessidade apenas do leite materno nos primeiros dez e doze meses de vida (VINAGRE et al., 2001).

Os períodos posteriores foram sendo marcados por ações em favor do aleitamento materno e pela mudança de concepção em relação ao colostro, considerado anteriormente como um alimento de qualidade ruim. No final dessa época, estavam disponíveis quatro formas de alimentação da criança: o aleitamento materno, a amamentação pela ama de leite, o leite animal e as papas (água quente e farinha ou pão embebido em água ou leite e ovo) e as panadas (caldo de cereais) (BASI; MACHADO, 2005; PAPASTAVROU, 2015).

Considera-se que o descobrimento da América foi um dos pontos chaves na valorização do aleitamento materno e no enfraquecimento das amas. Na chegada ao novo continente, os europeus foram expostos a uma cultura que envolvia uma amamentação materna a longo prazo, sendo a desnutrição infantil, que assolava a Europa, um problema não tão frequente no novo continente (GAMBOA, 2008; CASTILHO; BARROS FILHO, 2010; BOSI; MACHADO, 2005).

A importação e exportação de algumas doenças entre os continentes impulsionaram a crença de transmissão de enfermidades para a criança através do leite humano, colocando as amas de leite em situação de insegurança por parte dos seus empregadores quanto às doenças adquiridas por elas. Ainda, vale também destacar a disseminação que vinha ocorrendo na Europa sobre a importância da formação do vínculo afetivo entre a mãe e a criança por meio da amamentação (KOUTSOUKOS, 2009).

\section{I.1.2.2 - A amamentação no Brasil}

Em relação ao Brasil, assume-se que o aleitamento materno era uma prática enraizada ao costume indígena até a chegada da cultura do desmame provindo dos europeus. Inicialmente, a primeira figura da ama de leite, denominada até então como saloia brasileira, foram índias, até que as escravas acabaram substituindo-as pela rejeição cultural que as primeiras representavam aos colonizadores. Dentro desse âmbito, pode-se perceber o quanto a maternidade e todas as suas representações foram negadas às camadas sociais ditas como 
inferiores, diante de atender às exigências da família branca (ALMEIDA, 1999). Ao contrário do que acontecia frequentemente na Europa, as amas de leite residiam nas casas das famílias “contratantes” e permaneciam sob a sua vigilância (KOUTSOUKOS, 2009).

No século XIX, as questões alusivas ao Estado e à medicina resultaram na instauração da doutrina do higienismo. Dentro desse novo cenário de interesses ímpares, há o ideal de resgate da prática do aleitamento materno e a valorização da maternidade, evidenciando-se o binômio envolvendo a mãe e o filho como atores sociais fundamentais na saúde da criança. À vista disso, a utilização das amas de leite passa a ser condenada ao mesmo tempo em que a amamentação é reduzida a um sentido meramente biológico, caracterizado por uma prática voltada apenas para a nutrição e saúde da criança, sendo considerada instintiva, obrigatória, natural e intrínseca à espécie (VINAGRE et al., 2001).

Ainda no século XIX, surgem as primeiras normas com regulamentações sobre a amamentação no Brasil, estas fundamentadas nos princípios teóricos provindos da Europa. As convicções estabelecidas se sustentavam na responsabilidade e culpabilização da mãe, através do aleitamento materno, pela saúde do filho. A simbologia envolvendo o "leite fraco" manifestou-se como uma tentativa da cultura higienista para explicar o insucesso de algumas mulheres na prática da amamentação (ALMEIDA, 1999).

As transformações ocorridas na sociedade a partir do século XIX e o advento do século XX ocasionaram significativas modificações socioculturais. Muitos foram os fatores emergentes que possibilitaram mudanças no cotidiano da população: o processo crescente de urbanização (tendo como consequência a drástica redução da população rural e o aparecimento de grandes cidades), a inserção da mulher no mercado de trabalho e o desenvolvimento tecnológico e de assistência à saúde, dentre outros (SIMÕES; HASHIMOTO, 2012). O momento foi marcado por inúmeras inovações moldadas no novo estilo de vida que o próprio período acarretou. No tocante à alimentação, as mudanças nos padrões de consumo estão relacionadas aos contextos socioeconômicos e culturais da época (GOLDENBERG, 1988).

Como consequência das mudanças ocorridas na sociedade na época, foram observadas quedas nas taxas de aleitamento materno, sendo os principais responsáveis por este fenômeno: a industrialização, a urbanização, a entrada da mulher no mercado de trabalho - que proporcionou repercussões importantes na organização e na estrutura do funcionamento familiar -, a redução da importância social da maternidade, a elaboração de utensílios, como as mamadeiras, e o desenvolvimento da indústria dos alimentos infantis (SIMÕES; HASHIMOTO, 2012). 
O declínio da amamentação, seja através do aleitamento materno ou pelas amas de leite, foram acompanhados pelos avanços do aleitamento artificial ao final do século XIX (BOSI; MACHADO, 2005). A forte publicidade focalizada especialmente nos profissionais de saúde e os discursos sobre a segurança do processo de esterilização do leite de vaca propagados pela indústria alimentar, foram argumentos primordiais para a queda do sistema de amas de leite e, como resultado, do consumo de leite humano (GAMBOA, 2008; KOUTSOUKOS, 2009).

Até o início daquele século, nos primeiros anos de vida, praticamente todas as crianças alimentavam-se ao seio materno ou ao da ama de leite; porém, o reconhecimento de uma parcela cada vez maior da sociedade, estimulada pela concomitante comercialização em larga escala, fez com que o aleitamento artificial repercutisse de forma negativa na prática da amamentação (FREITAS; VELOSO, 2008). Fora isso, foi difundida e inserida na população, através da comunidade médica e pela impactante publicidade da indústria das fórmulas infantis, uma ideologia de que o aleitamento materno deveria ser complementado para um melhor estado nutricional da criança, o que também culminou como um incentivo ao desmame (ALMEIDA, 1999).

Pesquisas nacionais sobre a prevalência do aleitamento materno passaram a ser realizadas e os resultados mostraram uma baixa taxa de amamentação no Brasil, sendo considerado, inclusive, como um sério problema de saúde pública no final dos anos de 1970. A partir da década de 1980, várias iniciativas com o objetivo de formular políticas públicas de promoção, proteção e apoio ao aleitamento materno, são instauradas. Essas iniciativas buscavam a recuperação da prática de amamentar, além de ressaltar as consequências de um desmame precoce (VINAGRE; DINIZ; VAZ, 2001).

Levando-se em consideração os movimentos em favor da importância do aleitamento materno que vinham sendo reconhecidos na década de 1970 e nas recomendações internacionais que começavam a se fortalecer (como a de valorização do aleitamento materno pela OMS/UNICEF em 1979, a promulgação do "Código Internacional de Controle do Marketing de Alimentos Substitutos do Leite Materno” pela Assembleia Mundial de Saúde em 1981 e os "Dez Passos para o Sucesso do Aleitamento Materno" pela OMS e Fundo das Nações Unidas para a Infância), o Brasil iniciou, em 1981, a implantação do "Programa Nacional de Incentivo ao Aleitamento Materno" (PNIAM).

Em 1984 foi lançado pelo Ministério da Saúde os documentos do "Programa de Atenção Integral à Saúde da Criança" e do "Programa de Atenção Integral à Saúde da Mulher", ambos ressaltando a relevância da amamentação. Já em 1989, foi instituída a legislação sobre a proteção da gestante e da nutriz, bem como da licença à maternidade (DEVITO, 2010); ainda, 
em 1989, ocorreu a publicação da portaria ministerial referente às "Normas Brasileiras de Comercialização de Alimentos para Lactentes", repercutindo-se no impedimento das ações de marketing envolvidos no estímulo ao desmame precoce e em diversos programas e políticas de saúde nas décadas posteriores, como a implantação do Hospital Amigo da Criança, a criação dos Bancos de Leite Humano e a promoção dos "Dez Passos para a Alimentação Saudável" (VINAGRE; DINIZ; VAZ, 2001; ALVES, 2008).

As iniciativas mencionadas anteriormente resultaram em um aumento na prevalência e duração do aleitamento materno na época, evidenciados em pesquisas nacionais ainda na década de 1980 (DEVITO, 2010). Por sua vez, a indústria dos alimentos destinados aos lactentes passou por uma mudança de foco de suas ações, ou seja, encontrou na particularidade da criança - prematuridade, baixo peso, alergia e intolerâncias alimentares -, condições ideais para se estabelecer em um novo nicho de atuação (VINAGRE; DINIZ; VAZ, 2001).

A década de 1990 ainda é marcada pela representação da mulher e da maternidade pelo modelo biológico promovido pelos higienistas. Apesar do aumento das taxas de amamentação no país, essa evolução foi seguida por uma tendência de estabilização, demonstrando-se, portanto, um modelo atual ineficiente e desgastado. Em 1992, com a Iniciativa Hospital Amigo da Criança, houve uma evolução nas iniciativas de política pública sobre o aleitamento materno através da incorporação de conceitos relacionados não apenas à promoção da amamentação, como também na proteção do mesmo (ALMEIDA, 1999).

Por meio da divulgação de mais estudos sobre o tema e a valorização da amamentação, surgem pesquisas internacionais e nacionais sobre os riscos da inadequada introdução de alimentos complementares ou substitutos do leite materno em idades e condições não apropriadas. A OMS começa a recomendar a duração ideal da amamentação para uma adequada saúde infantil, e seguem-se as publicações dos "Guias alimentares", uma forma de auxiliar e apoiar os profissionais de saúde, além do fornecimento de informações de qualidade para toda a população (OMS, 2006).

A amamentação constantemente esteve amparada em eixos culturais, políticos e sociais (INFANTINI, 2011), percebendo-se muitas modificações em sua vivência ao longo da história e nos diferentes contextos socioculturais de cada época.

A inclusão do resgate histórico mostrou-se importante para a compreensão do ato, já que o aleitamento materno foi, e ainda é, uma prática arraigada de valores, experiências e significados ímpares para a mulher e a sociedade, indo muito além de ser apenas uma mera questão de escolha. 


\section{I.1.3 - A importância da amamentação para a criança e o seu núcleo social}

\section{I.1.3.1 - Aspectos nutricionais}

Muito se tem discutido sobre a relevância do aleitamento materno, principalmente nos primeiros meses de vida, refletindo na implantação de políticas e programas públicos que incentivam o ato através da difusão de conhecimentos para a população. As ações de promoção, proteção e apoio ao aleitamento materno mostram-se importantes para a melhoria da saúde da criança (BRASIL, 2009).

O leite materno maduro (após os quinze dias de ejeção, sendo posterior ao colostro e leite de transição) é constituído por cerca de $70 \mathrm{kcal}$ por $100 \mathrm{ml}$, sendo um fluido complexo contendo vitaminas, minerais, proteínas, lipídios e carboidratos, além de componentes relacionados à defesa imunológica e fatores tróficos ou moduladores de crescimento (PEREIRA et al., 2004).

A composição nutricional do leite humano mostra-se independente do estado nutricional da mãe, com exceção de vitaminas e alguns minerais, estes associados com a ingestão alimentar diária; ainda, podem ser encontrados variações no teor nutricional em decorrência de alguns aspectos, como as características inerentes à mãe (idade, paridade, condições específicas de saúde e idade gestacional), pelo esvaziamento das mamas, períodos do dia, prematuridade, mudanças temporais e também em casos de subnutrição grave (MELO; GONÇALVES, 2014; CARMO; COLARES; SAUNDERS, 2002).

\section{I.1.3.2 - Vantagens do aleitamento materno à saúde materno-infantil}

Através do leite materno, a criança recebe o aporte necessário para o seu crescimento e desenvolvimento saudáveis. Ele possibilita a proteção das vias respiratórias e do trato gastrointestinal contra doenças infecciosas no lactente, diminuindo a gravidade dos episódios e atuando na redução da mortalidade infantil (AMARAL; BASSO, 2009). De forma adicional, permite um ganho de peso adequado e, em muitos casos, garante a sobrevivência do lactente que está inserido em um ambiente desfavorável e/ou que nasceu com baixo peso. Ainda, o aleitamento materno é microbiologicamente seguro, sendo capaz de evitar riscos de contaminação sujeitos no preparo e manuseio do leite artificial (BRASIL, 2009).

Por ser "espécie-específico", o leite materno diminui o risco de alergias, como nos casos de alergia à proteína do leite de vaca (APLV), dermatite atópica, asma e sibilos recorrentes, 
intervindo na promoção de uma proteção imunológica, além de ser totalmente adaptado ao metabolismo do lactente e representar um alimento de alta qualidade nutricional (BRASIL, 2009).

Outras duas importantes vantagens do aleitamento materno a ser considerada são o estímulo do vínculo afetivo entre a mãe e o filho e o efeito positivo no desenvolvimento da capacidade cognitiva e emocional da criança, sendo este fato provavelmente relacionado à existência no leite humano de substâncias associadas ao aperfeiçoamento cerebral e/ou por fatores comportamentais alusivos ao ato de amamentar (ROSTADMO, 2018; CORRÊA et al., 2009).

A amamentação ainda é capaz de proporcionar o desenvolvimento adequado da musculatura e ossatura bucal do bebê (VIEIRA et al., 2009).

Salienta-se que o aleitamento materno mantém seus benefícios também em longo prazo, observações estas respaldadas por vários estudos que mostram que crianças amamentadas tendem a apresentar uma menor prevalência de hipertensão arterial, colesterol elevado, diabetes e obesidade na infância, entre outras doenças (OLIVEIRA; MARQUES, 2010; CARMO; COLARES; SAUNDERS, 2002; BRASIL, 2009).

Assim, tendo em vista todas as vantagens do leite materno já discutidas, evidencia-se a melhora na qualidade de vida geral da criança, repercutindo no bem-estar do lactente e da família que o cerca.

A temática envolvendo obesidade e aleitamento materno não é recente e, apesar de ainda não ser totalmente elucidada no meio científico, vem sendo cada vez mais discutida principalmente em virtude do aumento da prevalência do excesso de peso na infância. A literatura enfatiza o efeito protetor do aleitamento materno relacionado a um menor risco de sobrepeso e obesidade, inclusive na primeira infância (BELL et al., 2018; CONTARATO et al., 2016; MODREK et al., 2017; GARCÍA et al., 2018).

A prática correta do aleitamento materno é tão significativa para o crescimento e desenvolvimento saudáveis da criança quanto à introdução adequada da alimentação complementar a partir do sexto mês de vida. A introdução de alimentos na dieta infantil é uma etapa que pode conduzir ao déficit nutricional e a ocorrência de enfermidades quando o processo não é conduzido de forma adequada (SILVA; VENÂNCIO; MARCHIONI, 2010). Uma introdução tardia pode levar à desaceleração do crescimento, tornando maior o risco de deficiências de micronutrientes e de subnutrição (CORRÊA et al., 2009). Por outro lado, uma introdução precoce pode ocasionar aumento nos riscos de morbidade e mortalidade, já que a criança terá uma menor ingestão dos fatores protetores existentes no leite humano. A 
precocidade na alimentação complementar está ainda associada a um maior número de eventos adversos à saúde da criança, como diarreias, hospitalizações por doenças respiratórias, menor tempo de duração do aleitamento materno, aumento do risco de contaminação e reações alérgicas, além da possibilidade de diminuição na absorção de nutrientes importantes presentes no leite humano, como do zinco e o ferro. (DIAS; FREIRE; FRANCESCHINI, 2010; BRASIL, 2009; MONTE; GIUGLIANI, 2004).

Os benefícios do aleitamento materno vão além do próprio lactente, já que o ato também é importante do ponto de vista da mãe. Mulheres que amamentam recuperam a forma física pré-gestacional mais rapidamente, apresentam uma involução uterina mais acelerada que culmina com a diminuição do risco de hemorragia e, por conseguinte, de anemia após o parto. Ainda, elas possuem uma redução no risco de câncer de mama e de ovário, além da diminuição no risco de sofrer algumas fraturas ósseas. $\mathrm{O}$ aleitamento materno se constitui em um método natural contraceptivo, atuando como forma de evitar o surgimento de uma nova gravidez nos primeiros seis meses, desde que a mulher não tenha ainda menstruado e que esteja amamentando exclusivamente ou predominantemente em livre demanda (BRASIL, 2005 e 2009; CORRÊAA et al., 2009).

Como já mencionado, a amamentação também exerce um papel essencial na formação e no desenvolvimento do vínculo afetivo entre a mãe e o filho, proporcionando o contato íntimo entre eles, aflorando sensações, fortalecendo laços afetivos e produzindo benefícios psicológicos importantes para a díade (BRASIL, 2009).

Quando a criança não cresce de maneira satisfatória, mesmo com o aleitamento materno exclusivo nos primeiros seis meses de vida, faz-se relevante a realização de uma avaliação detalhada em busca de respostas para isso. Um dos pontos a serem observados é se o lactente está ingerindo pouco leite materno por má técnica de amamentação; esta situação resultaria em um esvaziamento inadequado das mamas e, assim sendo, à diminuição da lactação. Nesses casos, a orientação correta da mãe é um passo primordial para que a criança possas ter condições de aumentar a sua ingestão de leite e para que também não ocorra uma precocidade na introdução da alimentação complementar, a qual, muitas vezes, não seria necessária (MONTE; GIUGLIANI, 2004).

\section{I.1.3.3 - Vantagens socioeconômicas do aleitamento materno}

Os benefícios do aleitamento materno também se inserem no âmbito familiar. A família obtém vantagens econômicas quando se compara a ausência de custos da amamentação com a 
utilização dos substitutos do leite materno, além dos gastos com os utensílios, como as mamadeiras e os bicos, e o gás de cozinha, por exemplo (BRASIL, 2009).

Os proveitos podem ainda ser encontradas em relação aos menores gastos com doenças infantis em virtude da amamentação e a sua repercussão favorável na saúde da criança (ARAÚJO, 2004). Ainda, destaca-se o papel agregador da amamentação no favorecimento da nucleação familiar (MONSON, 1992).

Vale a pena frisar o impacto social e econômico do aleitamento materno, já que, através da amamentação, espera-se menor incidência de doenças infantis e maternas específicas, proporcionando melhor qualidade de vida a ambos e refletindo-se em menores gastos governamentais com atendimentos, hospitalizações e utilização de medicamentos, entre outras considerações (SOUZA; BULHOSA, [20--]). Tais vantagens perpassam do âmbito individual para o coletivo, transformando-se em vantagens plurais para toda a sociedade (ARAÚJO, 1997).

\section{I.1.3.4 - Prevalências do aleitamento materno no Brasil}

Mesmo com a implantação de políticas e programas públicos que incentivam o aleitamento materno e a sua duração ideal, a prática no Brasil ainda está aquém do preconizado.

De acordo com os dados levantados pelo Ministério da Saúde através da II Pesquisa de Prevalência de Aleitamento Materno nas Capitais Brasileiras e Distrito Federal (IIPPAM) (BRASIL, 2009), houve um aumento na mediana de duração do aleitamento materno entre os anos de 1999 e 2008 em cerca de 1 mês e meio, passando de 296 dias para 342 dias em 2008; esta pesquisa observou que houve maior expansão na região Nordeste (em 94 dias) e menor na região Norte (em 20,6 dias). Já em relação ao AME, constatou-se um aumento de 1 mês na mediana entre os anos considerados no estudo, de 24 para 54 dias; a região Centro-Oeste apresentou o aumento mais expressivo na duração do AME (em 47,1 dias) e a região Nordeste, o pior, passando de 26,3 para 34,9 dias (acréscimo de 8,6 dias).

Outro estudo de grande impacto foi realizado através da Pesquisa Nacional de Demografia e Saúde da Mulher e da Criança (PNDS) (BRASIL, 2009), em que a proporção do AME aos 2 e 3 meses de idade aumentou de 26,4\% em 1996 para 48,3\% em 2006.

Na Pesquisa Nacional de Saúde (PNS) realizada em 2013, foi evidenciada uma tendência de aumento das taxas de AME e AM quando comparadas com os inquéritos de 1986 e 2006; observou-se também certa estabilização nos índices entre 2006 e 2013 (BOCCOLINI, 2017). 


\section{2 - O estado nutricional da criança na primeira infância}

\section{2.1 - Avaliação antropométrica do estado nutricional da criança}

A avaliação do estado nutricional mostra-se essencial no acompanhamento da criança, visto que ela se apresenta em constante crescimento e desenvolvimento. A questão genética atua na definição das características físicas da mesma, porém fatores extrínsecos ou ambientais também podem repercutir na saúde, comprometendo seu desenvolvimento a depender do tempo de exposição, intensidade do agravo e da fase de vida em que se encontra (WEFFORT; LOPES, 2009).

Condições como o tempo de gestação, peso materno pré-gestacional e o ganho de peso durante a gestação são fatores importantes para o estado nutricional da criança ao nascer. Em seguida, as questões genéticas e dietéticas revelam-se como influenciadores marcantes no desenvolvimento e crescimento. As maiores velocidades de ganho do peso e aumento na estatura acontecem no primeiro ano de vida, assim, mostra-se importante o monitoramento do crescimento físico das mesmas (GILLMAN, 2008). Em menores de um ano, a monitoração do estado nutricional através dos parâmetros antropométricos geralmente envolve o peso, comprimento e o perímetro cefálico (VITOLO, 2008).

A avaliação nutricional é um instrumento de análise das condições nutricionais do indivíduo, sendo parte constituinte do diagnóstico nutricional (MUSSOI, 2014). Segundo as diretrizes sobre o tema, o diagnóstico nutricional deve ser integrado pela avaliação nutricional através das variáveis antropométricas, bioquímicas, além da história clínica e alimentar. A periodicidade da avaliação permite o acompanhamento do desenvolvimento, bem como o rastreamento precoce de situações de risco nutricional (DEVINCEZI; MATTA; CINTRA, 2010).

Entre as crianças na primeira infância, o estado nutricional pode ser avaliado com a complementação de diversas ferramentas. Porém, no enfoque pela antropometria no âmbito da saúde pública, a mensuração do peso, perímetro cefálico e estatura são as mais usualmente empregadas e permitem uma adequada descrição do crescimento infantil (BRASIL, 2010).

$\mathrm{Na}$ prática clínica ou em casos especiais, pode ser importante a inclusão de medidas complementares para avaliação. Exemplos dessas medidas são a circunferência do braço, que irá refletir as reservas energética e proteica; perímetro torácico, expressando a reserva adiposa e muscular; as dobras cutâneas (como a dobra tricipital e subescapular, por exemplo), estimando o tecido adiposo subcutâneo e reserva energética que, somadas às dobras bicipital e suprailíaca, 
permitem a mensuração da composição corporal da criança. A circunferência da cintura também é uma medida bastante utilizada na clínica, principalmente como um indicador de avaliação do risco cardiovascular. Finalmente, considera-se ainda sobre outros métodos complementares direcionados para a avaliação da composição corporal, como a bioimpedância elétrica. Tais técnicas são as mais utilizadas e possuem vantagens e limitações particulares (VITOLO, 2008; DEVINCEZI; MATTA; CINTRA, 2010).

Para o diagnóstico do estado nutricional a partir da obtenção das medidas de peso e comprimento/estatura, as curvas de crescimento da OMS de 2006 e 2007 são consideradas como uma das principais ferramentas utilizadas para a criança e o adolescente, tanto no âmbito individual quanto no populacional, justamente pela praticidade e facilidade exigidos. Por meio de sua aplicação podem-se ser detectadas situações de subnutrição, excesso de peso e/ou condições relacionadas ao crescimento e nutrição (BRASIL, 2010; OMS, 2006 e 2007).

Subdivididas em gêneros e por idade, as curvas para menores de cinco anos são categorizadas e classificadas de acordo com os pontos de corte (percentil ou z-escore) adotados pelo Sistema de Vigilância Alimentar e Nutricional (SISVAN); aqui, os índices antropométricos utilizados para a classificação nutricional são: peso por idade (P/I), comprimento/estatura por idade (E/I ou C/I), peso por comprimento/estatura (P/C ou P/E) e Índice de Massa Corporal (IMC) por idade (IMC/I) (BRASIL, 2010; OMS, 2006 e 2007).

No que se refere ao índice de P/I, a medida representa o peso em relação à idade cronológica e reflete o estado nutricional atual, tratando-se de um indicador muito utilizado entre menores de dois anos pela grande velocidade de crescimento do peso na faixa etária. As curvas de $\mathrm{E} / \mathrm{I}$ ou $\mathrm{C} / \mathrm{I}$ retratam o crescimento linear do indivíduo para determinada idade, sendo que inadequações podem configurar déficits nutricionais de longo prazo, permitindo-se a visualização de impactos de afecções crônicas no crescimento do indivíduo (BRASIL, 2010; OMS, 2006 e 2007; VITOLO, 2008).

Tem-se ainda o indicador $\mathrm{P} / \mathrm{C}$ ou $\mathrm{P} / \mathrm{E}$ que abrange o equilíbrio entre o peso e o crescimento da criança, revelando-se como um indicativo do estado nutricional atual ou de privação de curto prazo (BRASIL, 2010; OMS, 2006 e 2007; VITOLO, 2008).

Por fim, as curvas de IMC/I demonstram uma importante utilidade no rastreamento de condições nutricionais envolvendo o baixo peso e o excesso de peso e, em conjunto com o índice de $\mathrm{P} / \mathrm{E}$ ou $\mathrm{P} / \mathrm{C}$, denotam-se como os melhores indicadores antropométricos para avaliação de sobrepeso e obesidade (BRASIL, 2010; OMS, 2006 e 2007; VITOLO, 2008).

Isto posto, a avaliação antropométrica deve ser executada de forma periódica visando o acompanhamento do crescimento e desenvolvimento da criança, bem como para a detecção 
precoce de situações de risco que podem impactar de forma negativa o seu estado nutricional e, consequentemente, a saúde da mesma (WEFFORT; LOPES, 2009).

\section{2.2 - Panoramas do excesso de peso na infância no Brasil e no mundo}

A obesidade na infância vem atingindo, há tempos, números alarmantes e sendo considerada hoje como um importante problema de saúde pública em muitos países. Os percentuais de sobrepeso e obesidade infantil modificam-se conforme a faixa etária analisada.

Através de uma pesquisa realizada em 2010 abrangendo dados de diversas nacionalidades, foi encontrada uma prevalência de excesso de peso (sobrepeso e obesidade) em menores de cinco anos de idade de 6,7\%, sendo que 14,4\% apresentavam-se em risco nutricional de sobrepeso. Estima-se que, em 2020, 9,1\% das crianças da mesma faixa etária apresentarão excesso de peso no mundo (ONIS; BLOSSNER; BORGHI, 2010). Ainda, 9,7\% das crianças com até dois anos de idade foram classificadas com obesidade entre os anos de 2009 e 2010 em um estudo realizado nos Estados Unidos (OGDEN et al., 2014).

Segundo as informações disponibilizadas pelo relatório da Organização das Nações Unidas para Alimentação e Agricultura (FAO) em 2015, estima-se um excesso de peso no mundo de 6,2\% entre crianças menores de cinco anos de idade; no Brasil o número sobe para $7,2 \%$ (FAO, 2016). Já em outra referência foi apontado uma prevalência em torno de $12 \%$ no país, sendo maior no sexo masculino e inversamente proporcional à idade da criança (MULLER, 2014); adicionalmente, em um estudo foram encontradas prevalências de 2,5\% entre crianças de classe econômica mais baixa a 10,6\% nas classes mais elevadas (DA SILVA; BALABAM; MOTTA, 2005).

Obteve-se percentuais de 9,6\% de sobrepeso e 5,8\% de obesidade entre lactentes de um ano de idade e de $10 \%$ e $3,7 \%$, respectivamente, aos dois anos. Nesse mesmo estudo, as maiores taxas de excesso de peso em crianças foram encontradas nas famílias de nível socioeconômico médio, residentes da zona urbana e pertentes às regiões Sul, Sudeste e Centro-Oeste do país (PEREIRA et al., 2017). Ainda, foram identificados 6,5\% de excesso de peso em crianças menores de dois anos de idade (COCETTI et al., 2012). Por fim, em um estudo realizado em Minas Gerais com crianças entre 0 e doze meses de idade cadastradas nas Estratégias de Saúde da Família (ESF), obteve-se percentuais de excesso de peso em 7,2\% pelo índice de P/E e de $4,8 \%$, para o indicador de IMC/I (CAMARGOS et al., 2019). 
Ressalta-se que a classificação do estado nutricional pelos índices de P/E e IMC/I entre menores de cinco anos de idade, além de considerar o excesso de peso (sobrepeso e obesidade, P/E e IMC/I > percentil 97 - p97 - ou > escore-z +2 para idade e sexo pela curva da OMS de 2006), também possuem uma determinada faixa ( $>$ p85 e $\leq$ p97 ou $>$ escore- $z+1$ e $\leq$ escore- $z$ +2) classificada como de "risco de sobrepeso". Como as crianças dessa idade estão em um processo de crescimento ponderal e, também, pela existência de poucos dados sobre o significado funcional dos valores extremos do IMC, a OMS utiliza este critério como uma medida cautelosa para classificação nutricional (ONIS, 2015).

Fatores como hereditariedade, desmame precoce, introdução inadequada da alimentação complementar, distúrbios relacionados ao comportamento alimentar (ingestão alimentar excessiva e/ou uma ingestão inadequada em termos nutricionais), ambiente familiar/problemas na relação intrafamiliar e o sedentarismo são aspectos muito discutidos na gênese do excesso de peso (LOPES; PRADO; COLOMBO, 2010).

Crianças com sobrepeso ou obesidade na primeira infância têm aproximadamente quatro vezes mais chances de apresentar excesso de peso quando adulto jovem em comparação àqueles de peso normal (PAN et al., 2019).

Por conta do aumento da prevalência de excesso de peso na infância, crescem o número de estudos que visam identificar prováveis fatores de risco e de proteção como forma de prevenção às potenciais doenças relacionadas à obesidade e que também podem acabar repercutindo na idade adulta, como diabetes mellitus tipo 2, hipertensão arterial, dislipidemias, doenças cardiovasculares, entre outras (MARIM; NAVARRO, 2007).

\section{2.3 - Fatores de risco: o impacto do ambiente obesogênico}

A obesidade é uma doença complexa, de etiologia multifatorial, podendo ser definida como o acúmulo progressivo de gordura corporal capaz de provocar repercussões importantes à saúde (SILVEIRA; ABREU, 2006). Com o excesso de peso na infância aumentando de forma progressiva, demonstra-se, assim, a importância de sua prevenção, identificação precoce e tratamento.

Entre os fatores de risco modificáveis relacionados à terapêutica da obesidade apresentase o ambiente obesogênico, definido como o ambiente em que o indivíduo está inserido no qual, direta ou indiretamente, age como um influenciador e promotor do excesso de peso (WANDERLEY; FERREIRA, 2010). 
Sabe-se que os hábitos de vida são fortemente influenciados pelo ambiente, assim, a indução por determinado comportamento alimentar poderá ser facilitada ou não pelo meio (SOUZA; OLIVEIRA, 2008). No que concerne ao público infantil, o fator ambiental manifestase de forma marcante devido à maior dependência da criança perante o indivíduo adulto, como também na incorporação do hábito alimentar da família. $\mathrm{O}$ ambiente familiar demonstra-se como um dos primeiros fatores no que tange à influência no consumo alimentar baseado na observação dos comportamentos dos integrantes e na promoção de sensações de familiaridade pela criança por determinados alimentos (PETTY et al., 2015).

A questão hereditária mostra-se muito envolvida com o fenótipo da obesidade; assim, com a vivência em um ambiente obesogênico, indivíduos geneticamente suscetíveis apresentam um risco considerável de se tornarem obesos (BELL et al., 2005). Fatores ambientais agem em conjunto com a predisposição genética na ocorrência da obesidade, demostrando uma interação complexa entre ambos (HEBEBRAND et al., 2007). Discute-se sobre mutações gênicas envolvidos na regulação do apetite, nos mecanismos relacionados à taxa metabólica basal (TMB) e no gasto energético (LOPES et al., 2004).

O relacionamento com o mundo e, dessa forma, com a comida, é estabelecido ainda na infância. O leite materno ou o consumo das fórmulas infantis marcam o início da relação da criança com a comida, moldando a sua percepção e preferência por determinados tipos de alimentos. O desenvolvimento das atitudes alimentares tem suas raízes em conceitos relacionados à criação, família, tradições, ambiente e cultura (ALVARENGA et al., 2015).

A prática correta do aleitamento materno é tão importante quanto a introdução adequada da alimentação complementar no resultado do crescimento, desenvolvimento e qualidade de vida. A introdução inadequada dos alimentos complementares é capaz de desencadear o excesso de peso no primeiro ano de vida (COSTA; OLIVEIRA, 2010). A partir do exposto, destaca-se a importância do ambiente familiar nas práticas alimentares saudáveis, bem como na formação dos hábitos alimentares da criança.

Além dos tipos de alimentos que uma criança consome, o ambiente alimentar geral desempenha um papel muito importante no desenvolvimento da obesidade. As Influências e apresentações vão se tornando mais complexas à medida que as crianças crescem, com maior exposição ao marketing de alimentos e ao custo relativamente baixo de alimentos de alta densidade energética e pobre valor nutricional, podendo interferir nos comportamentos alimentares a longo prazo (MIHRSHAHI; BAUR, 2018).

De acordo com os estudos, a participação da família é fundamental no comportamento alimentar da criança, sendo a figura materna geralmente a principal influência no que se refere 
à alimentação infantil, sobretudo pela maior relação com o preparo das refeições e escolha dos alimentos (VICARI, 2013; BARROS; SEYFFARTH, 2008).

Apesar da atual reestruturação da rotina familiar especialmente pelo novo papel desempenhado pela mulher no mercado de trabalho, a mãe continua representando a principal provedora da alimentação da família (REICHEMBACH, 2004), sendo a mais predominante interlocutora envolvida na díade criança-ambiente (ENGSTRON; ANJOS, 1999).

Crianças pertencentes às famílias com mães e/ou pais obesos estão propensas a estar inseridas em um ambiente "obesogênico" e, em consequência, expostas às condições ambientais favorecedoras de hábitos de vida relacionados à instalação e manutenção do excesso de peso. Sabe-se que a criança é dependente da família e que os pais são os influenciadores diretos da alimentação dos mesmos, marcando as primeiras experiências infantis com alimentação e transmitindo suas próprias práticas alimentares; este é um fator preocupante ao considerar-se que a obesidade parental é apontada como um preditor para a obesidade infantil (SOUZA; OLIVEIRA, 2008).

Pesquisas sugerem que o IMC paterno também é importante e teria um efeito aditivo ao IMC materno. Melhorias no status do peso para casais que buscam a formação de uma família podem ser intervenções eficazes para reduzir a prevalência de obesidade infantil (MIHRSHAHI; BAUR, 2018).

Assim, a modificação ambiental trata-se de um dos maiores desafios atuais para a promoção da alimentação saudável e, consequentemente, na diminuição da obesidade. Intervenções de educação alimentar e nutricional (EAN) no ambiente familiar são uma das estratégias mais relevantes no combate às crescentes proporções no acometimento da doença na infância, desempenhando um papel relevante na tomada de decisões sobre a alimentação e atividade física e atuando na construção dos alicerces relacionados aos hábitos alimentares.

\section{3 - Estado nutricional materno, aleitamento materno e excesso de peso na infância}

O excesso de peso materno, incluindo o pré-gestacional, o ganho de peso excessivo durante a gestação e a retenção de peso pós-parto, são vistos como fatores de risco para a obesidade infantil; isso se deve às influências no período intrauterino, questões genéticas e na formação e transmissão de hábitos de vida e do comportamento alimentar (LEIRAS, 2015). 
Tais fatores podem interferir na saúde e qualidade de vida, sendo capazes de provocar impactos não apenas na infância, como também na idade adulta.

O sobrepeso e a obesidade materna pré-gestacional foram associados com o aumento do risco de excesso de peso infantil no primeiro ano de vida (BRIDGMAN et al., 2018). Um estudo avaliou o curso do IMC dos dois aos seis anos de idade e notou valores mais elevados, bem como na trajetória de aumento, entre crianças de mães com excesso de peso no período anterior à gestação e nos filhos das que apresentaram ganho de peso gestacional acima do recomendado (WANG et al., 2019). Em outro, para cada acréscimo em $1 \mathrm{~kg} / \mathrm{m}^{2}$ no IMC pré-gestacional, houve uma elevação, nos primeiros dois anos de vida, de 4,5\% no risco de obesidade em relação àquelas com mães eutróficas. Ainda, a chance também era maior entre crianças com mães que ganharam peso excessivo na gestação (OHLENDORF; ROBINSON; VILLARREAL; 2019).

A alimentação da criança do nascimento até os primeiros anos de vida apresenta repercussões significativas no seu crescimento e desenvolvimento, tanto a curto quanto em longo prazo. Do nascimento até o sexto mês de vida a amamentação é extremante importante para a saúde pediátrica.

A amamentação exclusiva foi associada a um risco diminuído de obesidade em crianças de dois a cinco anos de idade, em comparação às que não foram amamentadas ou que foram, porém, por menos de seis meses (PALAO, 2019). Crianças que receberam leite materno por seis meses ou mais apresentaram uma chance menor de ocorrência de sobrepeso e obesidade aos três anos de idade (PATTISON et al., 2019). Um estudo mostrou que lactentes que estiveram em AME em um período inferior a três meses apresentaram risco quatro vezes maior de desenvolverem obesidade (JURADO et al., 2016). Foi observada uma prevalência de excesso de peso $36 \%$ maior em crianças amamentadas de forma exclusiva até 120 dias quando comparadas àquelas amamentadas por um período mais prolongado (WANG et al., 2017).

As evidências são de que a amamentação seja protetora contra a obesidade e de que a proteção esteja associada ao tempo de duração, ou seja, uma duração maior aumentaria a proteção (FORBES et al., 2018). Demonstra-se que, quanto mais precocemente se dá a introdução dos substitutos do leite materno, maior é a relação com o excesso de peso em crianças em idade pré-escolar (NASCIMENTO et al., 2016; MUELLER; BLASER, 2018). A proteção também foi encontrada entre crianças de alto peso ao nascer (LEE et al., 2019) e em idades mais elevadas, inclusive na adolescência e idade adulta (RITO et al., 2019; TAMBALIS et al., 2018).

Mães obesas revelam maior risco para fatores estressantes e de complicações durante o parto, resultando no aumento da probabilidade de partos por cesariana, que estão relacionados 
ao retardo da lactogênese, interferindo, dessa forma, na produção de prolactina (FALIVENE; ORDEN, 2017). Este fato sugere que, assim como a duração, o início da amamentação pode ser igualmente afetado pelo excesso de peso materno.

Estudos associam a obesidade materna com um menor tempo de aleitamento e propensão para iniciá-lo, além de uma intenção em praticá-lo por períodos mais curtos (AMIR; DONATH, 2007). Mulheres obesas expressam menor confiança sobre a amamentação (CLAESSON et al., 2018), apresentam mais frequentemente problemas de saúde que podem comprometer o aleitamento materno e enfrentam maiores desafios no que tange ao tempo e ao posicionamento do bebê no momento de mamar (GARNER et al., 2016). A obesidade materna também pode ser considerada um fator de risco para a interrupção precoce do aleitamento no período pós-parto, após a saída hospitalar (RAMJI et al., 2016). Ainda, relata-se que mães obesas comem para aliviar sentimentos desagradáveis durante o período pós-natal, portanto, o pós-parto seria um momento oportuno para a instauração de mudanças em seus comportamentos alimentares e no bem-estar mental (FARIA-SCHÜTZER et al., 2018).

Discute-se hoje sobre a magnitude dos primeiros 1.000 dias, momento que abrange desde o período intrauterino (270 dias) até os dois anos de idade da criança (730 dias, ou seja, 365 dias correspondentes ao primeiro ano de vida e aos outros 365 no segundo).

Dentro da perspectiva da "Origem Desenvolvimentista das Doenças e da Saúde" $(\mathrm{DOHaD})$, a fase do desenvolvimento da criança no pré-natal e nos primeiros anos de vida são capazes de influenciar, em cascata, a sua vida pós-natal e nos anos posteriores. Trata-se de uma fase conhecida como "janelas de oportunidade", cruciais para o desenvolvimento e crescimento infantil e que também podem impactar e determinar a sua saúde na vida adulta através da modulação na "programação fetal” por alterações epigenéticas (LUCAS, 1990; HANSON, 2015). Dessa forma, um ambiente desarmônico entre o anterior e o posterior à gestação, atuariam aumentando o risco de desenvolvimento de doenças (YAJNIK; DESHMUKH, 2008; HANSON, 20015).

Fatores ambientais, como a nutrição, vem sendo relacionado a uma modificação na estrutura da cromatina e na expressão gênica que, consequentemente, agem determinando um arquétipo de saúde e doença (MATHERS, 2007). Nos primeiros anos de vida, valores mais elevados de IMC ou na velocidade de ganho de peso, mostram-se como elementos que aumentam o risco de obesidade na infância, adolescência e na idade adulta (DRUET et al., 2012; BAIRD et al., 2005).

Dado o exposto, situações inadequadas na fase intrauterina e primeira infância são apontadas em associação ao aumento de risco de doenças crônicas não transmissíveis (DCNT) 
ao logo da vida do indivíduo (CHALLER et al., 2009; TONG et al., 2009). Condições de vida modificáveis como o excesso de peso materno, ganho de peso durante a gestação, alimentação materna, amamentação e práticas alimentares inadequadas na infância, mostram-se como fatores importantes na prevenção do sobrepeso e obesidade infantil e, mais do que isso, nos indicadores de saúde e doença à curto e longo prazos (DATTILO, 2017). 


\section{II - HIPÓTESE}

Diante do exposto, é de conhecimento que o aleitamento materno possui inúmeros benefícios para a saúde, destacando-se entre eles a proteção contra o desenvolvimento de obesidade na infância. Desta forma, levantou-se a hipótese de que o AME superior a 120 dias quatro meses -, mesmo em filhos de mães portadoras de sobrepeso ou obesidade e que, consequentemente, pode representar um fator de risco para o ganho de peso excessivo da prole devido possíveis influências ambientais, seria um fator protetor para a ocorrência de excesso de peso entre os três primeiros anos de vida da criança. 


\section{III - JUSTIFICATIVA}

Considerando a considerável prevalência de sobrepeso e obesidade infantil no Brasil e no mundo, tornam-se cada vez mais necessários estudos que buscam evidenciar fatores capazes de influenciar no aumento do risco e/ou proteção para a população estudada.

O efeito protetor do leite materno no excesso de peso na criança é citado na literatura científica, porém ainda são escassos os estudos que associam esse efeito protetor em crianças que apresentam fatores de risco específicos para a sua ocorrência, como nos casos daquelas com mães obesas ou com sobrepeso.

Os achados deste estudo poderão auxiliar na elaboração de iniciativas que visam intervenções nutricionais precoces no ambiente familiar, sobretudo no que se refere à promoção, proteção e apoio à amamentação. 


\section{IV - OBJETIVOS}

\section{IV.1 - Objetivo primário}

- Verificar o risco para o desenvolvimento de excesso de peso em filhos de mães com sobrepeso e obesidade entre o primeiro e terceiro ano de vida segundo a duração do AME em uma coorte de nascimentos de Ribeirão Preto (SP) no ano de 2010.

\section{IV.2 - Objetivos secundários}

- Determinar a proporção de mães e lactentes entre o primeiro e terceiro ano de vida com excesso de peso na cidade estudada;

- Determinar a média e mediana de duração da amamentação (AM e AME) na cidade estudada;

- Determinar a duração da amamentação (AM e AME) de acordo com o estado nutricional materno. 


\section{V - MATERIAS E MÉTODOS}

\section{V.1 - Tipo de estudo}

Este é um estudo analítico, observacional, retrospectivo e de coorte, inserido no projeto temático "Fatores etiológicos do nascimento pré-termo e consequências dos fatores perinatais na saúde da criança: coortes de nascimentos em duas cidades brasileiras”, denominado Projeto BRISA - Brazilian Ribeirão Preto and São Luís birth cohort - (processo FAPESP n ${ }^{\circ}$ 08/53593-0). A principal finalidade deste estudo é a de investigar novos fatores de risco para a prematuridade (hipóteses neuroendócrina, imunoinflamatória e de intervenção médica), indicadores de saúde perinatal e a sua repercussão sobre o crescimento, em duas coortes realizadas nas cidades de Ribeirão Preto (SP) e São Luís (MA). Estas coortes foram avaliadas em três momentos distintos. O primeiro momento ocorreu durante a gestação, entre as $22^{\mathrm{a}}$ e $25^{\mathrm{a}}$ semanas, em uma coorte de conveniência de gestantes das duas localidades, (as gestantes participantes deste grupo compõem a intitulada coorte de pré-natal); o segundo, por ocasião do nascimento de crianças cujas mães eram residentes nos dois municípios do estudo durante o ano de 2010, (as mães e os recém-nascidos deste grupo constituem a designada coorte de nascimento; incluem-se neste grupo os lactentes da coorte de pré-natal que nasceram durante esse ano). O terceiro momento ocorreu entre o primeiro e terceiro ano de vida das crianças pertencentes às duas coortes anteriores, intitulada como coorte de seguimento.

Para este estudo, foram utilizados os dados obtidos da coorte de pré-natal, ou seja, com base nas avaliações realizadas com as gestantes e seus pares, a depender do momento, na gestação (pré-natal), nascimento e no seguimento (segundo e terceiro ano de vida da criança), daquelas pertencentes à cidade de Ribeirão Preto (SP).

\section{V.2 - Local de estudo}

O estudo foi realizado no município de Ribeirão Preto, localizado no interior paulista, pertencente à região Sudeste do Brasil, do qual ocupa uma área de 650,916 km² e possui densidade demográfica de $928,92 \mathrm{hab} / \mathrm{km}^{2}$. Com uma população estimada de 703.293 habitantes em 2019, obteve um crescimento populacional de 98.611 desde o último censo realizado em 2010 (IBGE, 2010 e 2019).

Em 2015, a cidade dispôs de um salário médio mensal de trabalhadores formais em três salários mínimos e, em 2010, de uma taxa de escolarização de 96,9\% entre crianças e 
adolescentes de seis a quatorze anos de idade (IBGE, 2010 e 2015). Além disso, a estimativa da mortalidade infantil, um indicador das condições de vida da população, foi de 9,7 óbitos por mil nascidos vivos em 2016; esta média revela-se baixa segundo os parâmetros estadual e nacional, sendo inclusive menor daquela considerada aceitável pela OMS, que é de dez mortes para cada mil nascimentos (SEADE, 2016). De acordo com o Índice de Desenvolvimento Humano Municipal (IDH-M), composto por indicadores relacionados à longevidade, educação e renda, Ribeirão Preto apresentou um valor de 0,8 no ano de 2010, significando um valor muito alto, colocando a cidade na $22^{\mathrm{a}}$ posição dentro do estado de São Paulo e na $40^{\mathrm{a}}$ no país (PNUD, 2010).

\section{V.3 - Amostra}

Foram estudadas as gestantes e seus respectivos filhos, inseridos na coorte de pré-natal, avaliados na cidade de Ribeirão Preto (SP). Trata-se de uma coorte aninhada ao projeto temático (Projeto BRISA), com uma amostra de conveniência, e foi calculada fundamentada nas prevalências referidas pelas variáveis explanatórias do projeto temático, alternando de 10 a $50 \%$. Tendo em vista uma taxa de prematuridade estimada em $12 \%$, foram recrutadas 3.000 gestantes, sendo 1.500 em cada cidade avaliada (Ribeirão Preto - SP e São Luís - MA), das quais deveriam resultar em 360 casos de prematuridade. Assim, em virtude de a taxa de prematuridade ter sido menor do que a esperada $(9,7 \%)$ inicialmente no trabalho principal, eventuais perdas de seguimento, ausência de informações sobre as variáveis selecionadas no presente estudo e inconsistências encontradas no banco de dados, a amostra final ficou concebida por 1.069 mães e seus filhos (Figura 1). 
Figura 1 - Organograma da coorte do pré-natal do projeto BRISA de Ribeiro Preto (SP) em seus três momentos de avaliação

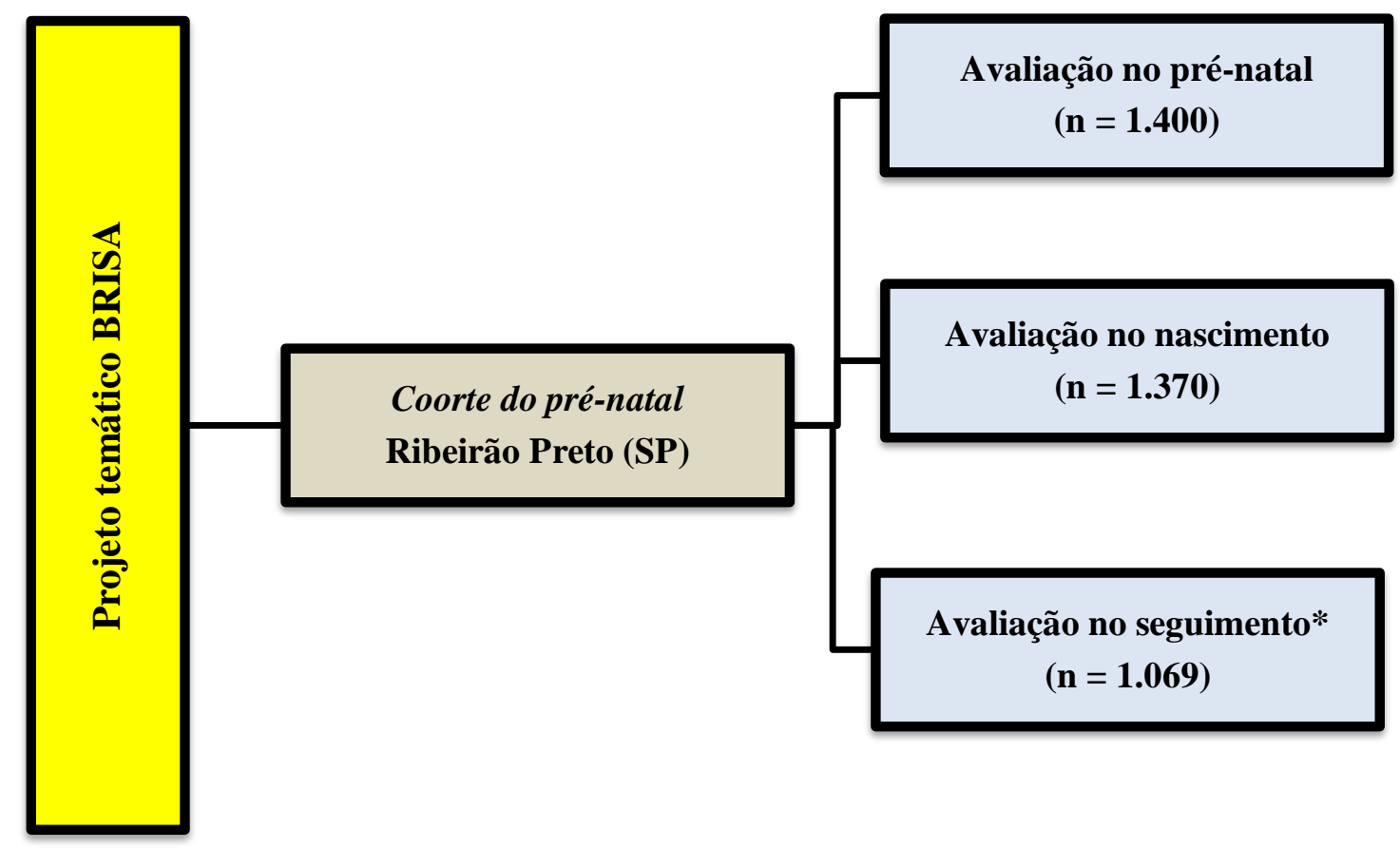

*Seguimento: entre o primeiro e terceiro ano de vida da criança.

\section{V.4 - Processo de obtenção da amostra}

As gestantes integrantes da coorte do pré-natal foram recrutadas em unidades de saúde em que realizaram o pré-natal, no primeiro trimestre gestacional, como também por meio de contato telefônico e carta (obtidos através das informações pessoais oriundas dos cadastros existentes no serviço de saúde). Assim, após o contato e a concordância da gestante em participar do estudo, foi agendada uma consulta de pré-natal a ser realizada entre a $20^{\mathrm{a}}$ e $25^{\mathrm{a}}$ semana de gravidez na Unidade de Pesquisa Clínica (UPC) do Hospital das Clínicas da Faculdade de Medicina de Ribeirão Preto da Universidade de São Paulo (HCFMRP-USP). As participantes compareceram no local referido uma única vez e permaneceram por lá em torno de 4 horas. Nesta consulta, aplicou-se um questionário padronizado e realizaram-se coleta de sangue para realização de exames laboratoriais, além da medição dos níveis pressóricos; de forma adicional, foram realizados exames ginecológicos com coleta de conteúdo vaginal, além de avalição antropométrica. Durante a entrevista, as gestantes receberam um cartão/diploma de identificação contendo um número/código (etiqueta colante com código de barras) para apresentação na maternidade no momento do parto. 
Para o recrutamento dos participantes na coorte de nascimento, durante o ano de 2010, uma equipe de entrevistadoras percorriam as maternidades públicas e privadas da cidade (Hospital Amico-Ribeirânia, HCFMRP-USP, Hospital São Lucas, Hospital Santa Lydia, Hospital Santa Casa, Centro de Referência da Saúde da Mulher de Ribeirão Preto - Mater, Hospital Sinhá Junqueira e Hospital São Paulo) para entrevistar as puérperas e coletar informações provenientes dos prontuários médicos sobre os recém-nascidos. Nesta etapa da coleta de dados, todas as parturientes residentes no município de Ribeirão Preto no ano de 2010, incluindo aquelas pertencentes à coorte de pré-natal eram, em princípio, elegíveis ao estudo original (projeto BRISA).

$\mathrm{Na}$ avaliação entre o primeiro e terceiro ano de vida (coorte de seguimento), a equipe entrava em contato com as mães ou outros responsáveis pelas crianças por meio de contato telefônico para agendamento de uma nova entrevista. Foi estabelecido novamente a UPC como local para a realização das mesmas; entretanto, em alguns casos, elas também ocorreram nos domicílios das famílias em razão da impossibilidade do comparecimento ao lugar mencionado.

\section{V.5 - Critérios de inclusão}

- Mulheres com gravidez única e residentes no município de Ribeirão Preto (SP);

- Avaliação nas três etapas do projeto original e que também foram estabelecidas para este estudo: pré-natal, com as gestantes pertencentes à coorte do pré-natal; nascimento, com as puérperas e seus respectivos filhos (coorte de nascimento) e seguimento (coorte de seguimento), com as mães e seus pares.

\section{V.6 - Critérios de exclusão}

- Perda de seguimento entre as três etapas do estudo: pré-natal, nascimento e seguimento;

- Participantes que continham informações inconsistentes ou incompletas (isto é, não possuíam informações referentes a todas as fases de avaliação para as variáveis selecionadas). 


\section{V.7 - Aspectos éticos}

O projeto temático BRISA foi aprovado pelo Comitê de Ética em Pesquisa do HCFMRP-USP (processo HCRP $n^{\circ}$ 11157/2008) e pelo Comitê de Ética em Pesquisa do Hospital Universitário Presidente Dutra da Universidade Federal do Maranhão, conforme parecer consubstanciado $n^{\circ} 223 / 2009$. Todos os participantes receberam e assinaram o Termo de Consentimento Livre e Esclarecido (TCLE), sendo as dúvidas elucidadas pela equipe de coleta em campo.

O presente estudo obteve aprovação pelo Comitê de Ética em Pesquisa do Hospital das Clínicas da Faculdade de Medicina de Ribeirão Preto da Universidade de São Paulo (parecer $\mathrm{n}^{\circ}$ 2356461/2017), com a dispensa de aplicação do TCLE.

\section{V.8 - Instrumentos utilizados}

$\mathrm{Na}$ avaliação realizada no pré-natal, foi aplicado um questionário padronizado que continha informações sobre: identificação da participante; dados socioeconômicos e demográficos; hábitos de vida; características da gestação atual e do pré-natal. Realizou-se ainda uma avaliação antropométrica contemplando: peso (em quilograma) e altura (em metros).

$\mathrm{Na}$ ocasião do nascimento, as puérperas foram entrevistadas novamente por meio de questionário padronizado com questões sobre: identificação da participante; dados socioeconômicos e demográficos; hábitos de vida; dados da saúde sexual e reprodutiva; informações sobre morbidades; características da gestação e do pré-natal; características do parto e do nascimento e informes colhidos diretamente do prontuário, conforme necessidade. Foram também aplicados questionários às mães para obtenção de informações sobre os seus filhos. Ainda, algumas informações adicionais sobre os recém-nascidos foram obtidas dos respectivos prontuários, a saber: peso (em gramas) e comprimento (em centímetros).

Por fim, ao longo do primeiro e terceiro ano de vida das crianças foram avaliadas as mães e seus respectivos filhos através da aplicação de um novo questionário que abordava a alimentação e saúde dos infantes; dados de saúde, métodos de contracepção e hábitos de vida da mãe; informações socioeconômicas, demográficas e de relacionamento. Neste momento, realizou-se mais uma vez o exame físico da mãe, mensurando-se o peso (em quilograma) e altura (em metros); em relação à criança, foram obtidos dados como peso (em quilogramas) e comprimento (em centímetros). 
As avaliações antropométricas foram executadas utilizando-se fita métrica inextensível para medição das circunferências e perímetros; antropômetro portátil para aferição das estaturas - para indivíduos com dois ou mais anos de idade - (com o participante em pé, descalço, ereto, cabeça erguida e olhando para um ponto fixo, braços estendidos ao longo do corpo, calcanhares e ombros alinhados) e comprimentos - para indivíduos com menos de dois anos de idade - (com a criança estendida e disposta em um local plano, a cabeça foi posicionada contra a parte fixa do antropômetro e os demais membros foram mantidos eretos com os pés em $90^{\circ}$ em relação ao eixo corporal e em contato com a superfície do aparelho); finalmente, para determinação do peso foi usada uma balança digital tipo Monitor de Composição Corporal modelo Tanita® (com a avaliada em pé, ereta, descalça, joelhos esticados e calcanhares alinhados com os eletrodos).

\section{V.9 - Organização do banco de dados}

Realizou-se um plano de codificação e foi elaborado um manual, convertendo as variáveis-resposta dos questionários em uma classificação numérica para consecutiva digitação no banco. Os questionários foram codificados e digitados em duplicata, com posterior conferência por técnica de amostragem (10\% das fichas), para identificação de erros sistemáticos. Conforme conferência, as fichas foram adicionadas no banco por duas pessoas capacitadas.

O banco de dados foi criado em Microsoft Office Access 2010, interligando-se as variáveis maternas e dos recém-nascidos pelo número de identificação (código fornecido durante a avaliação do pré-natal). Todas as variáveis que constituem o banco passaram por testes de consistência na entrada da digitação dos dados.

\section{V.10 - Variáveis de interesse ao presente estudo}

V.10.1 - Variável dependente:

- Classificação nutricional das crianças entre o primeiro e terceiro ano de vida: classificado de acordo com o índice antropométrico de IMC/Idade segundo as curvas da OMS de 2006 e definição do Sistema de Vigilância Alimentar e Nutricional (SISVAN) (Tabela 1). Para a realização da análise estatística, os indivíduos foram categorizados em dois grupos, ou seja, com excesso de peso (risco de sobrepeso, sobrepeso e obesidade) e não excesso de 
peso (eutrofia e magreza) e também em três grupos, com excesso de peso (sobrepeso e obesidade), sem excesso de peso (eutrofia e magreza) e em risco de sobrepeso.

Tabela 1 - Classificação do estado nutricional definido pelo SISVAN para o indicador antropométrico de IMC/Idade segundo as curvas da OMS (2006) para menores de 5 anos

\begin{tabular}{ccc}
\hline \multicolumn{2}{c}{ Valores estabelecidos para percentil e escore-z } & Classificação nutricional \\
\hline$<$ Percentil 0,1 & $<$ Escore- $\mathrm{z}-3$ & Magreza acentuada \\
$\geq$ Percentil $0,1 \mathrm{e}<$ percentil 3 & $\geq$ Escore-z $-3 \mathrm{e}<$ escore-z -2 & Magreza \\
$\geq$ Percentil $3 \mathrm{e} \leq$ percentil 85 & $>$ Escore- $\mathrm{z}-2 \mathrm{e} \leq$ escore- $\mathrm{z}+1$ & Eutrofia \\
$>$ Percentil $85 \mathrm{e} \leq$ percentil 97 & $>$ Escore- $\mathrm{z}+1 \mathrm{e} \leq$ escore- $\mathrm{z}+2$ & Risco de sobrepeso \\
$>$ Percentil $97 \mathrm{e} \leq$ percentil 99,9 & $>$ Escore- $\mathrm{z}+2 \mathrm{e} \leq$ escore- $\mathrm{z}+3$ & Sobrepeso \\
$>$ Percentil 99,9 & $>$ Escore- $\mathrm{z}+3$ & Obesidade \\
\hline
\end{tabular}

Fonte: SISVAN (2011).

V.10.2 - Variáveis independentes:

- Aleitamento materno exclusivo (AME): duração em meses. Para a análise estatística, categorizou-se a variável em três grupos: $<1$ mês, $\geq 1$ e $<4$ meses e $\geq 4$ meses.

- Aleitamento materno (AM): duração em meses, independentemente de ser exclusivo ou complementado com outros tipos de leite e/ou alimentos.

- Exposição a outros alimentos que não o leite materno: idade de introdução (em meses) de alimentos sólidos e semissólidos, líquidos e leite/fórmulas infantis. Para a análise estatística, considerou-se o tempo de exposição (em meses) do primeiro alimento introduzido que não o leite materno. A variável foi categorizada em tempo de exposição de até 3 meses de idade e maior que 3 meses de idade.

- Escolinha/creche: frequência da criança em escolinha ou creche ("sim" ou "não") e idade de início (em meses).

- Paridade: categorizada em multípara ou primípara. 
- Situação conjugal materna: categorizada em "com companheiro" (casada ou união consensual) e "sem companheiro" (solteira, separada/divorciada ou viúva).

- Trabalho materno remunerado: categorizado em "sim" ou "não".

- Relação de trabalho materno: categorizada em assalariada, autônoma, realização de "bicos" ou empregador.

- Condições socioeconômicas: em salário mínimo, posteriormente classificados de acordo com a pontuação por estrato socioeconômico da Associação Brasileira de Empresas de Pesquisa (ABEP) em A, B, C, D e E. Para a análise estatística, foi categorizada em dois grupos de acordo com a frequência encontrada, ou seja, $\mathrm{A} / \mathrm{B} / \mathrm{C}$ e $\mathrm{D} / \mathrm{E}$.

- Peso materno: medido entre o primeiro e terceiro ano de vida da criança e classificado de acordo com os valores para adultos do Índice de Massa Corporal (IMC) (WHO, 1997), através da fórmula "peso/altura" (Tabela 2). Para a análise estatística foram categorizados dois grupos de acordo com a classificação do IMC, isto é, com excesso de peso (sobrepeso/obesidade) e não excesso de peso (eutrofia/magreza).

Tabela 2 - Classificação do estado nutricional segundo IMC para adultos

\begin{tabular}{cc}
\hline IMC $\left(\mathbf{k g} / \mathbf{m}^{2}\right)$ & Classificação do estado nutricional \\
\hline$<18,5$ & Baixo peso \\
$\geq 18,5$ e $\leq 24,9$ & Peso adequado \\
$\geq 25,0$ e $\leq 29,9$ & Sobrepeso \\
$\geq 30$ e $\leq 39,9$ & Obesidade \\
$>40,0$ & Obesidade mórbida \\
\hline
\end{tabular}

Fonte: World Health Organization (1997).

- Peso ao nascer: categorizado em baixo peso ao nascer (BPN), $<2.500 \mathrm{~g}$, ou sem baixo peso ao nascer (SBP), $\geq 2.500 \mathrm{~g}$. 
- Hábito de sucção não nutritiva (uso de chupeta e/ou hábito de chupar dedos pela criança): categorizada em “ainda chupa", “já chupou” ou "nunca chupou”.

- Orientações sobre amamentação durante a gestação: categorizada em "sim" ou "não".

- Trabalho paterno/companheiro remunerado: categorizada em "sim" ou "não".

- Escolaridade materna: categorizados em ensino fundamental completo, ensino médio completo ou nível superior completo ou incompleto.

- Idade gestacional: em dias.

- Tipo de parto: categorizado em normal e cesárea.

- Uso de fumo, álcool e drogas pela mãe: categorizado em "sim" ou "não"; tipo de consumo (vinho/cerveja/destilados).

- Idade materna: em anos.

- Cor da pele materna (etnia): categorizada em etnia branca; preta/negra; parda/mulata/morena; amarelo/oriental.

- Internações hospitalares da criança: categorizada em sim ou não.

Para análise da hipótese levantada e para se atingir os objetivos propostos, construiu-se um modelo teórico com base nas variáveis relacionadas às questões de interesse e discutidas na literatura científica. Consecutivamente, as variáveis selecionadas foram analisadas através de um Diagrama Acíclico Direcionado (“Directed Acyclic Graph” - DAG) construído para o estudo. O DAG permite a identificação de potenciais fatores de confusão e a eliminação de variáveis que não causarão efeito no desfecho final da análise; assim, o DAG auxilia nas decisões sobre o condicionamento das variáveis visando um maior controle dos fatores de 
confusão na associação entre a exposição e o desfecho e, consequentemente, reduzindo ao máximo o viés de seleção das variáveis.

A teoria envolvendo os DAGs mostra-se como uma possível ferramenta a ser utilizada em estudos epidemiológicos. Através da construção de modelos gráficos, definidos como diagramas causais, há a investigação das relações causais entre as variáveis de um problema, identificando-se às que devem ser controladas e os possíveis fatores de confusão.

O diagrama causal construído para o estudo foi realizado através do software DAGitty. A partir do DAG (Figura 2), as variáveis identificadas foram: exposição aos outros alimentos, condições socioeconômicas, peso materno, peso ao nascer e tipo de parto.

Figura 2 - Gráfico acíclico direcionado (DAG) proposto para identificação e seleção das variáveis integrantes do modelo de análise do estudo "Impacto do aleitamento materno exclusivo no sobrepeso e obesidade em filhos de mães com excesso de peso"

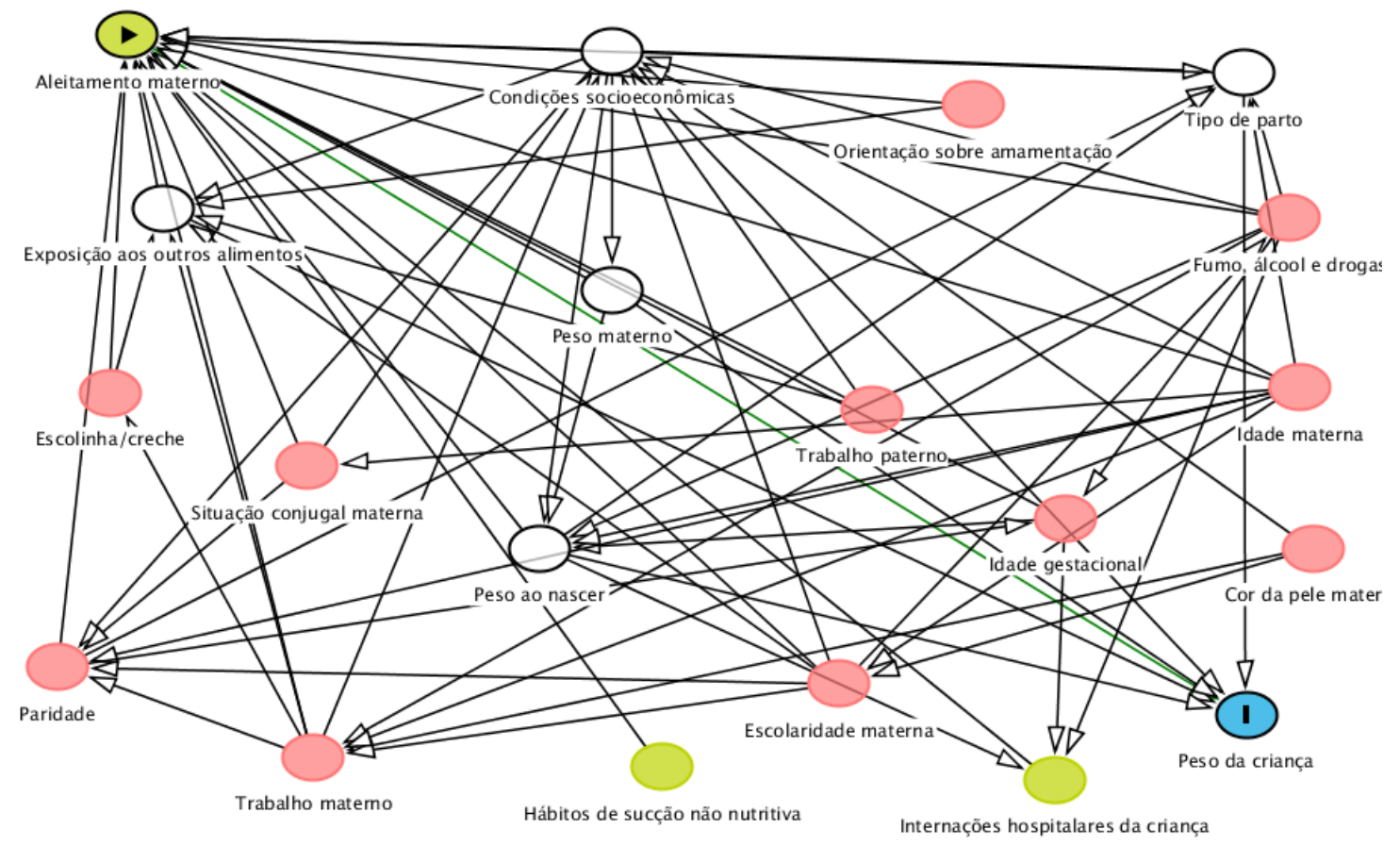

Fonte: DAGitty (2018).

(1) Variável de desfecho;

Variável de exposição;

Variável relacionada à exposição;

Variável relacionada ao desfecho;

Variável relacionada à exposição e ao desfecho;

Variável indicada para ajuste. 


\section{V.11 - Análise estatística}

Para a caracterização da amostra de estudo, foi realizada a descrição das variáveis a partir da determinação de medidas de tendência central (média e/ou mediana) e de dispersão (desvio padrão), além de valores percentuais.

Para a associação das variáveis de interesse (condições socioeconômicas, exposição aos outros alimentos, peso materno, AME, peso ao nascer e tipo de parto) com o excesso de peso no seguimento foram estimados riscos relativos (brutos e ajustados) e seus respectivos intervalos de confiança de 95\% (IC95\%), obtidos por meio de modelos de regressões logbinomiais.

Para a descrição e classificação dos índices antropométricos da criança, utilizaram-se os softwares WHO Anthro 3.2.2 e Epiinfo 7.2.

Os softwares SAS 9.4 e RStudio 8.3 foram utilizados para as análises estatísticas. 


\section{VI - RESULTADOS}

Dentre as 1.400 mulheres e seus pares incluídos na coorte de pré-natal, cerca de 1.069 $(76,3 \%)$ completaram as três etapas de estudo. Como nem todos os entrevistados souberam responder a todas as perguntas - opção "Não sabe" no questionário -, o número amostral foi bastante oscilante entre as variáveis.

A idade média materna foi de 26,4 anos $(\mathrm{DP}=6,1)$, sendo a maioria pertencente à etnia branca $(53,3 \%)$, vivendo com parceiros $(84,9 \%)$ e não exercendo atividade remunerada $(48,9 \%)$ (Tabela 3).

Tabela 3 - Situação socioeconômica das mães pertencentes ao estudo "Impacto do aleitamento materno exclusivo no sobrepeso e obesidade em filhos de mães com excesso de peso" (Ribeirão Preto, 2010-2013)

\begin{tabular}{cccc}
\hline Características & & n & \% \\
\hline \multirow{2}{*}{ Etnia } & Branca & 566 & 53,3 \\
& Negra & 117 & 11,0 \\
& Parda & 373 & 35,2 \\
& Oriental & 5 & 0,5 \\
& Ensino & & \\
Escolaridade & Fundamental & 287 & 26,9 \\
& Ensino Médio & 691 & 64,8 \\
& Superior & 39 & 3,7 \\
Atividade remunerada & Incompleto & & 4,7 \\
& Superior & 50 & 48,9 \\
& Completo & 524 & 51,1 \\
& Sim & 547 & 78,1 \\
Relação de trabalho & Não & & 3,8 \\
& Assalariado & 409 & 18,1 \\
& Empregador & 20 & \\
& Autônomo & 95 & 84,9 \\
& Com & & 15,1 \\
\hline \multirow{2}{*}{ Situação conjugal } & companheiro & 908 &
\end{tabular}

O hábito de fumar foi observado em $23,6 \%$ da amostra $(n=252)$, destes, 55,2\% permaneceram fumando durante a gestação. 25,4\% relataram a ingestão de algum tipo de bebida alcóolica durante a gestação. A maior parte dos partos deu-se pela via natural (60,3\%) e grande 
parcela das mães $(73,4 \%)$ havia recebido orientação sobre amamentação no período gestacional. A gestação atual não havia sido planejada para 56,1\% (Tabela 4).

Tabela 4 - Fatores relacionados à gestação de mães pertencentes ao estudo "Impacto do aleitamento materno exclusivo no sobrepeso e obesidade em filhos de mães com excesso de peso" (Ribeirão Preto, 2010-2013)

\begin{tabular}{cccc}
\multicolumn{1}{c}{ Características } & & $\mathbf{n}$ & \% \\
\hline \multirow{2}{*}{ Hábito de fumar } & Sim & 139 & 55,2 \\
& Não & 113 & 44,8 \\
Ingestão de bebida alcóolica & Sim & 271 & 25,4 \\
& Não & 798 & 74,6 \\
Planejamento da gestação & Sim & 468 & 43,9 \\
& Não & 598 & 56,1 \\
Orientação sobre amamentação & & & 73,4 \\
& Sim & 283 & 26,6 \\
Tipo de parto & Não & & 60,3 \\
& & 645 & 39,7 \\
\hline
\end{tabular}

A paridade média foi de dois filhos/mãe $(D P=1)$. Sobre as características antropométricas maternas, houve um aumento progressivo na média do IMC no decorrer das fases de vida da mesma (isto é, do período pré-gestacional até o final da gestação); observouse uma redução da média do IMC no seguimento, porém com um valor ainda maior do que o encontrado no momento que antecedeu a gestação (Tabela 5).

Tabela 5 - Características antropométricas de mães pertencentes ao estudo "Impacto do aleitamento materno exclusivo no sobrepeso e obesidade em filhos de mães com excesso de peso" (Ribeirão Preto, 2010-2013)

\begin{tabular}{ccccc}
\hline Antropometria & n & Média & Mediana & DP \\
\hline Peso pré-gestacional $(\mathrm{kg})$ & 1033 & 64,0 & 62,0 & 14,9 \\
Estatura $(\mathrm{cm})$ & 1069 & 161,0 & 161,0 & 6,3 \\
IMC pré-gestacional $\left(\mathrm{kg} / \mathrm{m}^{2}\right)$ & 1033 & 24,6 & 23,7 & 5,4 \\
Peso no pré-natal $(\mathrm{kg})$ & 1066 & 70,9 & 68,8 & 14,8 \\
IMC no pré-natal $\left(\mathrm{kg} / \mathrm{m}^{2}\right)$ & 1066 & 27,3 & 26,5 & 5,3 \\
Peso ao final da gestação $(\mathrm{kg})$ & 995 & 78,0 & 76,7 & 14,9 \\
IMC ao final da gestação $\left(\mathrm{kg} / \mathrm{m}^{2}\right)$ & 995 & 30,0 & 29,4 & 5,3 \\
Peso no seguimento $(\mathrm{kg})$ & 1062 & 70,4 & 67,6 & 17,0 \\
IMC no seguimento $\left(\mathrm{kg} / \mathrm{m}^{2}\right)$ & 1062 & 27,1 & 25,9 & 6,2 \\
\hline
\end{tabular}

IMC = Índice de Massa Corporal; DP = desvio padrão. 
No período anterior à atual gestação, 25,9\% apresentavam-se com excesso de peso e 14,3\%, obesidade. Em relação a recomendação de ganho de peso por classificação do IMC prégestacional do Institute of Medicine (IOM, 2009), observa-se que apenas as mulheres obesas ou com sobrepeso evoluíram com um ganho de peso médio maior do que o recomendado (Tabela 6).

Tabela 6 - Ganho de peso durante a gestação de acordo com o IMC pré-gestacional e recomendação da IOM antropométricas de mães pertencentes ao estudo "Impacto do aleitamento materno exclusivo no sobrepeso e obesidade em filhos de mães com excesso de peso" (Ribeirão Preto, 20102013)

\begin{tabular}{|c|c|c|c|c|c|c|c|}
\hline $\begin{array}{c}\text { Estado } \\
\text { nutricional pré- } \\
\text { gestacional }\end{array}$ & $\begin{array}{c}\text { IMC } \\
\left(\mathrm{kg} / \mathrm{m}^{2}\right)\end{array}$ & $\mathbf{n}$ & $\%$ & Média (kg) & Mediana (kg) & DP $(\mathbf{k g})$ & $\begin{array}{c}\text { Recomendação } \\
\text { IOM (kg) }\end{array}$ \\
\hline Baixo peso & $<18,5$ & 74 & 7,2 & 16,3 & 16,0 & 6,2 & 12,5 a 18 \\
\hline Peso adequado & $\begin{array}{l}\geq 18,5 \mathrm{e} \\
\leq 24,9\end{array}$ & 543 & 52,6 & 14,9 & 14,3 & 6,2 & 11 a 16 \\
\hline Sobrepeso & $\begin{array}{l}\geq 25,0 \mathrm{e} \\
\leq 29,9\end{array}$ & 268 & 25,9 & 13,7 & 14,0 & 6,6 & 7 a 11,5 \\
\hline Obesidade & $\geq 30$ & 148 & 14,3 & 10,1 & 9,9 & 7,5 & 5 a 9 \\
\hline
\end{tabular}

IMC = Índice de Massa Corporal; DP = desvio padrão; IOM = Institute of Medicine (2009).

No seguimento, quando comparado com os dados do período pré-gestacional, nota-se uma diminuição no percentual de mulheres com peso adequado, de 52,6 para 38,2\%, ao mesmo tempo de um aumento no número de sobrepeso e obesidade, de 25,9 para 31,2\% e de 14,3 para $26,9 \%$, consecutivamente (Tabela 7).

Tabela 7 - Estado nutricional pelo IMC no período entre um e três anos após o parto de mães pertencentes ao estudo "Impacto do aleitamento materno exclusivo no sobrepeso e obesidade em filhos de mães com excesso de peso" (Ribeirão Preto, 2010-2013)

\begin{tabular}{cccc}
\hline Estado nutricional & $\mathbf{I M C}\left(\mathbf{k g} / \mathbf{m}^{\mathbf{2}}\right)$ & $\mathbf{n}$ & $\boldsymbol{\%}$ \\
\hline Baixo peso & $<18,5$ & 39 & 3,7 \\
Peso adequado & $\geq 18,5 \mathrm{e} \leq 24,9$ & 406 & 38,2 \\
Sobrepeso & $\geq 25,0 \mathrm{e} \leq 29,9$ & 331 & 31,2 \\
Obesidade & $\geq 30$ & 286 & 26,9 \\
\hline
\end{tabular}

IMC = Índice de Massa Corporal; DP = desvio padrão. 
Entre aquelas mães com diagnóstico nutricional compatível com peso adequado no período pré-gestacional, 37,4\% evoluíram para excesso de peso (sobrepeso e obesidade) no seguimento. A maior parte das mulheres com sobrepeso permaneceram com o mesmo estado nutricional, porém uma parcela significativa $(39,0 \%)$ tornou-se obesa no período. Já entre as obesas, a maioria $(94,5 \%)$ manteve-se no mesmo patamar (Tabela 8 ).

Tabela 8 - Evolução do estado materno pelo IMC entre o período pré-gestacional e um a três anos após o parto de mães pertencentes ao estudo "Impacto do aleitamento materno exclusivo no sobrepeso e obesidade em filhos de mães com excesso de peso" (Ribeirão Preto, 2010-2013)

\begin{tabular}{|c|c|c|c|c|c|c|}
\hline $\begin{array}{c}\text { IMC } \\
\left(\mathrm{kg} / \mathrm{m}^{2}\right)\end{array}$ & $\begin{array}{c}\text { Estado } \\
\text { nutricional } \\
\text { pré- } \\
\text { gestacional }\end{array}$ & $\mathbf{N}$ & $\%$ & $\begin{array}{c}\text { Estado } \\
\text { nutricional } \\
\text { materno no } \\
\text { seguimento* }\end{array}$ & $\mathbf{n}$ & $\%$ \\
\hline$<18,5$ & Baixo peso & 74 & 7,2 & $\begin{array}{c}\text { Baixo peso } \\
\text { Peso adequado } \\
\text { Sobrepeso } \\
\text { Obesidade }\end{array}$ & $\begin{array}{c}26 \\
46 \\
2 \\
0\end{array}$ & $\begin{array}{c}35,1 \\
62,2 \\
2,7 \\
0\end{array}$ \\
\hline 18,5 a 24,9 & $\begin{array}{c}\text { Peso } \\
\text { adequado }\end{array}$ & 545 & 52,8 & $\begin{array}{c}\text { Baixo peso } \\
\text { Peso adequado } \\
\text { Sobrepeso } \\
\text { Obesidade }\end{array}$ & $\begin{array}{c}10 \\
331 \\
180 \\
24\end{array}$ & $\begin{array}{c}1,8 \\
60,7 \\
33,0 \\
4,4\end{array}$ \\
\hline 25 a 29,9 & Sobrepeso & 267 & 25,9 & $\begin{array}{c}\text { Baixo peso } \\
\text { Peso adequado } \\
\text { Sobrepeso } \\
\text { Obesidade }\end{array}$ & $\begin{array}{c}1 \\
23 \\
139 \\
104\end{array}$ & $\begin{array}{c}0,4 \\
8,6 \\
52,1 \\
39,0\end{array}$ \\
\hline$\geq 30$ & Obesidade & 146 & 14,1 & $\begin{array}{c}\text { Baixo peso } \\
\text { Peso adequado } \\
\text { Sobrepeso } \\
\text { Obesidade }\end{array}$ & $\begin{array}{c}0 \\
3 \\
5 \\
138\end{array}$ & $\begin{array}{c}0 \\
2,1 \\
3,4 \\
94,5\end{array}$ \\
\hline
\end{tabular}

IMC = Índice de Massa Corporal; DP = desvio padrão; *Seguimento: um a três anos após o parto.

$32,0 \%$ das mães com peso adequado ao final da gestação tornaram-se obesas ou com sobrepeso no seguimento. Entre as mulheres com sobrepeso, 59,6\% permaneceram na mesma faixa e 22,5\% evoluíram para obesidade. Já sobre as obesas, 14,2\% passaram para sobrepeso e $81,7 \%$ continuaram na mesma classificação de IMC (Tabela 9). 
Tabela 9 - Evolução do estado materno pelo IMC do final da gestação ao seguimento das mulheres pertencentes ao estudo "Impacto do aleitamento materno exclusivo no sobrepeso e obesidade em filhos de mães com excesso de peso" (Ribeirão Preto, 2010-2013)

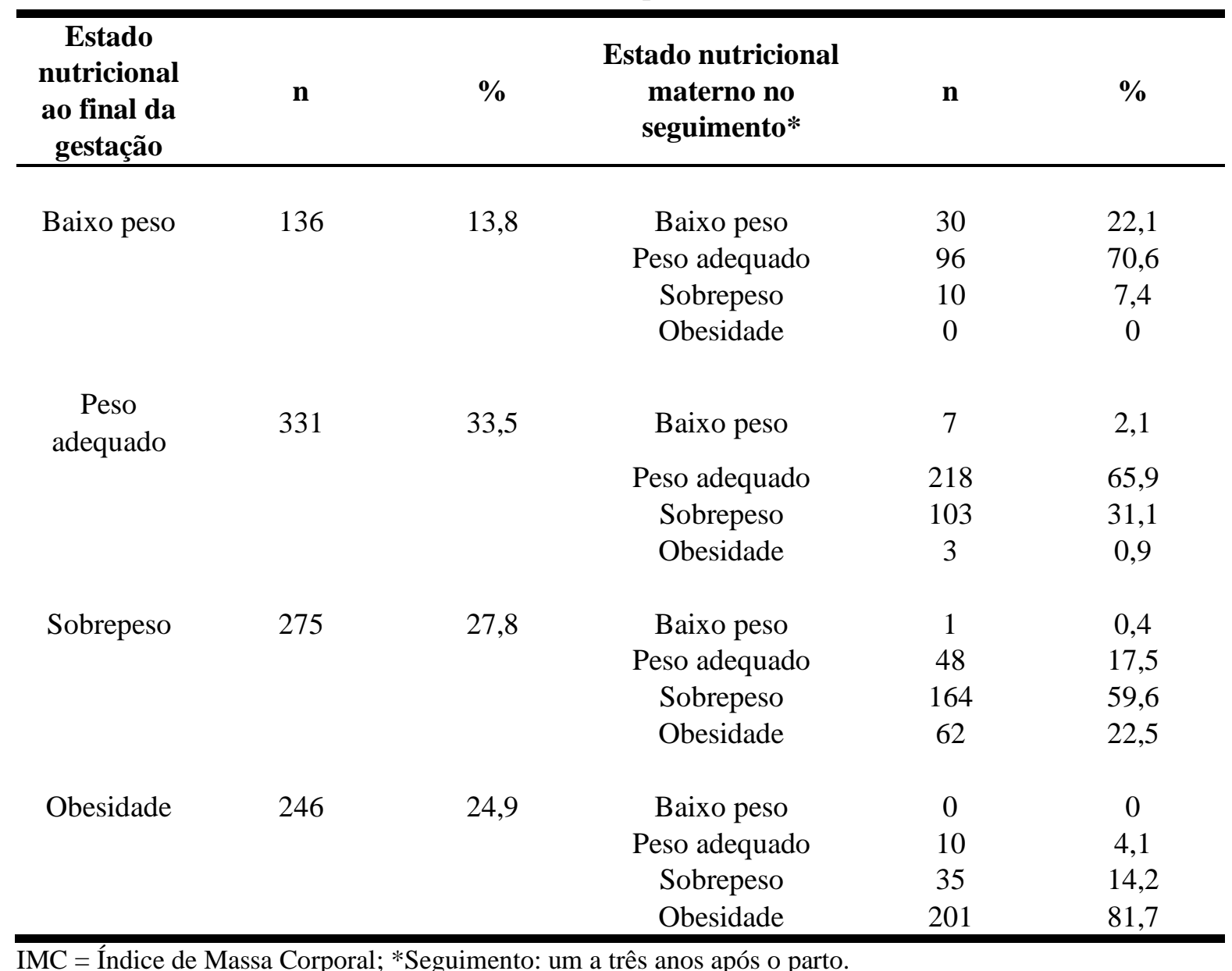

IMC = Índice de Massa Corporal; *Seguimento: um a três anos após o parto.

As famílias inseridas no presente estudo eram compostas por uma média de 3 residentes $(\mathrm{DP}=1,5)$ e dispunham de uma renda familiar mensal em cerca de 3 salários mínimos. A maioria das mães, $84,0 \%$, residiam com um companheiro, sendo este considerado o chefe da família para $73,1 \%$. Ainda, em $51,9 \%$ dos domicílios não havia a presença de outros filhos (Tabela 10). 
Tabela 10 - Características relacionados à residência familiar de mães pertencentes ao estudo "Impacto do aleitamento materno exclusivo no sobrepeso e obesidade em filhos de mães com excesso de peso" (Ribeirão Preto, 2010-2013)

\begin{tabular}{cccc}
\hline Características & & $\mathbf{n}$ & \% \\
\hline \multirow{2}{*}{ ABEP } & Classe A & 58 & 5,8 \\
& Classe B & 278 & 27,6 \\
& Classe C & 590 & 58,6 \\
& Classe D e E & 81 & 8,0 \\
Presença de companheiro & & & \\
& Sim & 898 & 84,0 \\
Presença de outros filhos & Não & 171 & 16,0 \\
& & & \\
& Sim & 514 & 48,1 \\
Chefe da família & Não & 555 & 51,9 \\
& & & 7,7 \\
& Entrevistada & 72 & 73,1 \\
& Companheiro & 779 & 19,2 \\
\hline
\end{tabular}

Em relação às crianças, existiu um equilíbrio entre os sexos (49,2\% masculino e 50,8\%, feminino); a idade média das crianças na entrevista do seguimento foi de 22,6 meses (DP = $3,4)$, distribuída da seguinte forma: 9,0\% de 1 a 1,5 ano $(\mathrm{n}=96) ; 71,7 \%, 1,6$ a 2,0 anos ( $\mathrm{n}=$ $767) ; 16,7 \%, 2,1$ a $2,5 \operatorname{anos}(\mathrm{n}=179) ; 2,5 \%$, de 2,6 a 3 anos $(\mathrm{n}=27) .47,4 \%$ frequentavam escolinha/creche, com uma idade média de início de 13,0 meses (DP $=5,8)$ e 25,3\% ainda estavam sendo amamentados no momento da última etapa da entrevista (Tabela 11). 
Tabela 11 - Características das crianças entre um e três anos de idade pertencentes ao estudo "Impacto do aleitamento materno exclusivo no sobrepeso e obesidade em filhos de mães com excesso de peso" (Ribeirão Preto, 2010-2013)

\begin{tabular}{|c|c|c|c|c|c|c|}
\hline \multicolumn{2}{|c|}{ Características } & \multirow{2}{*}{$\begin{array}{c}\mathbf{n} \\
526\end{array}$} & \multirow{2}{*}{$\begin{array}{c}\% \\
49,2\end{array}$} & \multirow{2}{*}{$\begin{array}{c}\text { Média } \\
-\end{array}$} & \multirow{2}{*}{$\begin{array}{c}\text { Mediana } \\
-\end{array}$} & \multirow{2}{*}{$\begin{array}{l}\text { DP } \\
-\end{array}$} \\
\hline Sexo & Masculino & & & & & \\
\hline & Feminino & 543 & 50,8 & - & - & - \\
\hline \multirow{2}{*}{$\begin{array}{l}\text { Internações do } \\
\text { nascimento até o } \\
\text { seguimento }\end{array}$} & Sim & 109 & 10,3 & - & - & - \\
\hline & Não & 955 & 89,7 & - & - & - \\
\hline \multirow{2}{*}{$\begin{array}{l}\text { Frequência em } \\
\text { escolinha/creche }\end{array}$} & Sim & 505 & 47,4 & - & - & - \\
\hline & Não & 562 & 52,6 & - & - & - \\
\hline Início da ida (meses) & - & 501 & - & 13,0 & 12,0 & 5,8 \\
\hline \multirow{2}{*}{$\begin{array}{c}\text { Amamentação no } \\
\text { momento da } \\
\text { entrevista }\end{array}$} & Sim & 270 & 25,3 & - & - & - \\
\hline & Não & 797 & 74,7 & - & - & - \\
\hline \multirow[t]{3}{*}{$\begin{array}{l}\text { Hábito de chupar o } \\
\text { dedo }\end{array}$} & $\begin{array}{l}\text { Ainda } \\
\text { chupa }\end{array}$ & 52 & 4,9 & - & - & - \\
\hline & Já chupou & 35 & 3,3 & - & - & - \\
\hline & $\begin{array}{l}\text { Nunca } \\
\text { chupou }\end{array}$ & 979 & 91,8 & - & - & - \\
\hline \multirow[t]{3}{*}{$\begin{array}{l}\text { Hábito de chupar } \\
\text { chupeta }\end{array}$} & $\begin{array}{l}\text { Ainda } \\
\text { chupa }\end{array}$ & 437 & 41,0 & - & - & - \\
\hline & Já chupou & 76 & 7,1 & - & - & - \\
\hline & $\begin{array}{l}\text { Nunca } \\
\text { chupou }\end{array}$ & 533 & 50,9 & - & - & - \\
\hline
\end{tabular}

$\mathrm{DP}=$ desvio padrão.

O peso médio ao nascer foi de $3,2 \mathrm{~kg}(\mathrm{DP}=0,5)$ e de $12,0 \mathrm{~kg}$ no seguimento $(\mathrm{DP}=1,8$ ) (Tabela 12). 
Tabela 12 - Características antropométricas das crianças entre um e três anos de idade pertencentes ao estudo "Impacto do aleitamento materno exclusivo no sobrepeso e obesidade em filhos de mães com excesso de peso" (Ribeirão Preto, 2010-2013)

\begin{tabular}{ccccc}
\hline Antropometria & n & Média & Mediana & DP \\
\hline Peso ao nascer $(\mathrm{kg})$ & 1069 & 3,2 & 3,2 & 0,5 \\
Comprimento ao nascer (cm) & 1060 & 48,7 & 49,0 & 2,5 \\
Idade gestacional (dias) & 1069 & 273,9 & 275,0 & 13,9 \\
Peso no seguimento (kg) & 1069 & 12,0 & 11,8 & 1,8 \\
Comprimento no seguimento & & & & \\
$(\mathrm{cm})$ & 1069 & 85,6 & 85,5 & 4,5 \\
\hline
\end{tabular}

DP = desvio padrão.

O estado nutricional, através do índice antropométrico de IMC/I, demonstrou que 7,5\% apresentavam-se com excesso de peso (sobrepeso e obesidade), sendo 6,3\% classificadas com sobrepeso e $1,2 \%$, obesidade. Uma parcela relevante da amostra, 17,4\%, mostrava-se em risco de sobrepeso; resultados muito semelhantes foram encontrados com o índice peso/estatura (Tabela 13).

Tabela 13 - Estado nutricional no seguimento das crianças entre um e três anos de idade pertencentes ao estudo "Impacto do aleitamento materno exclusivo no sobrepeso e obesidade em filhos de mães com excesso de peso" (Ribeirão Preto, 2010-2013)

\begin{tabular}{cccc}
\hline Índices antropométricos & Estado nutricional & n & \% \\
\hline \multirow{2}{*}{ Peso/Idade } & Baixo peso & 13 & 1,3 \\
& Peso adequado & 1003 & 93,7 \\
& Peso elevado & 53 & 5 \\
Estatura/Idade & Baixa estatura & 39 & 3,6 \\
& Estatura adequada & 1030 & 96,4 \\
& Magreza & 14 & 1,3 \\
& Eutrofia & 799 & 74,7 \\
Peso/Estatura & Risco de sobrepeso & 184 & 17,2 \\
& Sobrepeso & 60 & 5,6 \\
& Obesidade & 12 & 1,1 \\
& Magreza & 15 & 1,4 \\
& Eutrofia & 788 & 73,7 \\
& Risco de sobrepeso & 186 & 17,4 \\
& Sobrepeso & 67 & 6,3 \\
IMC/Idade & Obesidade & 13 & 1,2 \\
\hline
\end{tabular}

IMC = Índice de Massa Corporal. 
Sobre a rotina alimentar da criança, a duração média do AME foi de 3,7 meses (DP = 2,2) e do AM, 8,6 meses (DP = 6,2). Em relação à mediana, obteve-se um valor de 4,0 meses para o AME e de 7,0 meses para o AM. A média de idade da introdução de alimentos sólidos e semissólidos foi de 5,6 meses e a mediana, 6,0 meses. Em relação à média da idade de introdução de leite que não o materno e de fórmulas infantis foi de 3,8 meses e a mediana, 4,0 meses. Finalmente, média da idade de introdução de outros líquidos que não o leite foi de 3,7 meses e a mediana, 4,0 meses (Tabela 14).

Tabela 14 - Rotina alimentar das crianças entre um e três anos de idade pertencentes ao estudo "Impacto do aleitamento materno exclusivo no sobrepeso e obesidade em filhos de mães com excesso de peso" (Ribeirão Preto, 2010-2013)

\begin{tabular}{ccccc}
\hline Alimentação & n & Média & Mediana & DP \\
\hline $\begin{array}{c}\text { Duração do AME (meses) } \\
\text { Idade de introdução de } \\
\text { alimentos sólidos e }\end{array}$ & 1063 & 3,7 & 4,0 & 2,3 \\
$\begin{array}{c}\text { semissólidos (meses) } \\
\text { Idade de introdução de } \\
\text { líquidos (meses) }\end{array}$ & 1061 & 5,6 & 6,0 & 1,5 \\
$\begin{array}{c}\text { Idade de introdução de } \\
\text { leite/fórmulas (meses) }\end{array}$ & 1065 & 3,7 & 4,0 & 2,3 \\
Duração do AM (meses) & 1064 & 3,8 & 4,0 & 2,4 \\
\hline desvio padrão. & 755 & 8,6 & 7,0 & 6,2 \\
\hline
\end{tabular}

Não foram encontradas alterações entre a mediana de duração do AME de acordo com o estado nutricional da mãe. Sobre o AM, houve uma ligeira redução na duração entre aquelas com sobrepeso (Tabela 15). 
Tabela 15 - Duração da amamentação de acordo com o estado nutricional de mães pertencentes ao estudo "Impacto do aleitamento materno exclusivo no sobrepeso e obesidade em filhos de mães com excesso de peso" no período entre um e três anos após o parto (Ribeirão Preto, 2010-2013)

\begin{tabular}{|c|c|c|c|c|c|}
\hline Estado nutricional materno no seguimento* & Amamentação & $\mathbf{n}$ & $\begin{array}{c}\text { Média } \\
\text { (meses) }\end{array}$ & $\begin{array}{c}\text { Mediana } \\
\text { (meses) }\end{array}$ & $\begin{array}{c}\text { DP } \\
\text { (meses) }\end{array}$ \\
\hline \multirow[t]{2}{*}{ Baixo peso } & $\mathrm{AME}$ & \multirow{2}{*}{39} & 3,9 & 4,0 & 2,3 \\
\hline & $\mathrm{AM}$ & & 8,0 & 7,0 & 6,0 \\
\hline \multirow[t]{2}{*}{ Peso adequado } & AME & \multirow{2}{*}{407} & 3,8 & 4,0 & 2,2 \\
\hline & $\mathrm{AM}$ & & 9,2 & 7,0 & 6,6 \\
\hline \multirow[t]{2}{*}{ Sobrepeso } & AME & \multirow{2}{*}{335} & 3,5 & 4,0 & 2,3 \\
\hline & $\mathrm{AM}$ & & 8,2 & 6,0 & 6,2 \\
\hline \multirow{2}{*}{ Obesidade } & $\mathrm{AM}$ & \multirow{2}{*}{287} & 3,7 & 4,0 & 2,3 \\
\hline & $\mathrm{AM}$ & & 8,4 & 7,0 & 5,8 \\
\hline
\end{tabular}

$\mathrm{DP}$ = desvio padrão; $\mathrm{AME}=$ aleitamento materno exclusivo; $\mathrm{AM}=$ aleitamento materno; *Seguimento: um a três anos após o parto.

As tabelas 16 e 17 apresentam, respectivamente, o risco relativo bruto e ajustado do modelo final para as variáveis selecionadas no estudo, analisando-se apenas os dados de filhos de mães com excesso de peso (sobrepeso e obesidade). Foi considerada portadora de excesso de peso toda criança que apresentasse a classificação antropométrica do SISVAN/OMS como sobrepeso ou obesidade ou ainda, risco de sobrepeso. 
Tabela 16 - Riscos relativos brutos e seus respectivos intervalos de confiança para as variáveis de interesse em relação ao estado nutricional das crianças entre um e três anos de idade, filhos de mães com excesso de peso, pertencentes ao estudo "Impacto do aleitamento materno exclusivo no sobrepeso e obesidade em filhos de mães com excesso de peso" (Ribeirão Preto, 2010-2013)

\begin{tabular}{|c|c|c|c|c|c|}
\hline & \multicolumn{2}{|c|}{$\mathrm{IMC} / \mathrm{I}$} & \multicolumn{3}{|c|}{ IC95\% } \\
\hline & $\begin{array}{l}\text { Risco/Sobrepeso/Obeso } \\
(\mathrm{n} ; \%)\end{array}$ & $\begin{array}{c}\text { Sem excesso de } \\
\text { peso } \\
(\mathrm{n} ; \%)\end{array}$ & $\begin{array}{l}\text { RR } \\
\text { bruto }\end{array}$ & LI & LS \\
\hline \multicolumn{6}{|l|}{ AME } \\
\hline$<1 \mathrm{~m}$ & $26(25,49)$ & $76(74,51)$ & 0,89 & 0,60 & 1,31 \\
\hline $1 \mathrm{a} 4 \mathrm{~m}$ & $89(30,48)$ & $203(69,52)$ & 1,06 & 0,81 & 1,39 \\
\hline$>4 \mathrm{~m}$ & $65(28,76)$ & $161(71,24)$ & ref & ref & ref \\
\hline \multicolumn{6}{|l|}{ Outros alimentos } \\
\hline $\begin{array}{c}\text { Tempo de exposição }<3 \\
\text { meses }\end{array}$ & $74(28,24)$ & $188(71,76)$ & ref & ref & ref \\
\hline $\begin{array}{c}\text { Tempo de exposição }>3 \\
\text { meses }\end{array}$ & $58(30,05)$ & $135(69,95)$ & 1,06 & 0,80 & 1,42 \\
\hline \multicolumn{6}{|l|}{ ABEP } \\
\hline Classes A, B e C & $123(28,34)$ & $311(71,66)$ & ref & ref & ref \\
\hline Classes D e E & $50(31,06)$ & $111(68,94)$ & 1,10 & 0,83 & 1,44 \\
\hline \multicolumn{6}{|l|}{ Tipo de parto } \\
\hline Normal & $110(31,61)$ & $238(68,39)$ & ref & ref & ref \\
\hline Cesárea & $73(26.45)$ & $203(73,55)$ & 0,83 & 0,65 & 1,07 \\
\hline \multicolumn{6}{|l|}{ Peso de nascimento } \\
\hline BPN & $6(17,14)$ & $29(82,86)$ & ref & ref & ref \\
\hline SBPN & $177(30,05)$ & $412(69,95)$ & 1,75 & 0,84 & 3,67 \\
\hline
\end{tabular}

$\mathrm{AME}=$ aleitamento materno exclusivo; $\mathrm{m}=$ meses; $\mathrm{IMC}=$ índice de massa corporal; ABEP = Associação Brasileira de Empresas de Pesquisa; BPN = baixo peso ao nascer; SBPN = sem baixo peso ao nascer; RR = risco relativo; ref = referência; LI = limite inferior; LS = limite superior; IC95\% = intervalo de confiança de $95 \%$. 
Tabela 17 - Riscos relativos ajustados para o AME e seus respectivos intervalos de confiança para as variáveis de interesse em relação ao estado nutricional das crianças entre um e três anos de idade, filhos de mães com excesso de peso, pertencentes ao estudo "Impacto do aleitamento materno exclusivo no sobrepeso e obesidade em filhos de mães com excesso de peso" (Ribeirão Preto, 2010-2013)

\begin{tabular}{ccccccc}
\hline & IMC/I & & & \multicolumn{2}{c}{ Todas as } \\
variáveis & IC95\% \\
& $\begin{array}{c}\text { Risco/Sobrepeso/Obeso } \\
(\mathrm{n} ; \%)\end{array}$ & $\begin{array}{c}\text { Sem excesso de peso } \\
(\mathrm{n} ; \%)\end{array}$ & RRaj & LI & LS \\
\hline AME & & & & & \\
$<1 \mathrm{~m}$ & $26(25,49)$ & $76(74,51)$ & 0,61 & 0,33 & 1,15 \\
$1 \mathrm{a} 4 \mathrm{~m}$ & $89(30,48)$ & $203(69,52)$ & 0,86 & 0,55 & 1,34 \\
$>4 \mathrm{~m}$ & $65(28,76)$ & $161(71,24)$ & ref & ref & ref \\
\hline
\end{tabular}

AME $=$ aleitamento materno exclusivo; $\mathrm{m}=$ meses; $\mathrm{IMC}=$ índice de massa corporal; RRaj $=$ risco relativo ajustado; ref = referência; LI = limite inferior; LS = limite superior; IC95\% = intervalo de confiança de 95\%. *Refere-se às variáveis mencionadas (outros alimentos; ABEP; tipo de parto e peso de nascimento).

Já nas tabelas 18 e 19 há apresentação dos riscos relativos brutos e ajustados, respectivamente, do modelo final para as variáveis selecionadas no estudo, diferenciando-se das tabelas anteriores pela definição de excesso de peso da criança, utilizando-se apenas os dados de filhos de mães com excesso de peso (sobrepeso e obesidade). Para esta análise, o excesso de peso das crianças foi assim definido: sobrepeso e obesidade. 
Tabela 18 - Riscos relativos brutos e seus respectivos intervalos de confiança para as variáveis de interesse em relação ao estado nutricional das crianças entre um e três anos de idade, filhos de mães com excesso de peso, pertencentes ao estudo "Impacto do aleitamento materno exclusivo no sobrepeso e obesidade em filhos de mães com excesso de peso" (Ribeirão Preto, 2010-2013)

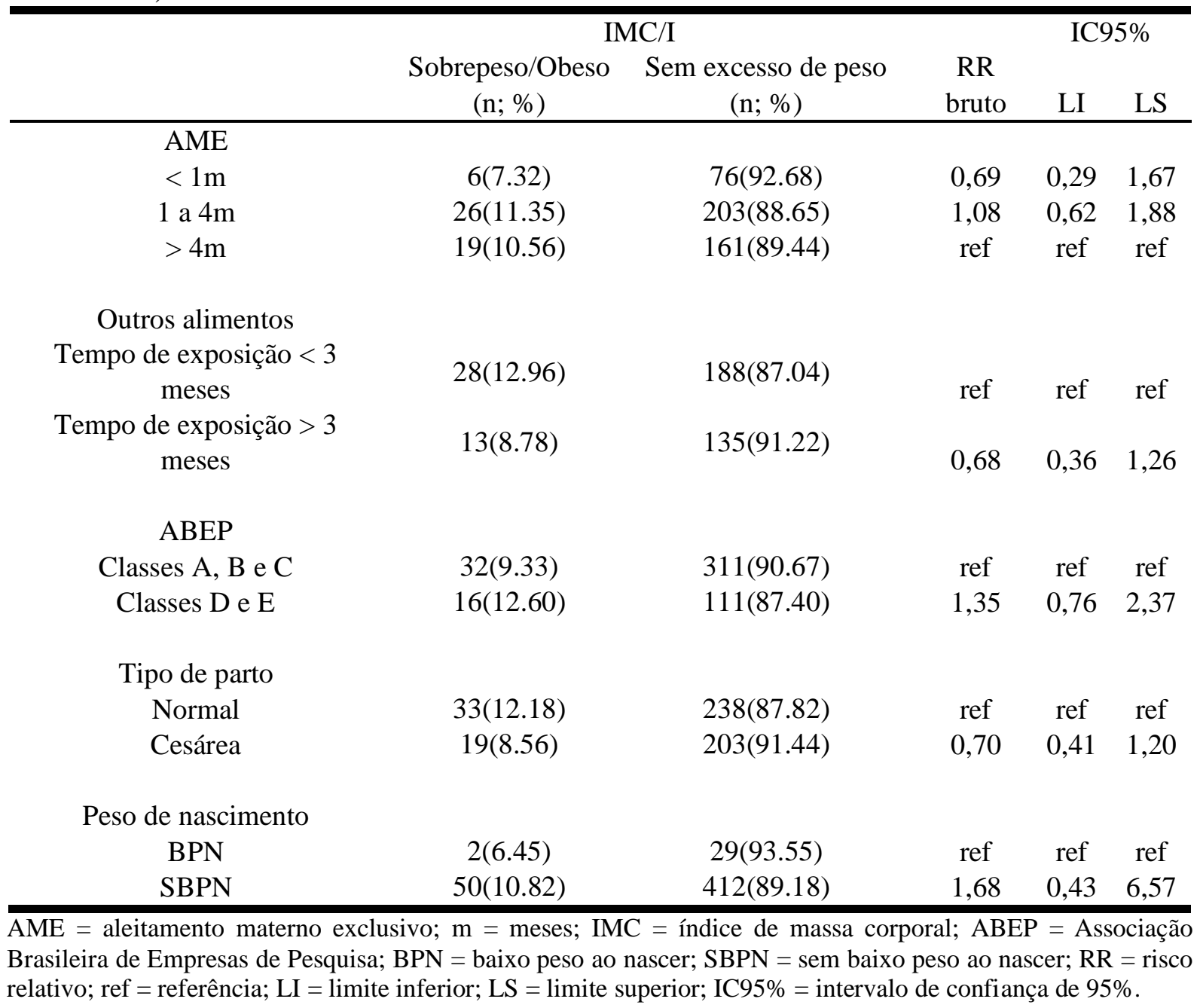


Tabela 19 - Riscos relativos ajustados para o AME e seus respectivos intervalos de confiança para as variáveis de interesse em relação ao estado nutricional das crianças entre um e três anos de idade, filhos de mães com excesso de peso, pertencentes ao estudo "Impacto do aleitamento materno exclusivo no sobrepeso e obesidade em filhos de mães com excesso de peso" (Ribeirão Preto, 2010-2013)

\begin{tabular}{ccccccc}
\hline & IMC/I & & \multicolumn{3}{c}{ Todas as } \\
variáveis & IC95\% \\
& $\begin{array}{c}\text { Sobrepeso/Obeso } \\
(\mathrm{n} ; \%)\end{array}$ & $\begin{array}{c}\text { Sem excesso de peso } \\
(\mathrm{n} ; \%)\end{array}$ & RRaj & LI & LS \\
\hline AME & & & & & & \\
$<1 \mathrm{~m}$ & $6(7.32)$ & $76(92.68)$ & 0,30 & 0,08 & 1,16 \\
$1 \mathrm{a} 4 \mathrm{~m}$ & $26(11.35)$ & $203(88.65)$ & 0,55 & 0,27 & 1,13 \\
$>4 \mathrm{~m}$ & $19(10.56)$ & $161(89.44)$ & ref & ref & ref \\
\hline
\end{tabular}

$\overline{\mathrm{AME}}=$ aleitamento materno exclusivo $\mathrm{m}=$ meses; $\mathrm{IMC}=$ índice de massa corporal; RRaj $=$ risco relativo ajustado; ref = referência; LI = limite inferior; LS = limite superior; IC95\% = intervalo de confiança de 95\%.

*Refere-se às variáveis mencionadas (outros alimentos; ABEP; tipo de parto e peso de nascimento).

Dessa forma, entre os filhos de mães com excesso de peso, não se observaram diferenças entre o RR das variáveis selecionadas para o excesso de peso entre os lactentes que estiveram em AME por um período mais prolongado ( $\geq 4,0$ meses) quando comparados aos que foram amamentados por menor tempo.

Nas tabelas 20 e 21 há a análise pelo modelo global das variáveis selecionadas, isto é, sem considerar apenas os filhos de mães com excesso de peso. Foi definida como portadora de excesso de peso toda criança que apresentasse a classificação antropométrica do SISVAN/OMS como sobrepeso ou obesidade ou ainda, risco de sobrepeso. 
Tabela 20 - Modelo global dos riscos relativos brutos e seus respectivos intervalos de confiança para as variáveis de interesse em relação ao estado nutricional das crianças entre um e três anos de idade pertencentes ao estudo "Impacto do aleitamento materno exclusivo no sobrepeso e obesidade em filhos de mães com excesso de peso" (Ribeirão Preto, 20102013)

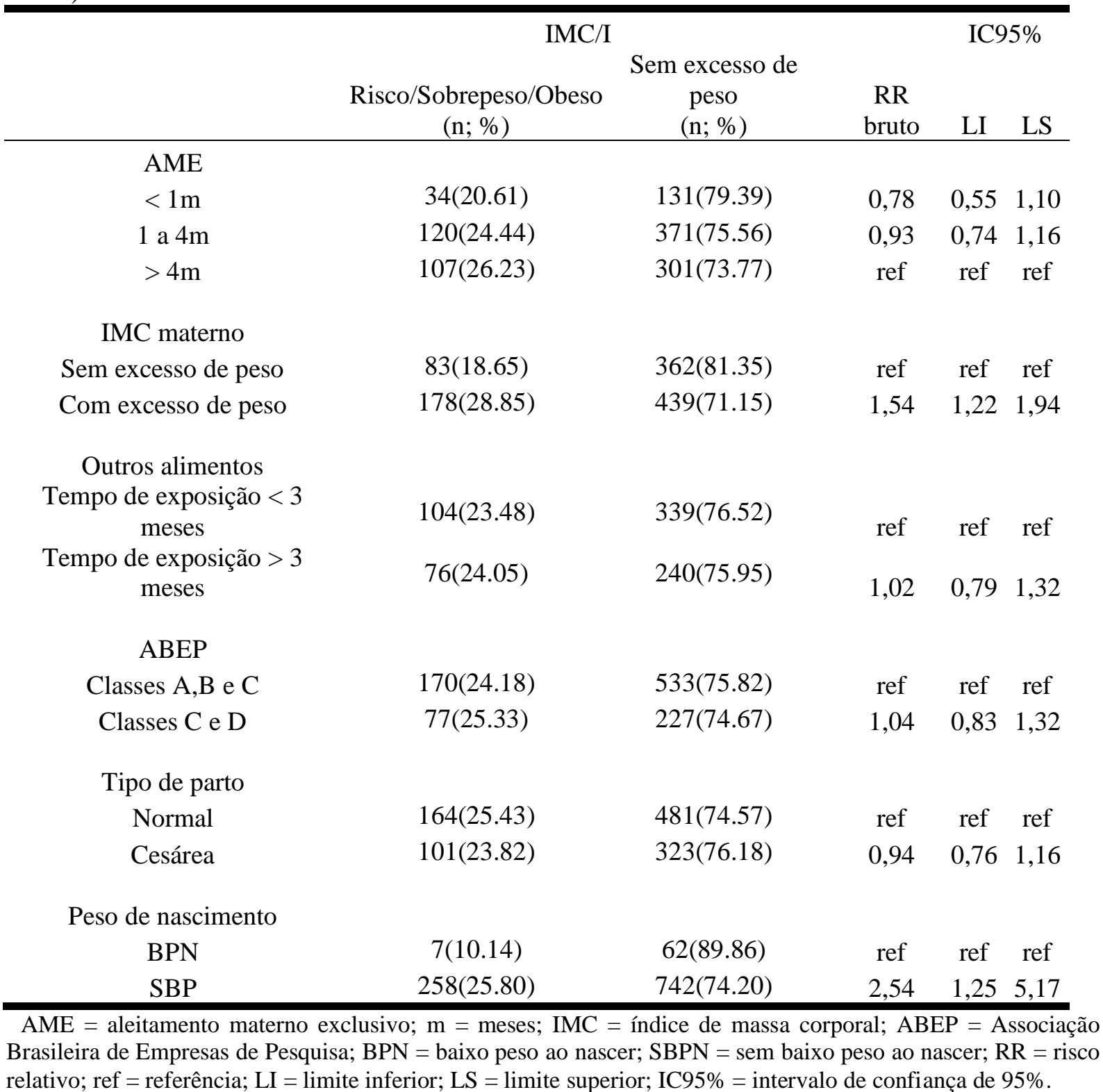

relativo; ref = referência; $\mathrm{LI}=$ limite inferior; $\mathrm{LS}=$ limite superior; IC95\% = intervalo de confiança de $95 \%$. 
Tabela 21 - Modelo global dos riscos relativos brutos e seus respectivos intervalos de confiança para as variáveis de interesse em relação ao estado nutricional das crianças entre um e três anos de idade pertencentes ao estudo "Impacto do aleitamento materno exclusivo no sobrepeso e obesidade em filhos de mães com excesso de peso" (Ribeirão Preto, 2010-2013)

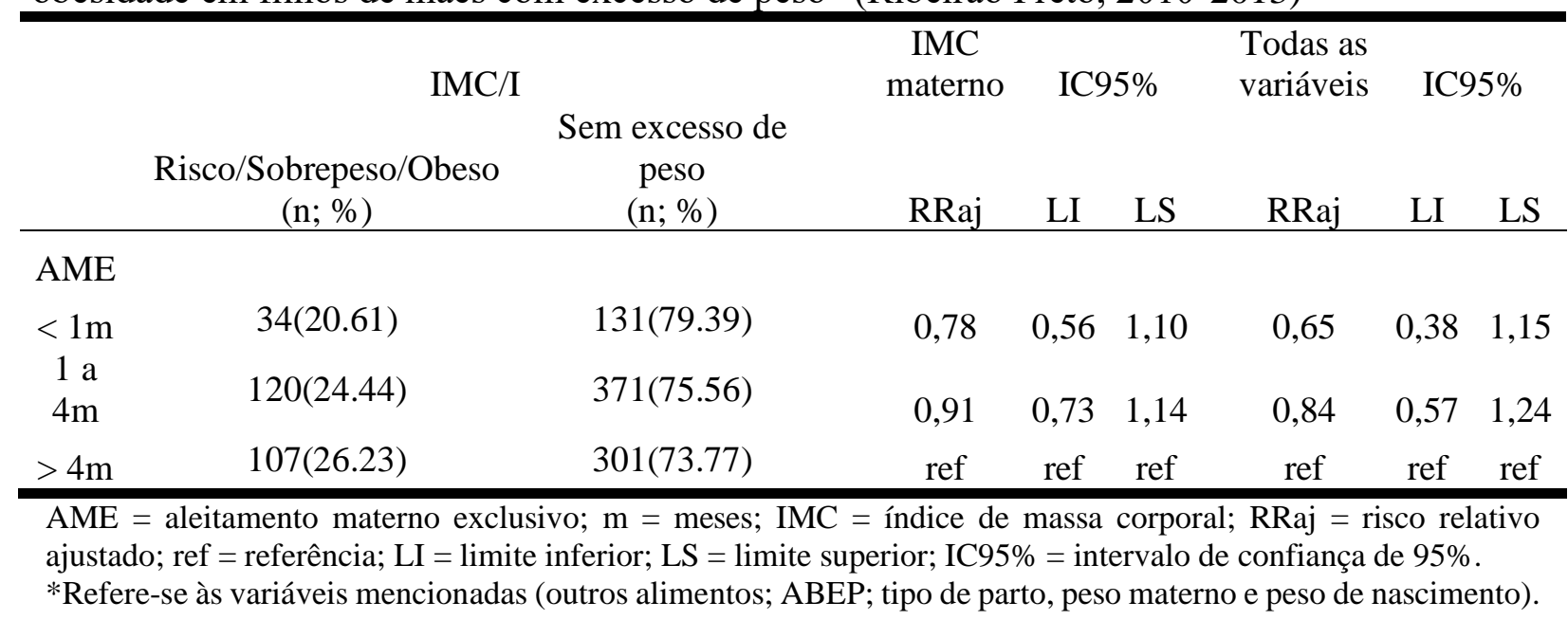

Analisados de forma independente, mães com sobrepeso e obesidade apresentaram risco relativo (RR) de 1,54 (IC95\%:1,22-1,94) de terem filhos com excesso de peso. O peso de nascimento $(\mathrm{RR}=2.54$; IC95\%:1,25-5,17) também se mostrou associado ao estado nutricional das crianças no seguimento. Após o ajuste para o IMC materno e demais variáveis, não se observaram diferenças entre o RR para o excesso de peso entre os lactentes que estiveram em $\mathrm{AME} \geq 4,0$ meses e naqueles que estiveram por um período inferior.

Nas tabelas 22 e 23 há a análise pelo modelo global das variáveis selecionadas, isto é, sem considerar apenas os filhos de mães com excesso de peso. Foi definida como portadora de excesso de peso toda criança que apresentasse a classificação antropométrica do SISVAN/OMS como sobrepeso ou obesidade. 
Tabela 22 - Modelo global dos riscos relativos brutos e seus respectivos intervalos de confiança para as variáveis de interesse em relação ao estado nutricional das crianças entre um e três anos de idade pertencentes ao estudo "Impacto do aleitamento materno exclusivo no sobrepeso e obesidade em filhos de mães com excesso de peso" (Ribeirão Preto, 20102013)

\begin{tabular}{|c|c|c|c|c|c|}
\hline & \multicolumn{2}{|c|}{ IMC/I } & & \multicolumn{2}{|c|}{ IC95\% } \\
\hline & $\begin{array}{c}\text { Sem excesso de } \\
\text { peso } \\
(\mathrm{n} ; \%)\end{array}$ & $\begin{array}{c}\text { Sobrepeso/Obesidade } \\
\text { (n; \%) }\end{array}$ & $\begin{array}{l}\text { RR } \\
\text { bruto }\end{array}$ & LI & LS \\
\hline \multicolumn{6}{|l|}{ AME } \\
\hline$<1 \mathrm{~m}$ & $155(94.51)$ & $9(5.49)$ & 0,68 & 0,33 & 1,39 \\
\hline $1 \mathrm{a} 4 \mathrm{~m}$ & 454(92.46) & $37(7.54)$ & 0,93 & 0,60 & 1,46 \\
\hline$>4 \mathrm{~m}$ & 375(91.91) & $33(8.09)$ & ref & ref & ref \\
\hline \multicolumn{6}{|l|}{ IMC materno } \\
\hline Sem excesso de peso & 417(93.71) & $28(6.29)$ & ref & ref & ref \\
\hline Com excesso de peso & 566(91.73) & $51(8.27)$ & 1,31 & 0,84 & 2,05 \\
\hline \multicolumn{6}{|l|}{ Outros alimentos } \\
\hline $\begin{array}{c}\text { Tempo de exposição }<3 \\
\text { meses }\end{array}$ & 404(91.20) & $39(8.80)$ & ref & ref & ref \\
\hline $\begin{array}{c}\text { Tempo de exposição }>3 \\
\text { meses }\end{array}$ & 296(93.67) & $20(6.33)$ & 0,72 & 0,43 & 1,21 \\
\hline \multicolumn{6}{|l|}{ ABEP } \\
\hline Classes A,B,C & 655(93.17) & $48(6.83)$ & ref & ref & ref \\
\hline Classes C e D & 279(91.78) & $25(8.22)$ & 1,20 & 0,76 & 1,92 \\
\hline \multicolumn{6}{|l|}{ Tipo de parto } \\
\hline Normal & 594(92.09) & $51(7.91)$ & ref & ref & ref \\
\hline Cesárea & 395(93.16) & $29(6.84)$ & 0,87 & 0,56 & 1,34 \\
\hline \multicolumn{6}{|l|}{ Peso de nascimento } \\
\hline BPN & 67(97.10) & $2(2.90)$ & ref & ref & ref \\
\hline SBP & 922(92.20) & $78(7.80)$ & 2,69 & 0,68 & 10,72 \\
\hline
\end{tabular}


Tabela 23 - Modelo global dos riscos relativos ajustados e seus respectivos intervalos de confiança para as variáveis de interesse em relação ao estado nutricional das crianças entre um e três anos de idade pertencentes ao estudo "Impacto do aleitamento materno exclusivo no sobrepeso e obesidade em filhos de mães com excesso de peso" (Ribeirão Preto, 20102013)

\begin{tabular}{|c|c|c|c|c|c|c|c|c|}
\hline & & MC/I & $\begin{array}{l}\text { IMC } \\
\text { materno }\end{array}$ & IC9 & $95 \%$ & $\begin{array}{c}\text { Todas as } \\
\text { variáveis* }\end{array}$ & IC9. & $5 \%$ \\
\hline & $\begin{array}{c}\text { peso } \\
(\mathrm{n} ; \%)\end{array}$ & $\begin{array}{c}\text { Sobrepeso/Obesidade } \\
(\mathrm{n} ; \%)\end{array}$ & RRaj & LI & LS & RRaj & LI & LS \\
\hline $\begin{array}{l}\text { AME } \\
<1 \mathrm{~m}\end{array}$ & $155(94.51)$ & $9(5.49)$ & 0,67 & 0,33 & 1,38 & 0,36 & 0,12 & 1,12 \\
\hline $\begin{array}{c}1 \mathrm{a} \\
4 \mathrm{~m} \\
>4 \mathrm{~m}\end{array}$ & $\begin{array}{l}454(92.46) \\
375(91.91)\end{array}$ & $\begin{array}{l}37(7.54) \\
33(8.09)\end{array}$ & $\begin{array}{c}0,90 \\
\text { ref }\end{array}$ & $\begin{array}{c}0,57 \\
\text { ref }\end{array}$ & $\begin{array}{c}1,42 \\
\text { ref }\end{array}$ & $\begin{array}{c}0,52 \\
\text { ref }\end{array}$ & $\begin{array}{c}0,26 \\
\text { ref }\end{array}$ & $\begin{array}{c}1,04 \\
\text { ref }\end{array}$ \\
\hline
\end{tabular}

Ao incluirmos a faixa "risco de sobrepeso" na classificação "sem excesso de peso", as diferenças encontradas anteriormente não se mantiveram na análise bruta. 


\section{VII - DISCUSSÃO}

O principal objetivo do estudo foi verificar se o AME (especialmente quando este tinha uma duração superior a 4,0 meses), mesmo em filhos de mães portadoras de sobrepeso e obesidade, seria um fator protetor ao desenvolvimento de excesso de peso entre os três primeiros anos de vida de crianças pertencentes a uma coorte. Além disso, visou também determinar a proporção de excesso de peso nas mães e seus respectivos filhos, bem como a duração da amamentação (AM e AME).

Até nosso conhecimento, destaca-se que são poucos os estudos com o mesmo foco de investigação e que tentam relacionar a duração da amamentação, principalmente do AME, no excesso de peso da criança em condições de obesidade materna.

Nos Estados Unidos, foi investigado se o AME (em comparação com a fórmula infantil industrializada) entre as mães obesas e eutróficas, estaria associado com um menor percentil no índice antropométrico de peso/comprimento (P/C) no $1^{\circ}$ ano de vida (YEUNG, LEFF e RHEE, 2016). Os resultados mostraram a amamentação exclusiva por quatro meses repercutindo em um menor aumento no percentil deste indicador em filhos de mães com excesso de peso.

Com dados de uma coorte nacional norte-americana de crianças entre o $2^{\circ}$ e o $14^{\circ}$ ano de vida, Li et al. (2012) relataram um maior risco de excesso de peso entre crianças de mães obesas e que nunca foram amamentadas quando comparadas àquelas que estiveram em aleitamento materno por um a três meses ou acima de quatro meses.

Em nosso estudo, não foi encontrada proteção conforme duração do AME para o excesso de peso em filhos de mães com sobrepeso e obesidade. Mais da metade das mulheres da amostra apresentaram excesso de peso e este fato pode ter contribuído para a não observância da proteção do AME contra o desenvolvimento de excesso de peso nas crianças. Além disso, é possível que o impacto do AME não seja tão expressivo na primeira infância, sem excluir a possibilidade de uma maior influência contra o desenvolvimento do excesso de peso em outras idades (SIMON et al., 2009; ARENZ et al., 2004; PACA et al., 2019; TAMBALIS et al., 2018). Ainda, também é possível que seja necessário um tempo mais longo de AME (seis meses) para que esse efeito de proteção seja notado, como já observado em outros estudos que não levaram em conta o estado nutricional das mães (CANFIELD et al., 2017; PALAO et al., 2019; RITO et al., 2019).

Por outro lado, sem se atentar especificamente ao estado nutricional materno, vários estudos observaram o "fator protetivo" do aleitamento materno em relação ao desenvolvimento do excesso de peso em fases posteriores da infância. 
Canfield et al. (2017), em estudo realizado nos Estados Unidos, observaram que a amamentação por um período superior a seis meses foi associada a um risco reduzido na ocorrência de obesidade entre crianças de dois anos de idade. No estudo de Palao et al. (2019) com crianças bolivianas de dois a cinco anos de idade, o AME, quando comparado com àquelas que não tinham sido amamentadas ou que foram por um período inferior a seis meses, foi associada a uma diminuição do risco de obesidade.

Rito et al. (2019), em um estudo transversal com amostra representativa de 22 países europeus, discutiram o efeito benéfico da amamentação contra a obesidade, que aumentou se as crianças nunca tivessem sido amamentadas ou amamentadas por menos tempo. O estudo utilizou dados de crianças de seis a nove anos de idade. A análise mostrou que, quando comparadas às crianças que foram amamentadas por, pelo menos, seis meses, as chances de serem obesas foram maiores entre as crianças que nunca foram amamentadas ou que foram por um período mais curto, tanto para o AM quanto para o AME.

Ainda, Jurado et al. (2016) realizaram um estudo com crianças mexicanas de dois a quatro anos de idade e relataram um risco quase três vezes maior de obesidade entre aquelas que foram amamentadas por menos de três meses.

Entretanto, vale ressaltar que alguns autores não observaram correlação entre excesso de peso e a duração de aleitamento materno (ZIVE et al., 2008; PUDLA et al., 2015; BURDETTE et al., 2006; GILLMAN et al., 2008; KWOK et al., 2010). Por outro lado, alguns estudos relataram que o AM - não apenas o exclusivo - pode trazer maiores benefícios protetivos contra a ocorrência do excesso de peso por uma provável relação protetora dosedependente (WEFFORT et al., 2018). No presente trabalho, não foi observada associação entre o excesso de peso infantil e a duração do AME. Uma das possíveis explicações para os achados em nosso trabalho é que - como já colocado anteriormente - a proteção considerada pela amamentação no excesso de peso infantil seja mais consistente e evidente em épocas mais tardias da infância, encontrando-se um efeito mais significativo do AM no IMC infantil em crianças a partir da segunda infância (GIBSON et al. 2016; WALLBY, LAGERBERG e MAGNUSSO, 2016). Ainda, outros fatores não abordados aqui - tais como, a alimentação da criança e o uso de fórmulas infantis -, podem estar exercendo um efeito mais acentuado no contexto discutido.

Neste estudo, 7,5\% das crianças apresentaram excesso de peso entre o primeiro e terceiro ano de vida, sendo $6,3 \%$ com sobrepeso e 1,2\%, obesidade; ainda, 17,4\% delas foram classificadas como em risco de sobrepeso pelo indicador de IMC/I. Nota-se que quase um 
quarto das crianças (incluindo aqueles lactentes classificados como em risco de sobrepeso) exibiam estado nutricional próximos ou acima dos limites para a eutrofia.

$\mathrm{Na}$ literatura, os valores de prevalência se diferenciam conforme a faixa etária considerada. Dois estudos com dados secundários da PNDS (2006) encontraram prevalências de excesso de peso (> escore- $\mathrm{Z}+2$ ) de 11,6\% em populações urbanas menores de cinco anos, sendo 6,5\% entre menores de dois anos de idade no Brasil e de 4,5\% apenas na região Sudeste (MULLER et al., 2014; COCCETI et al., 2012). Já Pereira et al. (2017), com dados da POF (2008-2009), relataram prevalências de 15,4\% em crianças de um ano, 13,7\%, de dois anos e 17,8\%, com três anos de idade. Os três estudos de prevalências apontados anteriormente utilizaram o indicador de P/E para definição de excesso de peso. Este fato deve ser considerado nas diferenças encontradas em relação ao presente trabalho. Por outro lado, deve ser salientado que as taxas de excesso de peso em nosso estudo utilizando o indicar P/E foram muito próximas as das observadas com o IMC/idade.

As diferenças entre as faixas etárias consideradas em cada estudo podem explicar as diferentes taxas de excesso de peso. Considerando que $80,7 \%$ da amostra eram de crianças menores de dois anos, as taxas do presente estudo se mostram maiores do que os dados oriundos da PNDS (2006) para o Brasil e a região Sudeste, embora menores do que os encontrados na POF (2008-2009).

Mueller et al. (2014) encontraram um maior percentual de recém-nascidos com $\geq 3.500$ $\mathrm{kg}$, de $30,9 \%$ versus os $27,1 \%$ aqui observados e também de bebês com $<2.500$, de 10,1\% e $6,4 \%$, respectivamente. Houve um menor percentual de crianças amamentadas por até 4,0 meses, de 54,7\% e 61,6\% no presente estudo, ainda, menor indicador de renda per capital familiar e de escolaridade materna. No estudo de Cocetti et al. (2012), 73,3\% apresentaram peso ao nascer $>3,0 \mathrm{~kg}$, aqui, 70,2\%. Menor porcentual de crianças amamentadas por até 5,0 meses, de $56,0 \%$ e aqui, $61,8 \%$. Menor indicador de renda per capita familiar e de escolaridade materna, com $62,3 \% \geq 7$ anos de estudo, contra $64,8 \%$ no presente trabalho. Assim, diferenças no peso ao nascer, na mediana do tempo de AME, na renda per capita e na escolaridade materna, podem ajudar a explicar as diferenças nas taxas de excesso de peso encontradas nas populações nos estudos citados e o presente estudo.

Muitos estudos abordam sobre a relação entre o peso ao nascer e o peso em outros momentos da infância. Aqui, considerando filhos de mães com ou não excesso de peso e tendo como referência as crianças classificadas com baixo peso ao nascer (BPN), as que nasceram sem essa particularidade (SBP) apresentaram um risco 2.54 vezes de terem excesso de peso entre o primeiro e terceiro ano de vida (não considerando o ajuste para os potenciais 
confundidores). As mesmas relações foram observadas no estudo de Reilly et al. (2005), em que a cada aumento de $100 \mathrm{~g}$ no peso ao nascer, houve um aumento em 1,05 no OR para a ocorrência de obesidade aos sete anos de idade. Kapral et al. (2018) realizaram um estudo com crianças menores de cinco anos e observaram um risco 1,91 vezes de terem excesso de peso. No estudo de Kim et al. (2018), 10\% das crianças com BPN desenvolveram sobrepeso ou obesidade, contra $15 \%$ naqueles com peso normal e mais de $25 \%$ entre os com alto peso ao nascer. Em comparação com os de peso normal ao nascer, aqueles com alto peso ao nascer tinham quase duas vezes mais chances de desenvolver excesso de peso aos 6 anos $(\mathrm{OR}=1,7-$ $2,35)$, enquanto os bebês com baixo peso ao nascer tinham mais probabilidade de ter baixo peso aos 6 anos em comparação aos de peso normal $(\mathrm{OR}=1,69-2,2)$.

O tipo de parto também é discutido no excesso de peso da criança durante a infância (GOMES et al., 2017; HUH et al., 2012; TAHA et al., 2019). Aqui, não foi encontrada associação. O elevado número de cesarianas $(39,7 \%)$ pode ser uma hipótese para a ausência de associação, pois os outros estudos encontraram taxas menores $(25,3 \%, 22,6 \%$ e 30,2\%, respectivamente).

Além disso, na análise bruta, considerando os filhos de mães eutróficas ou não, observou-se um risco 1,54 mais elevado de excesso de peso no lactente entre o primeiro e terceiro ano de vida quando a criança era filha de uma mãe com excesso de peso nessa fase da vida. Nossos achados vão de encontra ao estudo de Kneipp et al. (2015), com crianças matriculadas do $1^{\circ}$ ao $5^{\circ}$ ano em escolas de Itajaí (SC), em que $51 \%$ do excesso de peso esteve associado ao excesso de peso dos pais. Josey et al. (2019) observaram relação entre o IMC materno e o aumento geral de 0,04 no escore $\mathrm{z}$ da prole. Ainda, na revisão sistemática e metanálise de Heslehurst et al. (2019), foram observadas chances significativamente aumentadas para sobrepeso $(\mathrm{OR}=1,80)$ e obesidade $(\mathrm{OR}=1,89)$ infantil na vigência de excesso de peso materno.

Em nosso trabalho observou-se uma média de duração do AME aquém do recomendado pela OMS em decorrência do tempo de exposição aos outros alimentos que não o leite materno (principalmente pela introdução de leite ou fórmulas infantis). A importância desses fatores na gênese do excesso de peso infantil foi observada em estudos de Fisberg (2005), Carrazzoni et al. (2015) e Iguacel et al. (2019). Entretanto, essa variável não se mostrou como de risco no desenvolvimento do excesso de peso nas crianças no presente estudo. Mais uma vez, a idade (tempo de seguimento) dessas crianças pode ajudar a explicar tais achados, sendo possível que o efeito protetor do aleitamento materno contra o desenvolvimento do excesso de peso surja mais tarde. 
Vale a pena ser salientado que, no presente estudo, uma grande proporção de crianças frequentava escolinha/creche $(47,4 \%)$ e isso também poderia influenciar, em menor ou maior grau, o seu comportamento alimentar. Para Swinburn e Egger (2002) há uma soma de influências envolvidas no ambiente, sendo que, assim, o fácil acesso a hábitos saudáveis mostrase primordial para a promoção de um estilo de vida promovedor de saúde. Ainda, Saunders et al. (2012) relatam que o ambiente é intrinsecamente relacionado com a alimentação.

Pretto et al. (2014) encontraram excesso de peso em 56,8\% das crianças de três a seis anos que frequentavam uma creche em Porto Alegre (RS). Para estes, questões relacionadas ao ambiente e à própria alimentação, mostraram-se como fatores relevantes. No estudo de Dallabona et al. (2010) com crianças menores de cinco anos provenientes de creches públicas da cidade de Balneário Camboriú (SC), 87,8\% apresentavam-se eutróficas e 9,5\%, com sobrepeso. Idade inferior aos dois anos de idade, peso ao nascer, alto consumo alimentar na própria residência, foram os principais fatores associados à ocorrência de sobrepeso. Em nosso estudo, $80,7 \%$ das crianças tinham entre um a dois anos de idade, $47,7 \%$ frequentavam creches e a idade média de início foi de 13,0 meses. Não foi investigado o consumo alimentar das mesmas.

Muitos fatores associados ao ambiente, como sedentarismo, a ação dos meios de comunicação, fácil acesso infantil aos supermercados e o ambiente em que as mesmas estão inseridas, são fatores que podem favorecer a obesidade infantil (BOSWELL et al., 2019). Embora relevantes, tais fatores não foram abordados no presente estudo.

Sobre as características antropométricas maternas, houve um aumento no IMC médio do período pré-gestacional até o final da gestação (no nascimento da criança). Ao analisar o ganho de peso segundo a recomendação da IOM (2009) pela classificação do IMC prégestacional, percebe-se que somente as mães com excesso de peso (sobrepeso e obesidade) apresentaram um ganho médio superior ao recomendado. Nos estudos de Sato e Fujimore (2012); Nast et al. (2013) e Andreto et al. (2006) também foi observado associação entre o ganho de peso excessivo e o excesso de peso pré-gestacional. O estado nutricional materno inicial pode ser uma das hipóteses relacionadas ao ganho de peso excessivo na gestação no presente estudo.

Em nosso trabalho, após o nascimento e até o período entre o primeiro e terceiro ano de vida da criança, há uma diminuição no IMC médio, porém ainda maior do que no período prégestacional $\left(29,9 \mathrm{~kg} / \mathrm{m}^{2}\right.$ e $27,1 \mathrm{~kg} / \mathrm{m}^{2}$, respectivamente). Assim, o fato de já se iniciar a gestação com um maior IMC pré-gestacional e também apresentar um ganho de peso excessivo na 
gestação, aumentaria a chance de retenção de peso no pós-parto na amostra (CASTRO et al., 2009; REBELO et al., 2010; SKRYPNIK et al., 2019).

No momento anterior à gestação, 39,4\% das mulheres apresentavam-se com excesso de peso. No período entre o primeiro e terceiro ano após o parto, observou-se um aumento para $58,3 \%$ principalmente em decorrência das que eram eutróficas no período pré-gestacional. Entre essas, 60,7\% permaneceram com peso adequado, 33\% evoluíram para sobrepeso e 4,4\%, obesidade. Ao compararmos o estado nutricional materno ao final da gestação e no seguimento, percebe-se que 31,3\% das eutróficas avançaram para o sobrepeso; já entre as que já tinham sobrepeso, $22,5 \%$ tornaram-se obesas.

Como já discutido anteriormente, acredita-se que o ganho de peso excessivo na gestação e o acúmulo de peso no pós-parto, são capazes de explicar os acréscimos nos números. Apesar de não ter sido fornecidas informações sobre o consumo alimentar das mães do nosso estudo, discute-se que orientações nutricionais no acompanhamento nutricional da gestante poderiam evitar a ocorrência do ganho de peso excessivo na gestação, bem como no acúmulo de peso pós-parto, como visto no estudo de Rebelo et al. (2010).

Teruz (2017) destaca a diversidade e complexidade de aspectos, como biológicos, comportamentais e psicossociais, envolvidos no ganho de peso durante a gestação. Para Chagas et al. (2017), o ganho ponderal nesse período é o principal determinante para a retenção de peso no pós-parto em curto e longo prazo. Lipsky et al. (2012) ressaltam a gravidez e o pós-parto, pela exposição a fatores de risco desencadeantes do excesso de peso, como períodos extremamente relevantes para a saúde da mulher.

No presente trabalho, o AME foi praticado em média por quatro meses e o AM, por sete meses. A duração do AME deste estudo mostrou-se acima do levantado na II Pesquisa de Prevalência de Aleitamento Materno nas Capitais Brasileiras e Distrito Federal (IIPPAM) em 2008, que foi de menos de dois meses, porém, abaixo para o AM (11 meses). Resultados semelhantes ao nosso estudo forma encontrados por Freitas et al. (2010), Ramos et al. (2010) e Bastian et al. (2015) que observaram medianas de AME em torno dos três aos quatro meses.

Em relação à proporção de crianças em AME, apenas 23,8\% da amostra o fizeram por seis meses, um valor menor do que o divulgado em 2016 pelo Ministério da Saúde (41\%). Segundo informações veiculadas pelo mesmo órgão, estima-se que, neste ano, no continente americano, $38 \%$ das crianças sejam amamentadas de forma exclusiva até os seis meses, ao passo que somente $32 \%$ são continuamente amamentadas até os 24 meses. Em relação ao AM, na PNDS (2006), a mediana de duração foi de nove meses, valor próximo ao apresentado nos estudos de Minossi et al. (2013) e de Chaves et al. (2007), em cerca de oito meses. No presente 
estudo, 30,1\% das crianças foram amamentadas por mais de 12 meses e apenas 25,5\% ainda estavam sendo amamentadas no momento da entrevista (entre o primeiro e terceiro ano de vida).

Em nosso estudo, algumas hipóteses podem ser consideradas na baixa prevalência de AM, em particular, o de forma exclusiva. A elevada prevalência de partos cesarianos (HERGESSELLE e LOHMANN, 2017; SILVA et al., 2019; SANTOS et al., 2014; PRIOR et al., 2012; ESTEVES et al., 2014) e do uso de chupetas (SOARES et al., 2003; SPB, 2017; BUCCINI et al., 2016) podem ajudar a explicar esses achados.

Outros fatores podem ter influenciado na duração da prática do AME inferior àquela recomendada pela OMS no presente trabalho. Dentre esses, o não planejamento da gravidez pode ser um fator contribuinte, já que a gestação não havia sido planejada para mais da metade das mães. Alguns estudos relacionam a intenção materna pela gestação com o tempo de amamentação (KEDEEM et al., 2018; CHINEBUAH e ESCAMILLA, 2001; BRASILEIRO et al., 2010; VIEIRA et al., 2010).

Quase metade das mães (46,3\%) exerciam atividade remunerada; desse modo, o número considerável de mães que desempenhavam atividades laborais pode ajudar a explicar a baixa duração da amamentação neste grupo (FALEIROS et al., 2006; BAGIOLI et al., 2003; SIMON et al., 2009). É conhecido que muitas mães assalariadas não possuem trabalho formal e, à vista disso, não possuem proteção da lei trabalhista no que tange ao direito de se ausentar do trabalho no período pós-parto para amamentar o seu filho. Além disso, pela legislação brasileira, grande parte das mães com trabalho formal possui apenas um período de 120 dias de licença maternidade. Este lapso de tempo é o mesmo da mediana e muito próximo da média observada para o AME. Spinelli et al. (2002) evidenciaram o trabalho como um motivo alegado pelas mães para a interrupção precoce do aleitamento materno.

Por fim, ainda que não tenha sido abordado, fatores envolvidos no vínculo afetivo entre a mãe e o filho, crenças, mitos e valores culturais, utilização de medicamentos que podem ser transmitidos através do leite materno, oferecimento de outros alimentos - que não o leite materno - por parte das pessoas que convivem com a criança, falta de rede de apoio materno, enfermidades da nutriz e condições psicológicas, como depressão e stress, podem ser possíveis causas do desmame precoce (ARAÚJO et al., 2008).

Alguns pesquisadores relacionam o excesso de peso materno com um menor tempo de amamentação, bem como em sua iniciação (BJORSET et al., 2017; MANGEL et al., 2019; ODDY et al., 2006; PINHEIRO et al., 2018; HUANG et al., 2019). Aqui, a mediana de duração do AME e AM de acordo com o estado nutricional materno mostram-se bastante semelhantes entre si. Uma grande proporção de mães com excesso de peso no seguimento (entre um e três 
anos após o parto) - quase $60 \%$ - pode ajudar a explicar esse resultado, já que tal achado pode ter interferido nos resultados da análise.

Estudos ressaltam a importância do fornecimento de informações adequadas sobre a amamentação por parte dos gestores e profissionais de saúde para a população em geral (ARAÚJO et al., 2008; QUIRINO et al., 2011). Neste estudo, apesar da maioria das mulheres $(73,4 \%)$ relatarem o recebimento de orientação sobre a amamentação durante o pré-natal, como também observado por Alves et al. (2018) em 78,8\% das gestantes e por Pereira et al. (2010) em 76,2\%, a duração do AME esteve aquém do recomendada.

No estudo de Pereira et al. (2010) foi observado que as orientações sobre amamentação que ocorreram em grupo (31,9\% das mulheres) ocasionaram um aumento na prevalência do AME em 14\%. Não foram encontrados achados significativos em relação às consultas individuais. Guise et al. (2003) também destacam a importância das intervenções em grupo na atenção primária em saúde para o aumento das taxas da amamentação até os três meses. Os mesmos achados favoráveis sobre as orientações em grupo foram vistos por Oliveira (2005). Desta forma, a atenção deve ser dada não somente à informação propriamente dita, mas, também, à sua adequação (qualidade) ao "público-alvo", isto é, a futura nutriz e a sua família, nas ações realizadas e, ainda, na maneira de integração da gestante. Aqui, as orientações ocorreram em consulta individual e isso pode ter sido um fator associado à duração do AME abaixo do preconizado.

Como limitações deste estudo, cita-se a utilização única do IMC para classificação do estado nutricional materno. Apesar de representar um bom parâmetro antropométrico no âmbito da saúde pública, é inegável que outras ferramentas tornariam a definição do estado nutricional muito mais precisa.

Ademais, determinar o ambiente obesogênico apenas pelo ponto de vista antropométrico materno é uma visão muito reducionista, pois se sabe que outros fatores, como alimentação e estilo de vida, estão igualmente envolvidos. Acredita-se que, apesar de tal limitação, o peso materno pode estar refletindo, de forma factível, a condição ambiental, principalmente pela óptica da manutenção do estado nutricional materno nos mesmos níveis classificatórios em momentos distintos da avaliação.

Ainda, limitações inerentes ao método de pesquisa empregado, utilizando-se de um banco com dados já coletados, possui aspectos vantajosos e desfavoráveis. Sabe-se também que a utilização de questionário sempre possui os vieses de memória e de precisão das informações. Deve ser ressaltado também que as entrevistas da última etapa do estudo foram realizadas ao longo do segundo e terceiro anos de vida das crianças, em virtude da disponibilidade de 
comparecimento de seus responsáveis; consequentemente, há crianças com diferentes idades dentro da faixa etária estudada, o que pode ter afetado o resultado de algumas análises do presente trabalho. Finalmente, apesar de ter se utilizado de dados provenientes de um estudo de coorte, a presente pesquisa se constitui em um trabalho transversal; como tal, relações entre causa e efeito nem sempre são factíveis de serem demonstrados em estudo dessa natureza. 


\section{VIII - CONCLUSÃO}

Neste estudo, não foram observadas diferenças entre o risco de desenvolvimento de excesso de peso em filhos de mães com sobrepeso e obesidade segundo a duração do AME.

Foram observados altos percentuais de excesso de peso (sobrepeso e obesidade) entre as mães; em relação às crianças foram encontrados valores considerados moderados; entretanto, se as crianças classificadas como em "risco de sobrepeso" forem somadas aquelas com sobrepeso e obesidade, observa-se que um em cada quatro lactentes encontrava-se com o IMC próximo ou acima dos limites considerados normais.

A média e a mediana da duração do AME observada foi inferior à recomendada pela OMS; os mesmos achados foram observados em relação ao AM. Não houve importantes diferenças em relação às medianas de duração da amamentação pelo estado nutricional materno. 


\section{IX - REFERÊNCIAS ${ }^{1}$}

ALMEIDA, J.A.G. Amamentação: A relação entre o biológico e o social. In: Amamentação: um híbrido natureza-cultural. Rio de Janeiro: Editora Fiocruz, 1999. 120 p. 978-85-85239-17-4/ISBN.

ALVES, J.S.; DE OLIVEIRA, M.I.C.; RITO, R.V.V.F. Orientações sobre amamentação na atenção básica de saúde e associação com o aleitamento materno exclusivo. Rio de Janeiro: Rev. Ciência \& Saúde Coletiva, 2007. p. 241-246. vol. 83, nº 3.

AMARAL, S.; BASSO, C. Aleitamento materno e estado nutricional infantil. Santa Maria: Ciências da Saúde, 2009. p. 19-30. vol. 10, n 1.

AMIR, L.H.; DONATH, S. A systematic review of maternal obesity and breastfeeding intention, initiation and duration. Londres: BMC Pregnancy and Childbirth, 2007. p. 1-14. vol. $7, \mathrm{n}^{\circ} 9$.

ANDRETO, L.M. et al. Fatores associados ao ganho ponderal excessivo em gestantes atendidas em um serviço público de pré-natal na cidade de Recife, Pernambuco, Brasil. Cad. Saúde Pública vol.22 no.11 Rio de Janeiro Nov. 2006

ARAÚJO, M.F.M. et al. Custo e economia da prática do aleitamento materno para a família. Recife: Rev. Bras. Saúde Mater. Infant., 2004. p. 135-141. vol. 4, no 2.

ARAÚJO, O.D. et al. Aleitamento materno: fatores que levam ao desmame precoce. Rev. bras. enferm. vol.61 no.4 Brasília July/Aug. 2008.

BAIRD, J. et al. Being big or growing fast: systematic review of size and growth in infancy and later obesity. BMJ. 2005; 331(7522):929.

BALL, G.D.C; SAVU, A.; KAUL, P. Changes in the prevalence of overweight, obesity, and severe obesity between 2010 and 2017 in preschoolers: A population-based study. Pediatr Obes. 2019 Nov;14(11):e12561. doi: 10.1111/ijpo.12561. Epub 2019 Jul 18.

BASTIAN, D.P.; TERRAZZAN, A.C. Tempo de aleitamento materno e os fatores de risco para o desmame precoce. São Paulo: Rev. Nutrire, 2015. p. 278-286. vol. 40, nº 3.

BELL, S. et al. Duration of breastfeeding, but not timing of solid food, reduces the risk of overweight and obesity in children aged 24 to 36 months: findings from na Australian cohort study. Suiça: Int J Environ Res Public Health, 2018. 14 p. vol. 15, $\mathrm{n}^{\circ}$ 4. DOI: 10.3390/ijerph15040599.

BIDER-CANFIELD, Z. et al. Maternal obesity, gestational diabetes, breastfeeding and childhood overweight at age 2 years. Pediatr Obes. 2017 Apr;12(2):171-178. doi: 10.1111/ijpo.12125. Epub 2016 Mar 8.

\footnotetext{
${ }^{1}$ De acordo com as Diretrizes para Apresentação de Dissertações e Teses da USP - ABNT (2016).
} 
BJERTNAES, A.A. et al. No significant associations between breastfeeding practices and overweight in 8-year-old children. Acta Paediatr. 2020 Jan;109(1):109-114. doi: 10.1111/apa.14937. Epub 2019 Aug 23.

BOCCOLINI, C.S. et al. Tendência de indicadores do aleitamento materno em três décadas. São Paulo: Rev. Saúde Pública, 2017. 9 p. vol. 51, nº 108.

BOSWELL, N.; BYRNE, R.; DAVIES, P.S.W. Family food environment factors associated with obesity outcomes in early childhood. BMC Obes. 2019 Jun 3;6:17. doi: 10.1186/s40608019-0241-9. eCollection 2019.

BRASIL. Ministério da Saúde. Secretaria de Atenção à Saúde. Departamento de Atenção Básica. Saúde da criança: Aleitamento materno e alimentação complementar. $2^{\mathrm{a}}$ edição. Brasília: Editora do Ministério da Saúde, 2015. 186 p. Cadernos de Atenção Básica, no 23. 978 85-334-2290-2/ISBN.

BRASIL. Ministério da Saúde. Secretaria de Atenção à Saúde. Departamento de Atenção Básica. Saúde da criança: nutrição infantil: aleitamento materno e alimentação complementar. Brasília: Editora do Ministério da Saúde, 2009. 112 p. Série A. Normais e Manuais Técnicos. Cadernos de Atenção Básica, nº 23. 978-85-334-1561-4/ISBN.

BRASIL. Ministério da Saúde. Organização Pan-Americana de Saúde. Guia alimentar para crianças menores de 2 anos. Brasília: Editora do Ministério da Saúde, 2005. 152 p. Série A. Normas e Manuais Técnicos. 85-334-0344-5/ISBN.

BRASIL. Ministério da Saúde. Secretaria de Atenção à Saúde. Departamento de Ações Programáticas e Estratégicas. II Pesquisa de prevalência de aleitamento materno nas capitais brasileiras e Distrito Federal. Brasília: Editora do Ministério da Saúde, 2009. 108 p. Série C. Projetos, Programas e Relatórios. 978-85-334-1607-9/ISBN.

BRASIL. Ministério da Saúde. Pesquisa Nacional de Demografia e Saúde da Criança e da Mulher - PNDS 2006: dimensões do processo reprodutivo e da saúde da criança. Brasília: Editora do Ministério da Saúde, 2009. 300 p. Série G. Estatística e Informação em Saúde.

BRASIL. Ministério da Saúde. Vigilância alimentar e nutricional - SISVAN: orientações básicas para a coleta, processamento, análise de dados e informações em saúde. Brasília: Editora do Ministério da Saúde, 2004. 120 p. Série A. Normas e Manuais Técnicos.

BRIDGMAN, S.L. et al. Impact of maternal pre-pregnancy overweight on infant overweight at 1 year of age: associations and sex-specific differences. Pediatr Obes. 2018 Oct;13(10):579-589. doi: 10.1111/ijpo.12291. Epub 2018 May 25.

BUYKEN, A.E. et al. Effects of breastfeeding on trajectories of body fat and BMI throughout childhood. Obesity (Silver Spring). 2008 Feb;16(2):389-95. doi: 10.1038/oby.2007.57.

CAMARGO, A.P.P.M. Vida de mãe, vida de filho. Experiências de mães de crianças e adolescentes obesos e em tratamento ambulatorial. 2015. 92f. Tese (Doutorado em Ciências) Universidade Estadual de Campinas, Faculdade de Ciências Médicas, Campinas, 2015. 
CAMARGOS, A.C.R. et al. Prevalência de sobrepeso e de obesidade no primeiro ano de vida nas Estratégias Saúde da Família. Cad. Saúde Colet., 2019, Rio de Janeiro, 27 (1): 3238.

CANFIELD, Z.B. et al. Maternal obesity, gestational diabetes, breastfeeding and childhood overweight at age 2 years. Pediatr Obes. 2017 Apr;12(2):171-178. doi: 10.1111/ijpo.12125. Epub 2016 Mar 8.

CARMO, M.G.T.; COLARES, L.G.T.; SAUNDERS, C. Nutrição na lactação. In: ACCIOLY, E.; LACERDA, E.M.A; SAUNDERS, C. Nutrição em obstetrícia e pediatria. $1^{a}$ edição. Rio de Janeiro: Cultura Médica, 2002. p. 225-246.

CARRAZZONI, D.S. et al. Prevalência de fatores na primeira infância relacionados à gênese da obesidade em crianças atendidas em um ambulatório de nutrição. Revista Brasileira de Obesidade, Nutrição e Emagrecimento, São Paulo. v.9. n.50. p.74-81. Mar./Abril. 2015. ISSN 1981-9919.

CASTILHO, S.D.; BARROS FILHO, A.A. The history of infant nutrition. Rio de Janeiro: J. Pediatr, 2010. p. 179-188. vol. 86, nº 3. DOI:10.2223/JPED.1984.

COCETTI, M. et al. Prevalence and factors associated with overweight among Brazilian children younger than 2 years. J Pediatr (Rio J). 2012;88(6):503-8.http:// dx.doi.org/10.2223/JPED.2228. PMid:23269984

CONCEIÇÃO, S.P.; FERNANDES, R.A.Q. Influência da gravidez não planejada no tempo de aleitamento materno. Esc Anna Nery 2015;19(4):600-605.

CONTARATO, A.A.P.F. et al. Efeito independente do tipo de aleitamento no risco de excesso de peso e obesidade em crianças entre 12-24 meses de idade. Rio de Janeiro: Cad. Saúde Pública, 2016. 11 p. vol. 32, nº 12.

CORRÊA, E.N. et al. Alimentação complementar e características maternas de crianças menores de dois anos de idade em Florianópolis (SC). São Paulo: Rev. Paul. Pediatr., 2009. p. 258-264. vol. 27, no 3 .

COSTA, L.P; OLIVEIRA, L.R. Ambiente obesogênico em crianças dos 7 aos 9 anos de idade do Concelho da Calheita, região autônoma da Madeira (RAM). Portugal: Rev. da SPCNA, 2010. 12 p. vol. 6, nº 3 .

CHAGAS, D.C.; SILVA, A.A.M.; RIBEIRO, C.C.C.; BATISTA, R.F.L.; ALVES, M.T.S.S.B. Efeitos do ganho de peso gestacional e do aleitamento materno na retenção de peso pósparto em mulheres da coorte BRISA. Cadernos de Saúde Pública, v. 33, n.5, 2017

CHAOYANG, L.I. et al. Additive Interactions of Maternal Prepregnancy BMI and Breastfeeding on Childhood Overweight. Obes Res. 2005 Feb;13(2):362-71.

CLAESSON, I.M. et al. "You just need to leave the room when you breastfeed" Breastfeeding experiences among obese women in Sweden - A qualitative study. Londres: BMC Pregnancy Childbirth, 2018. 10 p. vol. 18, nº 39. 
DA SILVA, G.A.P.; BALABAN, G.; MOTTA, M.F.A. Prevalência de sobrepeso e obesidade em crianças e adolescentes de diferentes condições socioeconômicas. Recife: Rev. Bras. Saude Mater. Infant., 2005. p. 53-59. vol.5, $\mathrm{n}^{\circ} 1$.

DA SILVA, A.P.; DE SOUZA, N. Prevalência do aleitamento materno. Campinas: Rev. Nutr., 2005. p. 301-310. vol. 18, nº 3 .

DATTILO, A.M. Modifiable risk factors and interventions for childhood obesity prevention within the first $\mathbf{1 . 0 0 0}$ days. Suiça: Nestlé Nutr Inst Workshop Ser., 2017. p. 183196. vol. 87. DOI: 10.1159/000448966.

DEVINCEZI, M.U; MATTAR, M.J.G.; CINTRA, E.M. Nutrição no primeiro ano de vida. In: DA SILVA, S.M.C.S. Tratado de alimentação, nutrição, e dietoterapia. $2^{a}$ edição. São Paulo: Roca, 2010. cap. 20, p. 371-399.

DO NASCIMENTO, M.B.R.; ISSLER, H. Breastfeeding: making the difference in the development, health and nutrition of term and preterm newborns. São Paulo: Rev. Hosp. Clín. Fac. Med. S. Paulo, 2003. p. 49-60. vol. 58, no 3.

DOS SANTOS, G.M. et al. Aleitamento materno excluviso e (in) segurança alimentar e nutricional. São Caetano do Sul: Rev. Bras. Ciên. Saúde, 2016. p. 293-298. vol. 20, nº4.

DRUET, C. et al. Prediction of childhood obesity by infancy weight gain: an individuallevel meta-analysis. Paediatr Perinat Epidemiol. 2012;26(1):19-26. http://dx.doi. org/10.1111/j.1365-3016.2011.01213.x. PMid:22150704.

ESCRIVÃO, M.A.M.S. et al. Obesidade exógena na Infância e na Adolescência. J. Pediatr. 2000;76(03)305-10.

ESTEVES, T.M.B. Fatores associados à amamentação na primeira hora de vida: revisão sistemática. Rev Saúde Pública 2014;48(4):697-703.

FARIA-SCHUTZER, D.B. et al. Eating Behaviors in Postpartum: A Qualitative Study of Women with Obesity. Nutrients. 2018 Jul 10;10(7). pii: E885. doi: 10.3390/nu10070885.

FALIVENE, M.A; ORDEN, A.B. Fatores do comportamento materno que influenciam a retenção de peso pósparto: implicações clínico-metabólicas. Recife: Rev. Bras. Saúde Mater. Infant., 2017. p. 261-270. vol. 17, nº 2.

FERREIRA, G.R.; D'ARTIBALE, E.F.; BERCINI, L.O. Influência da prorrogação da licença maternidade para seis meses na duração do aleitamento materno exclusivo. Belo Horizonte: Rev. Min Enferm., 2013. p. 398-404. vol. 17, nº 2.

FORBES, J. D. et al. Association of exposure to formula in the hospital and subsequent infant feeding practices with gut microbiota and risk of overweight in the first year of life. JAMA Pediatr. https://doi.org/10.1001/ jamapediatrics.2018.1161 (2018).

FREITAS, M.C.S.; VELOSO, I.S. Alimentação e as principais transformações no século XX: uma breve revisão. In: Escritas e narrativas sobre alimentação e cultura. Salvador: EDUFBA, 2008. 422 p. 978-85-232-0543-0/ISBN. 
FUNDAÇÃO SISTEMA ESTADUAL DE ANÁLISE DE DADOS (SEADE). Mortalidade infantil no ano de 2016. São Paulo: SEADE, 2016. Disponível em: <http://www.seade.gov.br/produtos/mortalidade-infantil/>. Acesso em: 26 ago. 2018.

GARNER, C.D. et al. Obese women experience multiple challenges with breastfeeding that are either unique or exacerbated by their obesity: discoveries from a longitudinal, qualitative study. Estados Unidos: Maternal \& Child Nutrition, 2016. 12 p. vol. 13, nº 3.

GEA-HORTA, T. et al. Association between maternal socioeconomic factors and nutritional outcomes in children under 5 years of age'. J. Pediatr. (Rio J.) [online]. 2016, vol.92, n.6, pp.574-580. ISSN 0021-7557. http://dx.doi.org/10.1016/j.jped.2016.02.010.

GIBSON, L.A. et al. The effects of breastfeeding on childhood BMI: a propensity score matching approach. Inglaterra: J Public Health (Oxf)., 2017. p. 152-160. vol. 39, no 4. DOI: 10.1093/pubmed/fdw093.

GILLMAN, M.W. The first months of life: a critical period for development of obesity. Am J Clin Nutr. 2008;87(6):1587-9. http://dx.doi.org/10.1093/ ajcn/87.6.1587. PMid:18541543

GOLDENBERG, P. Repensando a desnutrição como questão social. $2^{\mathrm{a}}$ edição. Campinas: Editora UNICAMP, 159 p, 1988. 85-2490-203-5/ISBN.

GONÇALVES, C.V. et al. Índice de massa corporal e ganho de peso gestacional como fatores preditores de complicações e do desfecho da gravidez. Rev Bras Ginecol Obstet. 2012; 34(7):304-9.

GOMES, A.T. et al. Excess weight and factors associated in preschool of southwest of Bahia. Rev. Bras. Saude Mater. Infant. vol.17 no.2 Recife Apr./June 2017.

HESLEHURST, N. et al. The association between maternal body mass index and child obesity: A systematic review and meta-analysis. PLoS Med. 2019 Jun 11;16(6):e1002817. doi: 10.1371/journal.pmed.1002817. eCollection 2019 Jun.

HUANG, Y.; OUYANG, Y.Q,; REDDING, S.R. Maternal Prepregnancy Body Mass Index, Gestational Weight Gain, and Cessation of Breastfeeding: A Systematic Review and MetaAnalysis, 2019.

HUH, S.Y et al. Delivery by caesarean section and risk of obesity in preschool age children: a prospective cohort study. Arch Dis Child. 2012 Jul;97(7):610-6. doi: 10.1136/archdischild2011-301141. Epub 2012 May 23.

IGUACEL, I. et al. Feeding patterns and growth trajectories in breast-fed and formula-fed infants during the introduction of complementary food. Nutr Hosp. 2019 Aug 26;36(4):777785. doi: 10.20960/nh.02352.

INSTITUTO BRASILEIRO DE GEOGRAFIA E ESTATÍSTICA. Pesquisa de orçamentos familiares 2008-2009: antropometria e estado nutricional de crianças, adolescentes e adultos no Brasil. Coordenação de Trabalho e Rendimento. Rio de Janeiro: IBGE, 2011. 150 p. 
INSTITUTO BRASILEIRO DE GEOGRAFIA E ESTATÍSTICA. Cidade: Ribeirão Preto. Rio de Janeiro: IBGE, [s.d]. Disponível em: <https://cidades.ibge.gov.br/brasil/sp/ribeiraopreto/panorama>. Acesso em: 26 ago. 2018.

JANJUA, N.Z. et al. Maternal and Early Childhood Risk Factors for Overweight and Obesity Among Low-Income Predominantly Black Children at Age Five Years: A prospective Cohort Study.J Obes 2012;457173.

JOSEY, M.J. et al. Overall gestational weight gain mediates the relationship between maternal and child obesity. BMC Public Health volume 19, Article number: 1062 (2019).

JURADO, L.S. et al. Breastfeeding, complementay feeding and risk of childhood obesity. Espanha: Atención Primaria/Sociedad Espanola de Medicina de Familia y Comunitaria, 2016. p. 572-578. vol. 48, nº 9. DOI: 10.1016/j.aprim.2015.10.004.

KAPRAL, N. et al. Associations between birthweight and overweight and obesity in schoolage children. Pediatr Obes. 2018 Jun;13(6):333-341. doi: 10.1111/ijpo.12227. Epub 2017 Jul 6.

KIM, H.S. et al. SUN-075. Apresentado em: Reunião Anual da Sociedade Endócrina; 1720 de março de 2018; Chicago.

KNEIPP, C. et al. Excesso de peso e variáveis associadas em escolares de Itajaí, Santa Catarina, Brasil. Ciênc. saúde coletiva 20 (8) Ago 2015 • https://doi.org/10.1590/1413$\underline{81232015208.18752014 .}$

LEE, J.W. et al. The Protective Effect of Exclusive Breastfeeding on Overweight/Obesity in Children with High Birth Weight. J Korean Med Sci. 2019 Mar 8;34(10):e85. doi: 10.3346/jkms.2019.34.e85. eCollection 2019 Mar 18.

LEIRAS, E.M.V. Comportamento alimentar da criança: a influência materna. 2015. 151 p. Dissertação (Mestrado em Enfermagem de Saúde Comunitária) - Escola Superior de Saúde, Instituto Politécnico de Viana do Castelo, Portugal, 2015.

LIPSKY, L.M.; STRAWDERMAN, M.S.; OLSON, C.M. Maternal weight change between 1 and 2 years postpartum: the importance of 1 year weight retention. Obesity, v. 20, n. 7 , p. 1496-1502, 2012.

LOPES, P.C.S.; PRADO, S.R.L.A.; COLOMBO, P. Fatores de risco associados à obesidade e sobrepeso em crianças em idade escolar. Brasília: Rev. Bras, Enferm, 2010. p. 73-78. vol. $63, n^{\circ} 1$.

MANGEL, L. et al. Breastfeeding Difficulties, Breastfeeding Duration, Maternal Body Mass Index, and Breast Anatomy: Are They Related? Breastfeed Med. 2019 Jun;14(5):342346. doi: 10.1089/bfm.2018.0262. Epub 2019 Apr 26.

MARIM, L.M.; NAVARRO, F. Avaliação do risco cardiovascular na obesidade e diretrizes específicas de prevenção através da dieta e mudanças no estilo de vida. São Paulo: Rev. Brasileira de Obesidade, Nutrição e Emagrecimento, 2007. p. 77-93. vol.1, nº 4. 
MAYER-DAVIS, E.J. et al. Breast-Feeding and Risk for Childhood Obesity. Diabetes Care. 2006 October ; 29(10): 2231-2237. doi:10.2337/dc06-0974.

MEI, H. et al. Interactive Effects of Early Exclusive Breastfeeding and Pre-Pregnancy Maternal Weight Status on Young Children's BMI - A Chinese Birth Cohort. PLoS One. 2015 Dec 7;10(12):e0144357. doi: 10.1371/journal.pone.0144357. eCollection 2015.

MELO, C.D.S.; GOLÇALVES, R.M. Aleitamento materno versus aleitamento artificial. Goiânia: Rev. Estudos - Vida e Saúde (EVS), 2014. p. 7-14. vol. 41.

MINISTÉRIO DA SAÚDE. Departamento de Atenção Básica. Brasil é referência mundial em amamentação.

Disponível em:

$<$ http://dab.saude.gov.br/portaldab/noticias.php?conteudo=_\&cod=2223>. Acesso em: 26 ago. 2018.

MINISTÉRIO DA SAÚDE. Aleitamento materno. Disponível em: <http://portalms.saude.gov.br/saude-para-voce/saude-da-crianca/aleitamento-materno>.

Acesso em: 26 ago. 2018.

MINOSSI, V. et al. Duração do aleitamento materno e o excess de peso. Santa Cruz do Sul: Cinergis., 2013. p. 7-12. vol. 14, $\mathrm{n}^{\mathrm{o}} 1$.

MIHRSHAHI, S; BAUR, L.A. What exposures in early life are risk factors for childhood obesity? J Paediatr Child Health. 2018 Dec;54(12):1294-1298. doi: 10.1111/jpc.14195. Epub 2018 Aug 31.

MODREK, S. et al. Does breastfeeding duration decrease child obesity? An instrumental variable analysis. Inglaterra: Pediatr Obes., 2017. p. 304-311. vol.12, $\mathrm{n}^{\circ} 4$. DOI: 10.1111/ijpo.1214.

MONTE, C.M.G.; GIUGLIANI, E.R.J. Recomendações para alimentação complementar da criança em aleitamento materno. Rio de Janeiro: J. Pediatr, 2004. p. 131-141. vol. 80, nº 5.

MUELLER, E.; BLASER, M. Breast milk, formula, the microbiome and overweight. Nat Rev Endocrinol. 2018 Sep;14(9):510-511. doi: 10.1038/s41574-018-0066-5.

MULLER, R.M. et al. Excesso de peso e fatores associados em menores de cinco anos em populações urbanas no Brasil. São Paulo: Rev. Bras. Epidemiol., 2014. p. 285-296. vol. 17, n 2 . DOI: $10.1590 / 1809-4503201400020001$.

NAÇÕES UNIDAS NO BRASIL. Ministério da Saúde lança nova campanha de incentivo à amamentação. Disponível em: <https://nacoesunidas.org/ministerio-da-saude-lanca-novacampanha-de-incentivo-a-amamentacao/>. Acesso em: 26 ago. 2018.

NAÇÕES UNIDAS. Perspectiva global, reportagens humanas. UNICEF e OMS: apenas 40\% dos bebês de até 6 meses têm amamentação exclusiva. Disponível em: <https://news.un.org/pt/story/2017/08/1592121-unicef-e-oms-apenas-40-dos-bebes-ate-6meses-tem-amamentacao-exclusiva>. Acesso em: 26 ago. 2018. 
NASCIMENTO, V.G. et al. Aleitamento materno, introdução precoce de leite não materno e excesso de peso na idade pré-escolar. São Paulo: Rev. Paul. Pediatr, 2016. p. 454-459. vol. $34, n^{\circ} 4$.

NAST, M. et al. Ganho de peso excessivo na gestação é fator de risco para o excesso de peso em mulheres. Rev Bras Ginecol Obstet. 2013; 35(12):536-40.

NOGUEIRA, A.I.; CARREIRO, M.P. Obesidade e gravidez. Rev Med Minas Gerais 2013; 23(1): 88-98.

ODDY, W.H. et al. The association of maternal overweight and obesity with breastfeeding duration. J Pediatr. 2006 Aug;149(2):185-91.

ORGANIZAÇÃO PAN-AMERICANA DE SAÚDE. Organização Mundial da Saúde. Amamentação: uma questão contemporânea em um mundo globalizado. Disponível em: $<$ https://www.paho.org/bra/images/stories/Documentos2/brief\%20report\%202014\%20portug ues.pdf>. Acesso em: 26 ago. 2018.

OGDEN, C.L. et al. Prevalence of childhood and adult obesity in the United States, 20112012. JAMA. 2014;311(8):806-14.

OLIVEIRA, K.M.P.; MARQUES, I.S. Situação do aleitamento materno no Brasil: uma revisão. Santo Amaro: Revista de Enfermagem da UNISA, 2010. p. 73-78. vol. 12, nº 1.

ONIS, M.; BLOSSNER, M.; BORGHI, E. Global prevalence and trends of overweight and obesity among preschool children. Estados Unidos: Am. J. Clin. Nutr., 2010. p. 1257-64. vol. $92, n^{\circ} 5$.

ONIS, M. ECOG Obesity Ebook: World Health Organization Reference Curves. Europa: Grupo Europeu de Obesidade na Infância, 2005. Disponível em: <http://ebook.ecogobesity.eu/wp-content/uploads/2014/10/ECOG-Obesity-eBook-World-Health-OrganizationReference-Curves-V1.pdf>. Acesso em: 07 set. 2018.

ORTEGA-GARCÍA, J.A. et al. Full Breastfeeding and Obesity in Children: A Prospective Study from Birth to 6 Years. Child Obes. 2018 Jul;14(5):327-337. doi: 10.1089/chi.2017.0335. Epub 2018 Jun 18.

OHLENDORF, J.M; ROBINSON, K.; GARNIER-VILLARREAL, M. The impact of maternal BMI, gestational weight gain, and breastfeeding on early childhood weight: Analysis of a statewide WIC dataset. Prev Med. 2019 Jan;118:210-215. doi: 10.1016/j.ypmed.2018.11.001. Epub 2018 Nov 7.

PACA-PALAO, A. et al. Association between exclusive breastfeeding and obesity in children: a cross-sectional study of three Latin American countries. Gac Sanit. 2019 Nov 28. pii: S0213-9111(19)30212-2. doi: 10.1016/j.gaceta.2019.09.002. 
PAN, L. et al. State-Specific Prevalence of Obesity Among Children Aged 2-4 Years Enrolled in the Special Supplemental Nutrition Program for Women, Infants, and Children - United States, 2010-2016. MMWR Morb Mortal Wkly Rep. 2019 Nov 22;68(46):1057-1061. doi: 10.15585/mmwr.mm6846a3.

PATTISON, K.L. et al. Breastfeeding initiation and duration and child health outcomes in the first baby study. Prev Med. 2019 Jan;118:1-6. doi: 10.1016/j.ypmed.2018.09.020. Epub 2018 Oct 1.

PAPASTAVROU, M. et al. Breastfeeding in the course of history. Estados Unidos: J Pediatr Neonatal Care, 2015. 9 p. vol. 2, nº 6. DOI: 10.15406/jpnc.2015.02.00096.

PEREIRA, M.J.B. et al. Indicadores do aleitamento materno no município de Ribeirão Preto, São Paulo. São Paulo: Rev. Bras. Epidemiol., 2004. p. 36-43. vol. 7, nº 1.

PEREIRA, I.F.S. et al. Estado nutricional de menores de 5 anos de idade no Brasil: evidências da polarização epidemiológica nutricional. Rio de Janeiro: Ciênc. Saúde Colet., 2017. p. 3341-3352. vol. 22, nº 2.

PRIOR, E. et al. Breastfeeding after cesarean delivery: a systematic review and meta-analysis of world literature. The American Journal of Clinical Nutrition, Volume 95, Issue 5, May 2012, Pages 1113-1135, https://doi.org/10.3945/ajcn.111.030254.

PROGRAMA DAS NAÇÕES UNIDAS PARA O DESENVOLVIMENTO (PNUD). Ranking IDHM Municípios 2010. Disponível em:

<http://www.br.undp.org/content/brazil/pt/home/idh0/rankings/idhm-municipios-2010.html>. Acesso em: 26 ago. 2018.

QUIRINO, L.S. et al. Significado da experiência de não amamentar relacionado às intercorrências mamárias. Cogitare Enferm. 2011 Out/Dez; 16(4):628-33.

RAMJI, N. et al. The impact of maternal obesity on breastfeeding. Canadá: J. Obstet. Gynaecol Can., 2016. p. 703-711. vol. 38, $\mathrm{n}^{\circ} 8$.

RAMOS, C.V. et al. Prevalência do aleitamento materno exclusivo e os fatores a ele associados em crianças nascidas nos Hospitais Amigos da Criança de Teresina - Piauí. Brasília: Rev. Epidemiol. Serv. Saúde, 2010. 10 p. vol. 19, nº 2.

REILLY, E. et al. Early life risk factors for obesity in childhood: cohort study. BJM 2005; 330: 1357- 64.

RIBEIRO, A.M. et al. Baixo peso ao nascer e obesidade: associação causal ou casual? Revista Paulista de Pediatria (English Edition), Volume 33, Issue 3, September 2015, Pages 340-348.

RITO, A.I. et al. Association between Characteristics at Birth, Breastfeeding and Obesity in 22 Countries: The WHO European Childhood Obesity Surveillance Initiative - COSI 2015/2017. Obes Facts. 2019;12(2):226-243. doi: 10.1159/000500425. Epub 2019 Apr 26.

ROSTADMO, M. Breastfeeding as a global public health measure. Noruega: Tidsskrift for Norsk psykologforening, 2018. 3 p. vol. 138, no 9. DOI: 10.4045/tidsskr.18.0432. 
SATO, A.P.S.; FUJIMORi, E. Estado nutricional e ganho de peso de gestantes. Rev. LatinoAm. Enfermagem 20(3):[7 telas] maio-jun. 2012.

SILVEIRA, S.; ABREU, S.M. Fatores que contribuem para a obesidade infantil. São Paulo: Rev. de Enfermagem UNISA, 2006. p. 59-62. vol. 7, nº 1.

SIMÕES, F.I.W.; HASHIMOTO, F. Mulher, mercado de trabalho e as configurações familiares do século XX. Minas Gerais: Revista Vozes dos Vales, 2012. Publicações acadêmicas. p. 1-25. vol. 1, no 2 .

SIMON, V.G.N. et al. Prática e duração do aleitamento materno de crianças matriculadas em escolas particulares do município de São Paulo, SP. São Paulo: Rev. bras. crescimento desenvolv. hum., 2009. p. 403-411. vol. 19, no 3.

SIMON, V.G.N.; SOUZA, J.M.P.; SOUZA, S.B. Aleitamento materno, alimentação complementar, sobrepeso e obesidade em pré-escolares. Rev Saúde Pública 2009;43(1):609.

SOCIEDADE BRASILEIRA DE PEDIATRIA. Manual de orientação para a alimentação do lactente, do pré-escolar, do escolar, do adolescente e na escola. Sociedade Brasileira de Pediatria. Departamento de Nutrologia. $3^{a}$ edição. Rio de Janeiro: SPB, 2012. 148 p. 978-8588520-22-6/ISBN.

SOCIEDADE BRASILEIRA DE PEDIATRIA. Uso de chupeta em crianças amamentadas: prós e contras. Sociedade Brasileira de Pediatria. Guia prático de atualização. $3^{\mathrm{a}}$ edição. Rio de Janeiro: SPB, 2017. 16p.

SOUZA, M.A.A.; BULHOSA, M.S. A relevância do aleitamento materno como política pública de redistribuição de renda: $O$ caso do município pesqueiro de Rio Grande no Estado do Rio Grande do Sul. Rio Grande: Sociedade Brasileira de Economia, Administração e Sociologia Rural, [20--]. 12 p.

SOUZA, N.P.P.; OLIVEIRA, M.R.M. O ambiente como elemento determinante da obesidade. Botucatu: Rev. Simbio-Logias, 2008. 17 p. vol. 1, $\mathrm{n}^{\mathrm{o}} 1$.

SWINBURN, B.; EGGER, G. Preventive strategies against weight gain and obesity. Obesity Reviews 2002; 3:289-301.

SKRYPINIK, D. et al. Role of gestational weight gain, gestational diabetes, breastfeeding, and hypertension in mother-to-child obesity transmission. Pol Arch Intern Med. $2019 \mathrm{Apr}$ 30;129(4):267-275. doi: 10.20452/pamw.4426. Epub 2019 Jan 28.

TAMBALIS, K.D. et al. Association of Exclusive Breastfeeding with Risk of Obesity in Childhood and Early Adulthood. Breastfeed Med. 2018 Nov 9. doi: 10.1089/bfm.2018.0117.

TAHA, Z. et al. Prevalence and Associated Factors of Caesarean Section and its Impact on Early Initiation of Breastfeeding in Abu Dhabi, United Arab Emirates. Nutrients. 2019 Nov 10;11(11). pii: E2723. doi: 10.3390/nu11112723. 
TERUZ, A.C.A. Manejo nutricional do excesso de peso gestacional no pós-parto. 2017. Monografia (Graduação em Nutrição) - Centro Universitário Hermínio da Silveira. Rio de Janeiro, 2017.

VICARI, E.C. Aleitamento materno, a introdução da alimentação complementar e sua relação com a obesidade infantil. São Paulo: Rev. Brasileira de Obesidade, Nutrição e Emagrecimento, 2013. p. 72-83. vol. 7, nº 40.

VIEIRA, R.W. et al. Do aleitamento materno à alimentação complementar: Atuação do profissional nutricionista. Duque de Caxias: Saúde \& Ambiente em Revista, 2009. p. 1-8. vol. $4, n^{\circ} 2$.

VINAGRE, R.D.; DINIZ, E.M.A.; VAZ, F.A.C. Leite humano: um pouco de sua história. São Paulo: Revista de Pediatria, 2001. p. 340-345. vol. 23, nº 4.

VITOLO, M.R. Aspectos fisiológicos e nutricionais na gestação. In: _. Nutrição: da gestação ao envelhecimento. Rio de Janeiro: Editora Rubio, 2008. cap. 5, p. 41-45.

VITOLO, M.R. Aspectos fisiológicos e nutricionais na infância. In: _. Nutrição: da gestação ao envelhecimento. Rio de Janeiro: Editora Rubio, 2008. cap. 19, p. 167-170.

VITOLO, M.R. Avaliação nutricional da criança. In: Nutrição: da gestação ao envelhecimento. Rio de Janeiro: Editora Rubio, 2008. cap. 20, p. 171-189.

WANDERLEY, E.N.; FERREIRA, V.A. Obesidade: uma perspectiva plural. Rio de Janeiro: Rev. Ciênc. Saúde Coletiva, 2010. p. 185-194. vol. 15, nº 1.

WANG, L. et al. Breastfeeding reduces childhood obesity risks. Estados Unidos: Child Obes., 2017. 8 p. vol. 13, no 3. DOI: 10.1089/chi.2016.0210.

WANG, X. et al. BMI growth trajectory from ages 2 to 6 years and its association with maternal obesity, diabetes during pregnancy, gestational weight gain, and breastfeeding. Pediatr Obes. 2020 Feb;15(2):e12579. doi: 10.1111/ijpo.12579. Epub 2019 Nov 5.

WALLBY, T.; LAGERBERG, D.; MAGNUSSON, M. Relationship between breastfeeding and early childhood obesity: Results of a prospective longitudinal study from birth to 4 years. Estados Unidos: Breastfeed Med., 2017. p. 48-53. vol. 12. DOI: 10.1089/bfm.2016.0124.

YEUNG, H.; LEFF, M.; RHEE, K.E. Effect of exclusive breastfeeding among overweight and obese mothers on infant weight-for-length percentile at 1 year. Estados Unidos: Breastfeeding Medi 2016. p. 39-47. Vol. 12. DOI: 10.1089/bfm.2016.0071. 


\section{A - ANEXOS}

\section{ANEXO A - APROVAÇÕES DO PROJETO BRISA PELO CEP}

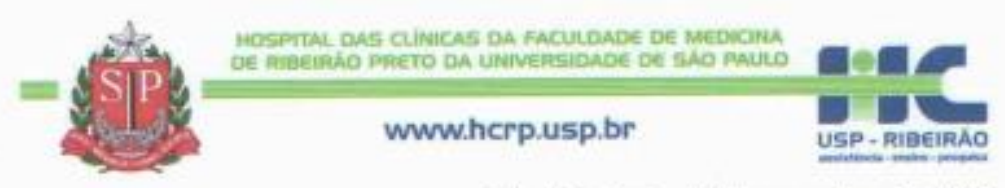

Ribeirâo Preto, 13 de novembro de 2009.

Oficio $n^{\circ}, 4116 / 2008$

CEP/ SPC

Prezados Professores,

O trabalho intitulado "FATOREs ETIOLóGicos DO NASCIMENTO PRÉ-TERMO E CONSEQUENCIAS DOS FATORES PERINATAIS NA SAÛDE DA CRIANCCA: COORTES DE NASCIMENTOS EM DUAS CIDADES BRASILEIRAs" foi analisado pelo Comitê de Etica em Pesquisa em sua $276^{*}$ Reuniâo Ordinária, realizada em 10/11/2008, e enquadrado na categoria: APROVADO, bem como o Termo de Consentimento Livre e Esclarecido, de acordo com o Processo HCRP $\mathrm{n}^{0}$. $11157 / 2008$.

Este Comitê seque integralmente a Conferẻncia Internacional de harmonizaçao de Boas Práticas Clinica (KCH-GCP), bem como a Resoluçao n' $196 / 96$ CNS/ MS.

Lembramos que devem ser apresentados a este CEP, 0 Relatório Parclal eo Relatório Final da Pesquisa.

Atenciosamente.

Ilustrissimos Senhores

PROF. DR. MARCO ANTONIO BARBIERI

PROF DR ${ }^{\mathrm{a}}$ HELOISA BETTIOL

Departamento de Puericultura e Pediatria. 


\section{ANEXO B - APROVAÇÕES DO PRESENTE ESTUDO PELO CEP}

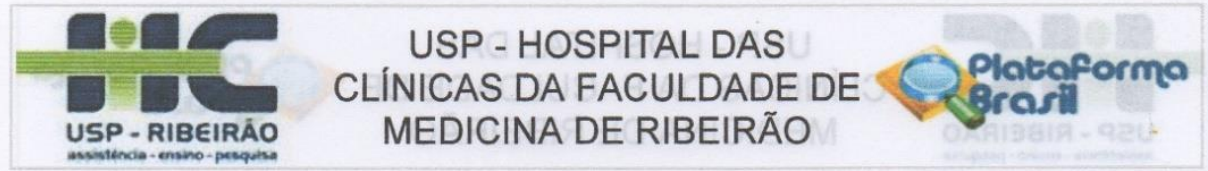

Continuaçăo do Parecer: 2.356 .461

\section{Comentários e Considerações sobre a Pesquisa:}

Trata-se de um estudo analítico, observacional, retrospectivo e de coorte, inserido no projeto temático BRISA (Brazilian Ribeirão Preto and São Luís birth cohort - "Fatores etiológicos do nascimento pré-termo e consequências dos fatores perinatais na saúde da criança: coortes de nascimentos em duas cidades brasileiras"). Os dados provenientes do banco de dados do projeto temático serão utilizados para a elaboraçăo da presente pesquisa.

Considerações sobre os Termos de apresentação obrigatória:

Documentos devidamente apresentados. Solicita a dispensa da aplicação do Termo de Consentimento Livre e Esclarecido do presente estudo com a justificativa de ser um estudo retrospectivo e observacional, utilizando-se os dados proveniente de um banco de dados de um projeto no qual já houve a aplicação do TCLE e aprovação pelo Comitê de Ética em Pesquisa das duas instituições envolvidas.

Recomendações:

năo se aplica

Conclusões ou Pendências e Lista de. Inadequações:

Diante do exposto e à luz da Resolução CNS 466/2012, o projeto de pesquisa, assim como a solicitação de dispensa de aplicaçăo do Termo de Consentimento Livre e Esclarecido, podem ser enquadrados na categoria APROVADO.

Considerações Finais a critério do CEP:

Projeto Aprovado: Tendo em vista a legislação vigente, devem ser encaminhados ao CEP, relatórios parciais anuais referentes ao andamento da pesquisa e relatório final ao término do trabalho. Qualquer modificação do projeto original deve ser apresentada a este CEP em nova versão, de forma objetiva e com justificativas, para nova apreciação.

Este parecer foi elaborado baseado nos documentos abaixo relacionados:

\begin{tabular}{|l|l|c|l|c|}
\hline \multicolumn{1}{|c|}{ Tipo Documento } & \multicolumn{1}{|c|}{ Arquivo } & Postagem & Autor & Situação \\
\hline $\begin{array}{l}\text { Informaçōes Básicas } \\
\text { do Projeto }\end{array}$ & PB_INFORMAÇǑES_BASICAS_DO_P & $27 / 10 / 2017$ \\
$09: 47: 40$ & & Aceito \\
\hline Projeto Detalhado / & projeto_de_pesquisa.pdf & $27 / 10 / 2017$ \\
Brochura & & $09: 47: 11$ & Gabriela Marques & Aceito \\
Investigador & & $26 / 10 / 2017$ & Gabriela Marques & Aceito \\
\hline Cronograma & cronograma.pdf & $19: 43: 54$ & & \\
\hline
\end{tabular}

Endereço: CAMPUS UNIVERSITARIO Bairro: MONTE ALEGRE

CEP: $14.048-900$

UF: SP Municipio: RIBEIRAO PRETO

Telefone: (16)3602-2228 Fax: (16)3633-1144 E-mail: cep@hcrp.usp.br 


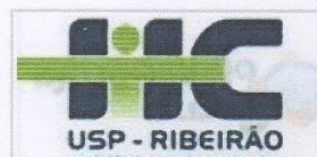

USP - RIBEIRAOO

Continuaçăo do Parecer: 2.356 .461

\begin{tabular}{|l|l|c|l|c|}
\hline $\begin{array}{l}\text { TCLE / Termos de } \\
\text { Assentimento / } \\
\text { Justificativa de } \\
\text { Ausência }\end{array}$ & TCLE_dispensa.pdf & $26 / 10 / 2017$ \\
$19: 18: 25$ & Gabriela Marques & Aceito \\
\hline Outros & & & & \\
& CRC_pediatria.pdf & $26 / 10 / 2017$ & Gabriela Marques & Aceito \\
\hline Outros & comite_de_etica_BRISA.pdf & $26 / 10 / 2017$ & Gabriela Marques & Aceito \\
\hline Orçamento & orcamento_detalhado.pdf & $26 / 10 / 2017$ & Gabriela Marques & Aceito \\
& & $18: 53: 17$ & & \\
\hline Orçamento & UPC.pdf & $26 / 10 / 2017$ & Gabriela Marques & Aceito \\
\hline Folha de Rosto & folha_de_rosto.pdf & $26 / 10 / 2017$ & Gabriela Marques & Aceito \\
\hline
\end{tabular}

Situação do Parecer:

\section{Aprovado}

Necessita Apreciação da CONEP:

Não

RIBEIRAO PRETO, 30 de Outubro de 2017

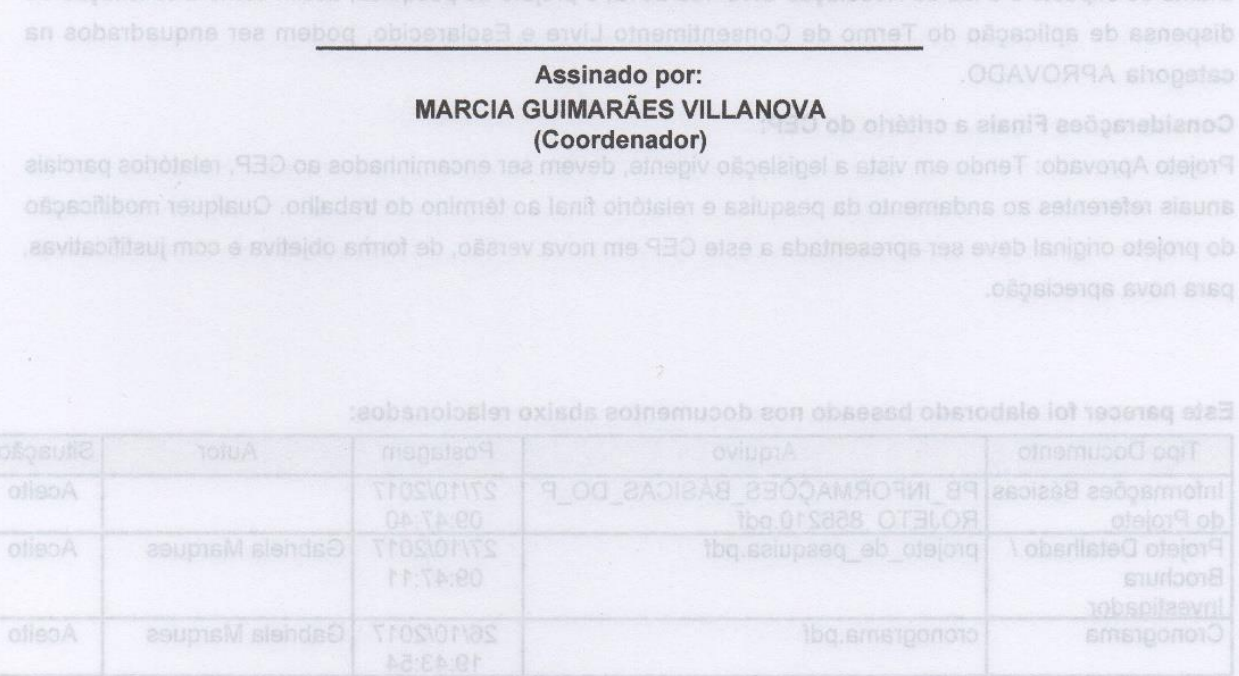

Endereço: CAMPUS UNIVERSITÁRIO

Bairro: MONTE ALEGRE

CEP: $14.048-900$

UF: SP Município: RIBEIRAO PRETO

Telefone: (16)3602-2228 Fax: (16)3633-1144 E-mail: cep@hcrp.usp.br

Platoforma Brasi MEDICINA DE RIBEIRÃO

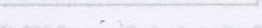

s. 


\section{ANEXO C - QUESTÕES DOS QUESTIONÁRIOS DE PRÉ-NATAL, NASCIMENTO E SEGUIMENTO}

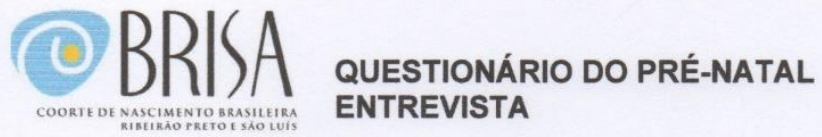

\section{BLOCO A - DADOS DE IDENTIFICACÃO}

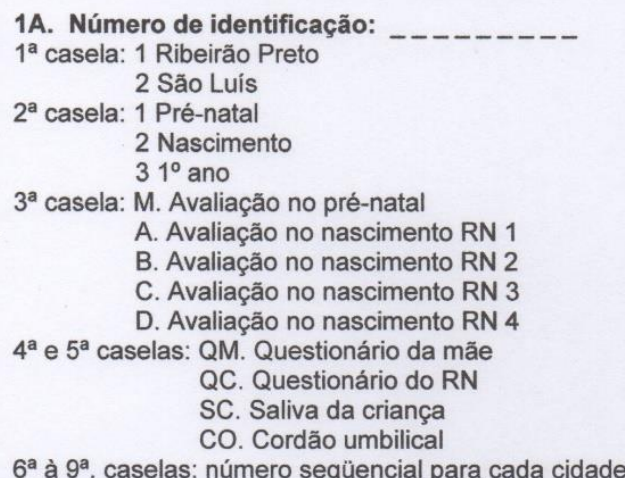

\section{A. Cidade:}

1. $\square$ Ribeirão Preto

2. $\square$ São Luís

3A. Data da Entrevista (DD/MM/AAAA): Entrevistador (a) :

4A. Nome completo da gestante (não abreviar):

5A. Data de nascimento da gestante (DD/MM/AAAA):

$-{ }^{\prime}-{ }^{\prime}$ '- - -

6A. Idade da gestante

99. $\square$ Não sabe

7A. Data da ultrassonografia do recrutamento (DD/MM/AAAA):

$$
-{ }^{-1}-{ }^{\prime}
$$

99999999. $\square$ Não sabe

8A. Idade gestacional pela ultrassonografia do recrutamento: - - semanas

99. $\square$ Não sabe

9A. Idade gestacional atual (pela USG):

semanas

99. $\square$ Não sabe

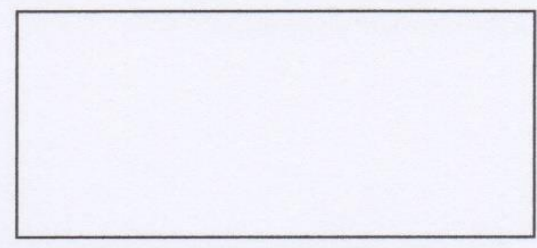

NUMERO $\square \square \square \square \square \square \square \square \square$

CIDADEP

DATAENTP

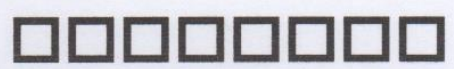

NOMEG

DNGEST

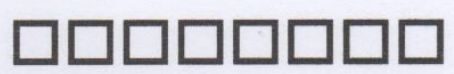

IDADEG

DATUSR

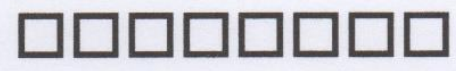

IDGESTUSR

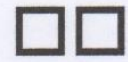

IDGESTAT 
2G. Qual a data da sua última menstruação (DD/MM/AAAA)?

- - ' - ' - - -

99999999. $\square$ Não sabe

3G. Caso não saiba o dia, informar o mês e o ano(MM/AAAA)?

888888. $\square$ Não se aplica

999999. $\square$ Não sabe

4G. Qual o seu peso antes de engravidar?

$\mathrm{kg}$

9999. $\square$ Não sabe

5G. Qual a sua altura antes de engravidar? $\mathrm{cm}$

9999. $\square$ Não sabe

6G. A sra está fazendo pré-natal?

1. $\square \operatorname{Sim}$

2. $\square$ Não Passe para a questão $11 G$

9. $\square$ Não sabe

7G. Qual a data da primeira consulta pré-natal (DD/MM/AAAA)? _- '

88888888. $\square$ Não se aplica

99999999. $\square$ Não sabe

8G. Em que mês de gravidez a sra. iniciou as consultas de pré-natal?

88. $\square$ Não se aplica

99. $\square$ Não sabe

9G. Quantas consultas de pré-natal a sra. fez no $1^{\circ}$ trimestre de a gestação?

88. $\square$ Não se aplica

99. $\square$ Não sabe

10G. Onde a sra. está realizando o pré-natal nesta gestação?

1. $\square$ sus (posto de saúde, hospital universitário)

2. Plano de Saúde

3. $\square$ particular

8. $\square$ Não se aplica

9. $\square$ Não sabe

11G. A sra tem hipertensão (pressão alta) fora da gestação diagnosticada por médico ou enfermeiro?

1. $\square \operatorname{Sim}$

2. $\square$ Não

9. $\square$ Não sabe

12G. A sra. tem hipertensão (pressão alta) na gestação atual?

1. $\square \operatorname{Sim}$

2. $\square$ Não

9. $\square$ Não sabe sump $\square \square \square \square \square \square \square \square$

$\begin{array}{ll}\text { MESANOUMP } & \square \square \square \square \square \square \\ \text { PESOANTESP } & \square \square \square \square\end{array}$

PNP

DT1CPNP $\square \square \square \square \square \square \square \square$

MES1CPNP

$\square \square$

QTCPN1TP

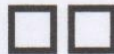

LOCALPN

HIPERTF

HIPERTG 
BLOCO J-EXAME CLÍNICO

1J. Peso (medido): ___'_Kg

2J. Percentual de gordura corporal: _ _._ $\%$

PESO

PGORDURA

3J. Altura (medida): _. _, _cm

4J. Pressão arterial sistólica $1^{\mathrm{a}}$. medida: _ _ $\mathrm{mmHg}$

ALTURA

PAS1

5J. Pressão arterial sistólica $2^{\mathrm{a}}$. medida: _ _ $\mathrm{mmHg}$

PAS2

6J. Pressão arterial diastólica $1^{\mathrm{a}}$. medida: $\ldots$

PAD1

7J. Pressão arterial diastólica $2^{\mathrm{a}}$. medida: _ _ $\mathrm{mmHg}$

PAD2

8J. Pulso: batimentos por minuto

PULSO

ㅁㅁㅁㅁ $\square \square \square$ वपवर ㅁㅁ $\square \square \square$ $\square \square \square$ $\square \square \square$ $\square \square \square$

\section{MATERIAL BIOLÓGICO E EXAMES DA GESTANTE}

9J.Foi feita coleta de sangue?

1. $\square$ Sim

2. $\square$ Não

10J. Foi feita coleta de urina?

SANGUE

1. $\square \operatorname{Sim}$

2. $\square$ Não

11J. Foi feita coleta de secreção vaginal?

1. $\square$ Sim

2. $\square$ Não

12J. Foi feito exame odontológico?

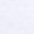

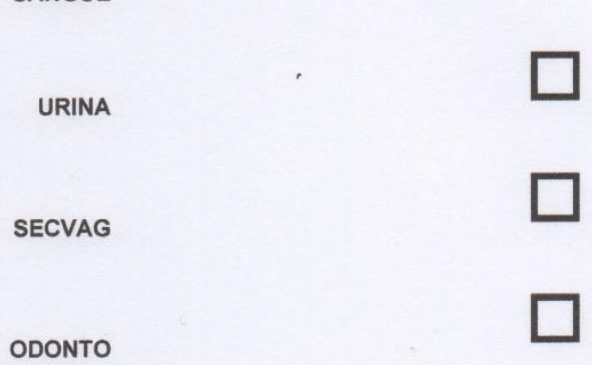

2. $\square$ Não

ODONTO

13J. Foi feita ultrassonografia?

1. $\square$ Sim

2. $\square$ Não

USGP 


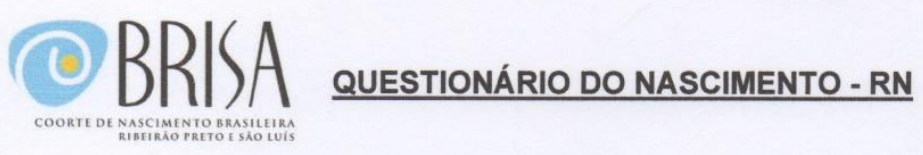

\section{BLOCO A - DADOS DE IDENTIFICACÃO}

1A. Número de identificação:
1a casela: 1 Ribeirão Preto 2 São Luís
$2^{\mathrm{a}}$ casela: 1 Coorte iniciada no Pré-natal
2 Coorte iniciada no nascimento
$3^{\text {a }}$ casela: 1 Questionário do pré-natal
2 Questionário do nascimento
3 Questionário do $1^{\circ}$ ano
$4^{\text {a }}$ casela: 0 Questionário do nascimento-mãe
1 Questionário do nascimento RN 1
2 Questionário do nascimento RN 2
3 Questionário do nascimento RN 3
4 Questionário do nascimento RN 4
5 Questionário do nascimento RN 5
8 saliva
9 cordão

2A. Cidade:

1. $\square$ Ribeirão Preto

2. $\square$ São Luís

3A. Data da Entrevista (DD/MM/AAAA):

- ' - ' '---

4A. Entrevistador (a) :

5A. Data do nascimento do RN (DD/MM/AAAA):

$--{ }^{\prime}+$ '--

6A. Caso tenha nascido mais de um filho, indique qual a sequência de nascimento desse RN?
1. $\square 1^{\circ}$
2. $\square 2^{\circ}$
3. $\square 3^{\circ}$
4. $\square 4^{\circ}$
5. $\square 5^{\circ}$
8. $\square$ Não se aplica
9. $\square$ Não sabe

7A. Qual o sexo do recém-nascido?

1. $\square$ Masculino

2. $\square$ Feminino

9. $\square$ Não sabe

8A.Como nasceu o filho da sra.?

1. $\square$ Vivo

2. $\square$ Morto

9. $\square$ Não sabe

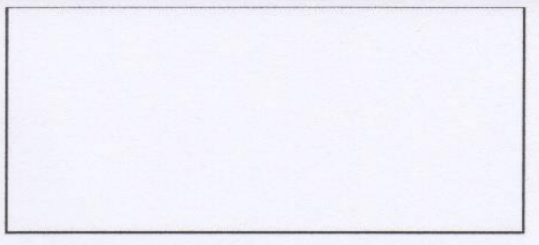

CIDADE

DATAENT प्रणप्रणपर
DATANASC

ORDEMNASC

SEXO

\section{ㅁपㅁㅁㅁ}


E

9A. Qual foi a ap̉resentação do bebê na hora do parto?

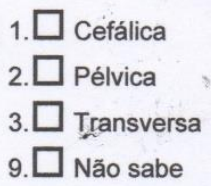

APRESENT

Caso o RN tenha nascido morto, passe para o Bloco B

10A. Qual nome a sra. pretender dar ao seu bebê?

11A.O RN apresentou algum problema de saúde?

NOME

(perguntar para a mãe e anotar do prontuário)

1. $\square \operatorname{sim}$

2. $\square$ Não Passe para a questão 17A

8. $\square$ Não se aplica

9. $\square$ Não sabe "

Caso tenha apresentado problema, nos diga qual foi.

PROBLEMA

- 12A.Problema

88. $\square$ Não se aplica

99. $\square$ Não sabe

PROB1

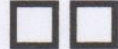

13A.Problema

88. $\square$ Não se aplica

99. $\square$ Não sabe

14A.Problema

PROB2

88. $\square$ Não se aplica

99. $\square$ Não sabe

PROB3

15A.Problema

88. $\square$ Não se aplica

99. $\square$ Não sabe

PROB4

16A.Problema

88. $\square$ Não se aplica

99. $\square$ Não sabe

PROB5 


\section{ANTROPOMETRIA DO RN}

7B.Peso do RN: g

9999. $\square$ Não avaliado

PESONASC

8B.Comprimento: _-_-_ cm

999. $\square$ Não avaliado

9B.Perimetro cefálico: ___·_ $\mathrm{cm}$

999. $\square$ Não avaliado

10B.Peso da placenta: _. _ _ _ kg

9999. $\square$ Não avaliado
COMPNASC

PCNASC

PLACENTA

CORDAO

SALIVA
प्वप्र

$\square \square \square$

$\square \square \square$

प्वप्र

\section{MATERIAL BIOLÓGICO DO RN}
11B.Foi feita coleta de tecido do cordão umbilical?
1. $\square \operatorname{Sim}$
2. $\square$ Não
12B.Foi feita coleta de saliva?
1. $\square \mathrm{Sim}$
2. $\square$ Não 


\section{(U) BR/SA QUESTIONÁRIO dO NASCIMENTO - MÃE COORTE DE NASCIMEN FO BRASHLERA}

\section{BLOCO A - DADOS DE IDENTIFICACÃO}

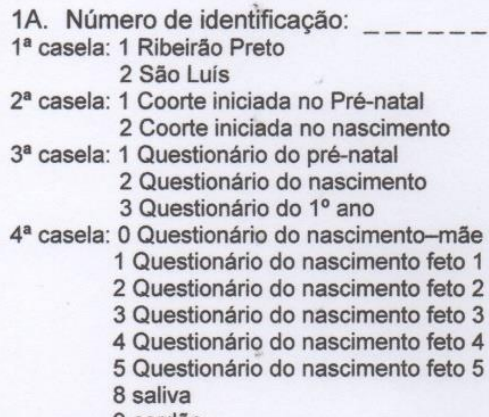

1A. Número de identificação:

$1^{\text {a }}$ casela: 1 Ribeirăo Preto

2 São Luís

$2^{\mathrm{a}}$ casela: 1 Coorte iniciada no Pré-natal

2 Coorte iniciada no nascimento

$3^{\text {a }}$ casela: 1 Questionário do pré-natal

2 Questionário do nascimento

3 Questionário do $1^{\circ}$ ano

$4^{\text {a }}$ casela: 0 Questionário do nascimento-mãe

1 Questionário do nascimento feto 1

2 Questionário do nascimento feto 2

3 Questionário do nascimento feto 3

4 Questionário do nascimento feto 4

5 Questionário do nascimento feto 5

8 saliva

$5^{\mathrm{a}}$ à $8^{\mathrm{a}}$. casela: número seqüencial para cada cidade

2A. Cidade:

1. $\square$ Ribeirão Preto

2. $\square$ São Luís

3A. Coorte

1. $\square$ Iniciada no Pré-natal

2. $\square$ Iniciada no Nàscimento

4A. Data da Entrevista (DD/MM/AAAA): _- '

Entrevistador (a)

5A. Hospital de Nascimento:

5A. Hospital de Nascimento:
\begin{tabular}{|l|l|}
\hline \multicolumn{1}{|c|}{ SÃO LUIS } & \multicolumn{1}{|c|}{ RIBEIRÃO PRETO } \\
1. $\square$ HU Materno- Infantil & 12. $\square$ Hospital das Clínicas \\
2. $\square$ Benedito Leite & 13. $\square$ Hospital Ribeirânia \\
3. $\square$ Marly Sarney & 14. $\square$ Hospital São Lucas \\
4. $\square$ Santa Casa & 15. $\square$ Hospital Santa Lydia \\
5. $\square$ Maria do Amparo & 16. $\square$ Hospital Santa Casa \\
6. $\square$ N Sra da Penha & 17. $\square$ Mater \\
7. $\square$ Clínica São Marcos & 18. $\square$ H. Sinhá Junqueira \\
8. $\square$ Clínica Luiza Coelho & 19. $\square$ Hospital São Paulo \\
9. $\square$ Hospital S Domingos & \\
10. $\square$ Hospital Aliança & \\
11. $\square$ Cínica São José &
\end{tabular}

6A. Nome completo da mãe do RN (não abreviar):

7A. Data de nascimento da mãe do RN (DD/MM/AAAA):

- '
NUMERO

\section{ㅁㅁㅁㅁㅁ}

CIDADE

COORTE

DATAENT

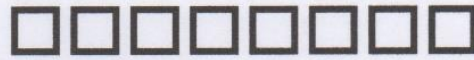

HOSPITAL

NOMEMAE

DNMAE 


\section{BLOCO C-DADOS SOCIOECONÔMICOS E DEMOGRÁFICOS}

1C. A sra. sabe ler e escrever?

1. $\square$ Sim

2. $\square$ Não

9. $\square$ Não sabe

LERMAE

2C. A sra. frequenta ou frequentou escola?

1. $\square$ Sim

2. $\square$ Não Passe para a questão $6 \mathrm{C}$

9. $\square$ Não sabe

ESCOLMAE

3C. A sra. ainda estuda?

1. $\square$ Sim

2. $\square$ Não

8. $\square$ Não se aplica

9. $\square$ Não sabe

MAEESTUDA

4C. Qual foi o último curso que a sra frequentou ou frequenta?

1. $\square$ Alfabetização de jovens e adultos

2. $\square$ Ensino fundamental ou 10 grau

3. $\square$ Ensino médio ou 20 grau

4. $\square$ Superior graduação incompleto Passe para a questão 6C

5. $\square$ Superior graduação completo Passe para a questäo $6 \mathrm{C}$

8. $\square$ Não se aplica

9. $\square$ Não sabe

CURSOMAE

5C. Até que série a sra. frequentou ou ainda frequenta?

1. $\square$ Primeira

2. $\square$ Segunda

3. $\square$ Terceira

4. $\square$ Quarta

5. $\square$ Quinta

6. $\square$ Sexta

7. $\square$ Sétima

8. $\square$ Oitava

88. $\square$ Não se aplica

99. $\square$ Não sabe

6C. Qual a cor da sua pele?

1. $\square$ branca

2. $\square$ preta/negra

3. $\square$ parda/mulata/cabocla/morena

4. $\square$ amarelo/oriental

5. $\square$ indígena

9. $\square$ não sabe

SERIEMAE

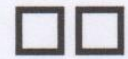

CORMAE 
7C. Qual a situação conjugal atual da sra.?
1. $\square$ Casada
2. $\square$ União consensual (Mora junto)
3. $\square$ Solteira
4. $\square$ Separada/desquitada/divorciada
5. $\square$ Viúva
9. $\square$ Não sabe

SITCONMAE

8C. Quantas pessoas vivem atualmente na casa onde a sra. mora? (Considere apenas as pessoas que estão morando na casa há pelo menos 3 meses, e que não são temporários, como um tio que está temporariamente vivendo com a sra. por menos de 3 meses ou visitantes).

99. $\square$ Não sabe

9C.A sra. mora atualmente com o marido ou companheiro?
1. $\square \mathrm{Sim}$
2. $\square$ Não
9. $\square$ Não sabe

10C. A sra. mora atualmente com filhos (biológicos ou não)?

1. $\square \mathrm{Sim}$

2. $\square$ Não Passe para a questão $12 \mathrm{C}$

9. $\square$ Não sabe

11C. Caso sim, com quantos filhos?

88. $\square$ Não se aplica

99. $\square$ Não sabe

12C. A sra. mora atualmente com outros familiares?

1. $\square \mathrm{Sim}$

2. $\square$ Não Passe para a questão $14 \mathrm{C}$

9. $\square$ Não sabe

13C. Caso sim, com quantos familiares? _-

88. $\square$ Não se aplica

99. $\square$ Não sabe

$14 \mathrm{C}$. A sra. mora atualmente com outras pessoas que não são familiares?
1. $\square \operatorname{Sim}$
9. $\square$ Não sabe
99. $\square$ Não sabe
1. $\square \mathrm{Sim}$
2. $\square$ Não
9. $\square$ Não sabe

2. $\square$ Não Passe para a questão $16 \mathrm{C}$

15C. Caso sim, com quantos não familiares?

88. $\square$ Não se aplica

16C. A sra. tem alguma religião ou culto? 
17C. Caso tenha alguma religião, qual é a sua religião?

1. $\square$ Católica

2. $\square$ Evangélica. Ex: Batista, Assembléia de Deus, Bethesda, Universal, Adventista ,Testemunha de Jeová, Luterana.

3. $\square$ Espírita/Kardecista

4. $\square$ Umbanda/Candomblé

5. $\square$ Judaica

6. $\square$ Orientais. Ex: Budista

7. $\square$ Outra, Qual?

88. $\square$ Não se aplica

99. $\square$ Não sabe

RELIGIAO

18C. A sra. exerce alguma atividade remunerada dentro ou fora de casa?

1. $\square \operatorname{Sim}$

2. $\square$ Não Passe para a questão $26 \mathrm{C}$

9. $\square$ Não sabe

ATIVREM

CASO NÃO TENHA ALGUMA ATIVIDADE REMUNERADA OU NÃO SAIBA, PASSE PARA A QUESTÃO $26 C$

19C. Qual a sua ocupação ( o que faz atualmente no trabalho)?

88. $\square$ Não se aplica

99. $\square$ Não sabe

OCUPMAE

20C. Qual a sua relação de trabalho?

1. $\square$ Trabalha por conta própria

2. $\square$ Assalariado ou empregado

3. $\square$ Dono de empresa-empregador

4. $\square$ Faz bico

8. $\square$ Não se aplica

9. $\square$ Não sabe

RELACAO

21C. Quantos dias por semana a sra. trabalhava com remuneração durante a gestação?

8. $\square$ Não se aplica

9. $\square$ Não sabe

22C. Nos dias de trabalho remunerado durante a gestação, quantas horas por dia a sra. trabalhava?
88. $\square$ Não se aplica

99. $\square$ Não sabe

HORATRAB

23C. Durante o seu trabalho, a sra. tinha que ficar em pé a maior parte do tempo?
1. $\square$ Sim
2. $\square$ Não
8. $\square$ Não se aplica
9. $\square$ Não sabe

DIATRAB 
24C. Durante o seu trabalho, a sra. tinha que levantar coisas pesadas?
1. $\square \mathrm{Sim}$
2. $\square$ Não
8. $\square$ Não se aplica
9. $\square$ Não sabe

$25 \mathrm{C}$. Há quantas semanas atrás a sra. parou de trabalhar?

00. $\square$ menos de 1 semana

88. $\square$ Não se aplica

99. $\square$ Não sabe

26C. Na sua casa, quem faz o trabalho de casa para sua familia?
1. $\square$ A sra. faz todo trabalho
2. $\square$ A sra. faz parte do trabalho
3. $\square$ Outra pessoa
9. $\square$ Não sabe

27C. Quem é a pessoa da família com maior renda atualmente? (considerar chefe da família aquele de maior renda)
1. $\square$ A entrevistada
Passe para a questão $36 \mathrm{C}$
2. $\square$ Companheiro

3. $\square$ Mãe

4. $\square$ Pai

5. $\square$ Avó

6. $\square$ Avô

7. $\square$ Madrasta

8. $\square$ Padrasto

9. $\square$ Tia

10. $\square$ Tio

11. $\square$ Irmã

12. $\square$ Irmão

13. $\square$ Outro

99. $\square$ Não sabe

CHEFE

28C. Qual o sexo da pessoa da família com maior renda?
1. $\square$ Masculino
2. $\square$ Feminino
8. $\square$ Não se aplica
9. $\square$ Não sabe

29C. Qual a idade da pessoa da família com maior renda (anos completos)?
88. $\square$ Não se aplica

99. $\square$ Não sabe

IDCHEFE 
30C. Essa pessoa sabe ler e escrever?

1. $\square \operatorname{Sim}$

2. $\square$ Não

8. $\square$ Não se aplica

9. $\square$ Não sabe

31C. Essa pessoa frequenta ou frequentou escola?

LERCHEFE

1. $\square \mathrm{Sim}$

2. $\square$ Não Passe para a questão 34C

8. $\square$ Não se aplica

9. $\square$ Não sabe

ESCCHEFE

32C. Qual foi o último curso que essa pessoa frequentou ou frequenta?

1. $\square$ Alfabetização de jovens e adultos

2. $\square$ Ensino fundamental ou $10 \mathrm{grau}$

3. $\square$ Ensino médio ou 20 grau

4. $\square$ Superior graduação incompleto Passe para a questão $34 \mathrm{C}$

5. $\square$ Superior graduação completo Passe para a questão $34 \mathrm{C}$

8. $\square$ Não se aplica

9. $\square$ Não sabe

33C. Qual a série que essa pessoa frequenta ou até que série frequentou?
1. $\square$ Primeira
2. $\square$ Segunda
3. $\square$ Terceira
4. $\square$ Quarta
5. $\square$ Quinta
6. $\square$ Sexta
7. $\square$ Sétima
8. $\square$ Oitava
88. $\square$ Não se aplica
99. $\square$ Não sabe

CURSOCHEFE

34C. Qual a ocupação atual (ou no que trabalha) a pessoa com a maior renda da família? (Descreva a ocupaçäo. Caso seja aposentado, colocar a última atividade que exerceu)

88. $\square$ Não se aplica

99. $\square$ Não sabe

35C. Qual a relação de trabalho do chefe da família?

OCUPCHEFE
1. $\square$ Trabalha por conta própria
2. $\square$ Assalariado ou empregado
3. $\square$ Dono de empresa-empregador
4. $\square$ Faz bico
8. $\square$ Não se aplica
9. $\square$ Não sabe

SERIECHEFE

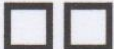




\section{BLOCO D - HÁBITOS DE VIDA}

Agora vamos conversar um pouco sobre o consumo de bebida alcoólica.

1D. Durante a gravidez, a sra. tomou cerveja?

1. $\square$ Sim

2. $\square$ Não Passe para a questão 14D

9. $\square$ Não sabe

CERVEJA

2D. Durante a gravidez, a sra. tomou cerveja nos três primeiros meses de gravidez?

1. $\square$ Sim

2. $\square$ Não Passe para a questão 6D

8. $\square$ Não se aplica

9. $\square$ Não sabe

3D. Quantos dias por semana?

8. $\square$ Não se aplica

9. $\square$ Não sabe

4D. Quanto tomava por dia (número de vasilhas)

88. $\square$ Não se aplica

99. $\square$ Não sabe

5D.Qual o tipo de vasilha?

1. $\square$ Copo comum $(200 \mathrm{ml})$

2. $\square$ Lata $(350 \mathrm{ml})$

3. $\square$ Garrafa pequena $(300 \mathrm{ml})$ - long neck

4. $\square$ Garrafa (600-720ml)

5. $\square$ Outro

8. $\square$ Não se aplica

9. $\square$ Não sabe

6D. Durante a gravidez a sra tomou cerveja dos 4 aos 6 meses

TIPOCERV1T de gravidez?
1. $\square \operatorname{Sim}$
2. $\square$ Não Passe para a questão 10D
8. $\square$ Não se aplica
9. $\square$ Não sabe
CERVEJA2T
7D. Quantos dias por semana?
8. $\square$ Não se aplica
9. $\square$ Não sabe
8D. Quanto tomava por dia (número de vasilhas)
88. $\square$ Não se aplica
99. $\square$ Não sabe
DIACERV2T
QTCERV2T

CERVEJA1T

DIACERV1T

QTCERV1T 
9D. Qual o tipo de vasilha?
1. $\square$ Copo comum $(200 \mathrm{ml})$
2. $\square$ Lata (350ml)
3. $\square$ Garrafa pequena $(300 \mathrm{ml})$ - long neck
4. $\square$ Garrafa (600-720ml)
5. $\square$ Outro
8. $\square$ Não se aplica
9. $\square$ Não sabe

TIPOCERV2T

10D. Durante a gravidez a sra. tomou cerveja dos 7 meses ao final da gravidez?
1. $\square$ Sim
2. $\square$ Não Passe para a questão 14D
8. $\square$ Não se aplica
9. $\square$ Não sabe
11D. Quantos dias por semana?
8. $\square$ Não se aplica
9. $\square$ Não sabe

12D. Quanto tomava por dia (número de vasilhas) _-

88. $\square$ Não se aplica

99. $\square$ Não sabe

13D. Qual o tipo de vasilha?

1. $\square$ Copo comum (200ml)

2. $\square$ Lata (350ml)

3. $\square$ Garrafa pequena $(300 \mathrm{ml})$ - long neck

4. $\square$ Garrafa (600-720ml)

5. $\square$ Outro

8. $\square$ Não se aplica

9. $\square$ Não sabe

14D. Durante a gravidez a sra tomou vinho?

1. $\square \operatorname{Sim}$

2. $\square$ Não Passe para a questão 27D

9. $\square$ Não sabe

15D. Durante a gravidez a sra tomou vinho nos três primeiros meses de gravidez?
1. $\square \operatorname{sim}$
2. $\square$ Não Passe para a questão 19D
8. $\square$ Não se aplica
9. $\square$ Não sabe
16D. Quantos dias por semana?
8. $\square$ Não se aplica
9. $\square$ Não sabe

CERVEJA3T

DIACERV3T

QTCERV3T

TIPOCERV3T

VINHO

17D. Quanto tomava por dia (número de vasilhas) -

DIAVINHO1T

88. $\square$ Não se aplica

99. $\square$ Não sabe

QTVINHO1T

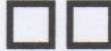


18D. Qual o tipo de vasilha?

1. $\square$ Copo comum $(200 \mathrm{ml})$

2. $\square$ Cálice ou taça $(400 \mathrm{ml})$

3. $\square$ Garrafa pequena $(300 \mathrm{ml})$

4. $\square$ Garrafa (600-720ml)

5. $\square$ Outro

8. $\square$ Não se aplica

9. $\square$ Não sabe

19D. Durante a gravidez a sra. tomou vinho dos 4 aos 6 meses

TIPOVINHO1T de gravidez?

1. $\square$ Sim

2. $\square$ Não Passe para a questão 23D

8. $\square$ Não se aplica

9. $\square$ Não sabe

20D. Quantos dias por semana?

8. $\square$ Não se aplica

9. $\square$ Não sabe

DIAVINHO2T

21D. Quanto tomava por dia (número de vasilhas)

88. $\square$ Não se aplica

99. $\square$ Não sabe

22D. Qual o tipo de vasilha?

1. $\square$ Copo comum (200ml)

2. $\square$ Cálice ou taça $(400 \mathrm{ml})$

3. $\square$ Garrafa pequena $(300 \mathrm{ml})$

4. $\square$ Garrafa (600-720ml)

5. $\square$ Outro

8. $\square$ Não se aplica

9. $\square$ Não sabe

23D. Durante a gravidez a sra. tomou vinho dos 7 meses ao final da gravidez?

1. $\square$ Sim

2. $\square$ Não Passe para a questão 27D

8. $\square$ Não se aplica

9. $\square$ Não sabe

VINHO3T

24D. Quantos dias por semana?

8. $\square$ Não se aplica

9. $\square$ Não sabe

25D. Quanto tomava por dia (número de vasilhas)

88. $\square$ Não se aplica

99. $\square$ Não sabe

QTVINHO2T

DIAVINHO3T

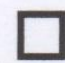

QTVINHO3T 
26D. Qual o tipo de vasilha?

1. $\square$ Copo comum (200ml)

2. $\square$ Cálice ou taça $(400 \mathrm{ml})$

3. $\square$ Garrafa pequena $(300 \mathrm{ml})$

4. $\square$ Garrafa (600-720ml)

5. $\square$ Outro

8. $\square$ Não se aplica

9. $\square$ Não sabe

TIPOVINHO3T

27D. Durante a gravidez a sra. tomou algum outro tipo de bebida como uisque, vodka, gim, rum?

1. $\square \operatorname{Sim}$

2. $\square$ Não Passe para a questão 40D

9. $\square$ Não sabe

DEST

28D. Durante a gravidez a sra. Tomou algum outro tipo de gravidez?

1. $\square \mathrm{Sim}$

2. $\square$ Não Passe para a questão 32D

8. $\square$ Não se aplica

9. $\square$ Não sabe

29D.Quantos dias por semana?

8. $\square$ Não se aplica

9. $\square$ Não sabe

30D. Quanto tomava por dia (número de vasilhas) _-

88. $\square$ Não se aplica

99. $\square$ Não sabe

QTDEST1T

31D. Qual o tipo de vasilha?

1. $\square$ Copo comum (200ml)

2. $\square$ Cálice, taça (400 ml)

3. $\square$ Martelo, copo de pinga (100ml)

4. $\square$ Lata $(350 \mathrm{ml})$ retirar

5. $\square$ Garrafa pequena (300ml)

6. $\square$ Garrafa $(600-720 \mathrm{ml})$

7. $\square$ Outro

8. $\square$ Não se aplica

9. $\square$ Não sabe

32D. Durante a gravidez a sra tomou algum outro tipo de bebida como uisque, vodka, gim, rum dos 4 aos 6 meses de gravidez?

1. $\square$ Sim

2. $\square$ Não Passe para a questão 36D

8. $\square$ Não se aplica

9. $\square$ Não sabe

33D.Quantos dias por semana?

DEST1T

DIADEST1T

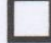

8. $\square$ Não se aplica

9. $\square$ Não sabe

TIPODEST1T

DEST2T

DIADEST2T 
34D. Quanto tomava por dia (número de vasilhas)

88. $\square$ Não se aplica

99. $\square$ Não sabe

QTDEST2T

35D. Qual o tipo de vasilha?

1. $\square$ Copo comum (200ml)

2. $\square$ Cálice, taça $(400 \mathrm{ml})$

3. $\square$ Martelo, copo de pinga (100ml)

4. $\square$ Lata (350ml)

5. $\square$ Garrafa pequena $(300 \mathrm{ml})$

6. $\square$ Garrafa (600-720ml)

7. $\square$ Outro

8. $\square$ Não se aplica

9. $\square$ Não sabe

36D. Durante a gravidez a sra tomou algum outro tipo de bebida como uisque, vodka, gim, rum dos 7 meses ao final da

gravidez?

1. $\square \mathrm{Sim}$

2. $\square$ Não Passe para a questão $40 \mathrm{D}$

8. $\square$ Não se aplica

9. $\square$ Não sabe

DEST3T

37D. Quantos dias por semana?

8. $\square$ Não se aplica

9. $\square$ Não sabe

38D. Quanto tomava por dia (número de vasilhas) _-

DIADEST3T

88. $\square$ Não se aplica

99. $\square$ Não sabe

TIPODEST2T

39D. Qual o tipo de vasilha?

1. $\square$ Copo comum (200ml)

2. $\square$ Cálice, taça (400 ml)

3. $\square$ Martelo, copo de pinga (100ml)

4. $\square$ Lata (350ml)

5. $\square$ Garrafa pequena $(300 \mathrm{ml})$

6. $\square$ Garrafa (600-720ml)

7. $\square$ Outro

8. $\square$ Não se aplica

9. $\square$ Não sabe

TIPODEST3T

Agora vamos conversar um pouco sobre o hábito de fumar.

40D. A sra. tem ou teve o hábito de fumar cigarros?

1. $\square \mathrm{Sim}$

2. $\square$ Não Passe para a questão 51D

9. $\square$ Não sabe

HABITOFUMO 
$5 \mathrm{~F}$. Quantas vezes a sra. engravidou? (incluindo a gravidez atual) Contar todas as gestações até as que não chegaram no final, inclusive abortos.

99. $\square$ Não sabe

GESTA

$6 \mathrm{~F}$. A gravidez atual foi planejada?

1. $\square \mathrm{Sim}$

2. $\square$ Não

9. $\square$ Não sabe

7F. Quantos filhos nasceram vivos (incluindo o atual)?

99. $\square$ Não sabe

8F. Qual a idade da sra. no início da gestação anterior?

98. $\square$ Não se aplica

99. $\square$ Não sabe

9F. Quantos partos a sra. teve (incluindo o atual)?

99. $\square$ Não sabe

10F. Quantos partos foram cesáreas (incluindo o atual, caso tenha sido cesárea)?

9. $\square$ Não sabe

11F. O parto anterior da sra. foi:

1. $\square$ Vaginal/Naginal com fórceps

2. $\square$ Cesárea

8. $\square$ Não se aplica

9. $\square$ Não sabe

TIPARTOANT

12F. Quantos partos anteriores da sra. foram antes do tempo (prematuros) incluindo o atual?

9. $\square$ não sabe

13F. A sra. teve algum aborto?

1. $\square \operatorname{Sim}$

2. $\square$ Não Passe para questão $15 \mathrm{~F}$

9. $\square$ Não sabe

14F. Caso sim, quantos abortos foram?

8. $\square$ Não se aplica

9. $\square$ Não sabe

$15 \mathrm{~F}$. A sra teve algum filho que nasceu morto (incluir atual)?

1. $\square$ Sim

2. $\square$ Não Passe para a questão $17 \mathrm{~F}$

9. $\square$ Não sabe

16F. Caso sim, quantos foram (incluir atual)?

8. $\square$ Não se aplica

9. $\square$ Não sabe

PLANGEST

NASCVIVO

IDULTGEST

$\square \square$

PARTOS

PARTOCESA

PARTOANTPT

ABORTO

$\square$

$\square \square$

$\square$

$\square$

$17 \mathrm{~F}$. Quantos filhos vivos a sra. tem atualmente?

99. $\square$ Não sabe

NASCMORTO

QTMORTO

NFILHOS 
$49 \mathrm{H}$. Fez fertilização in vitro (bebê de proveta)?

1. $\square$ Sim

2. $\square$ Não

8. $\square$ Não se aplica

9. $\square$ Não sabe

FERTILIZA

$50 \mathrm{H}$. Fez injeção de espermatozóides?

1. $\square \mathrm{Sim}$

2. $\square$ Não

8. $\square$ Não se aplica

9. $\square$ Não sabe

INJECAO

\section{BLOCOI - CARACTERÍSTICAS DO PARTO E DO NASCIMENTO}

11. Qual foi o tipo de parto?

1. $\square$ Normal

2. $\square$ Cesárea

3. $\square$ Fórceps

4. $\square$ Vácuo extração

9. $\square$ Não sabe

21. Se normal, a sra. fez episiotomia (corte, pique)?

TIPARTO

1. $\square \operatorname{Sim}$

2. $\square$ Não

8. $\square$ Não se aplica

9. $\square$ Não sabe

31. Quantas horas decorreram entre a internação e o parto

EPISIO normal?

88. $\square$ Não se aplica

99. $\square$ Não sabe

4I. Foi feita anestesia nas costas?

HORASPARTO

$\square \square$

1. $\square \operatorname{sim}$

2. $\square$ Não

9. $\square$ Não sabe

ANESTESIA 
QUESTIONÁRIO DO $1^{\circ}$ ANO ENTREVISTA

OBRISA

Etiqueta

\section{BLOCO A - DADOS DE IDENTIFICACÃO}

1A. Número de identificação:

1a casela: 1 Ribeirão Preto

2 São Luís

$2^{\mathrm{a}}$ casela: 1 Pré-natal

2 Nascimento

$3^{a}$ casela: F. Avaliação da mãe no $1^{\circ}$ ano

A. Avaliação no $1^{\circ}$ ano RN 1

B. Avaliação no $1^{\circ}$ ano RN 2

C. Avaliação no $1^{\circ}$ ano RN 3
D. Avaliação no $1^{\circ}$ ano RN 4

$4^{\mathrm{a}}$ e $5^{\mathrm{a}}$ caselas: QG. Questionário geral da criança

QM. Questionário de saúde da mulher

QP. Questionário da psiquiatria

SG. Sangue

SR. Soro

HM. Hemograma da criança

TB. Teste de Bayley

AO. Avaliação Odontológica

ID. Identificação

NT. Questionário nutricional

6a à 9a. caselas: número seqüencial para cada cidade (colocar o mesmo número seqüencial do nascimento)

2A. Cidade:

01. $\square$ Ribeirão Preto

02. $\square$ São Luís

3A. Data da Entrevista (DD/MM/AAAA):

Entrevistador (a):

4A. Nome completo da mãe (não abreviar):

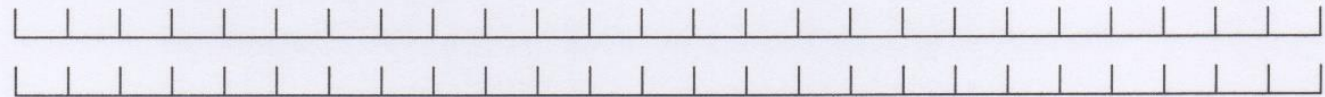

5A. Nome completo da criança (não abreviar):

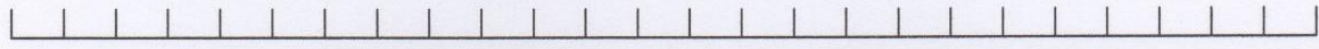

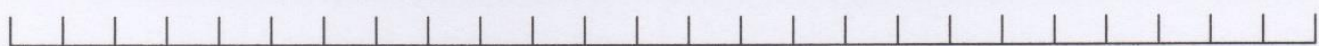


1C. Qual a cor de <CRIANÇA $>$ ?
01. $\square$ Branca
02. $\square$ Preta/negra
03. $\square$ Parda/mulata/cabocla/morena
04. $\square$ Amarelo/oriental
05. $\square$ Índigena
09. $\square$ Não sabe

2C. <CRIANÇA > vai à escolinha ou creche?
01. $\square \mathrm{Sim}$
02. Não Passe para a questão $4 \mathrm{C}$
09. $\square$ Não sabe Passe para a questão $4 \mathrm{C}$

3C. Se sim, desde que idade <CRIANÇA> frequenta a escolinha ou creche? $\downarrow \backslash \downarrow$ meses

88. $\square$ Não se aplica

99. $\square$ Não sabe

4C. A criança ONTEM recebeu leite do peito?

01. $\square$ Sim Passe para a questão 6C

02. $\square$ Não

09. $\square$ Não sabe

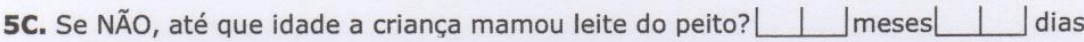

88. $\square$ Não se aplica (nunca mamou)

99. $\square$ Não sabe

6C. Até que idade seu filho ficou em aleitamento materno exclusivo? (ler para a mãe: aleitamento materno exclusivo é só leite do peito, sem chá, água, outros leites, outras bebidas ou alimentos)

$\bigsqcup \perp$ meses $\bigsqcup \perp$ dias

88. $\square$ Não se aplica

99. $\square$ Não sabe

7C. Considerando apenas os últimos três meses, a senhora tem o.hábito de oferecer o peito para $<$ CRIANÇA > depois que ele(a) já adormeceu à noite

01. $\square$ Sim

02. $\square$ Não

08. Não se aplica

09. $\square$ Não sabe

Quando a senhora inseriu estes alimentos ou bebidas na rotina alimentar de <CRIANÇA >?

8C. Leite (líquido ou pó)

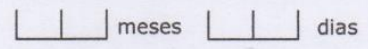

88. $\square$ Nunca

99. $\square$ Não sabe

9C. Leite tipo fórmula?

$\bigsqcup \perp$ meses $\bigsqcup \perp$ dias

88. $\square$ Nunca

99. $\square$ Não sabe

10C. Outros líquidos (chás, sucos)

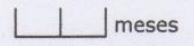

88. $\square$ Nunca

99. $\square$ Não sabe

11C. Semi-sólido ou sólido?

$\bigsqcup \perp\rfloor$ meses $\downarrow \perp\rfloor$ dias

88. $\square$ Nunca $\quad 99 . \square$ Não sabe

12C. A Sra. usa açúcar (ou mel, nescau, toddy ou algo doce) para adoçar alguns desses alimentos?
01. $\square$ Sim
08. $\square$ Não se aplica
09. $\square$ Não sabe

13C. Considerando apenas os últimos três meses, <CRIANÇA> costuma usar mamadeira durante a noite, após já ter adormecido?
01. $\square \mathrm{Sim}$
02. $\square$ Não
08. Não se aplica
09. ए Não sabe 
14C. Atualmente $<$ CRIANÇA $>$ usa chupeta?

01. $\square$ Sim usa atualmente

02. Não, parou de usar

03. Nunca usou Passe para a questão $18 \mathrm{C}$

09. $\square$ Não sabe

15C. Qual era a idade da $\angle$ CRIANÇA $>$, quando começou a usar chupeta? $L \perp$ meses $L \perp$ dias 88. $\square$ Não se aplica

99. $\square$ Não sabe

16C. Qual o tipo de chupeta $<$ CRIANÇA $>$ usava?

01. $\square$ Ortodôntica

02. $\square$ Convencional

08. $\square$ Não se aplica

09. $\square$ Não sabe

17C. Quando parou de usar chupeta?

$\llcorner\perp\rfloor$ meses $L \perp\rfloor$ dias

88. $\square$ Não se aplica

99. $\square$ Não sabe

18C. <CRIANÇA > chupa dedo?

01. $\square$ Sim chupa atualmente

02. $\square$ Não, parou de chupar

03. $\square$ Nunca chupou Passe para a questão 1D

09. $\square$ Não sabอ

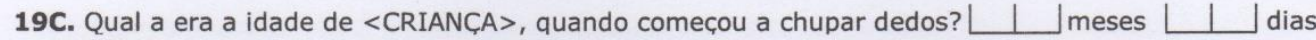
88. $\square$ Não se aplica

99. $\square$ Não sabe

20C. Quando parou de chupar dedo? $\lfloor\perp\rfloor$ meses $\lfloor\perp\rfloor$ dias

88. $\square$ Não se aplica

99. $\square$ Não sabe

BLOCO D -SAÚDE DA CRIANÇA

Agora vou fazer algumas perguntas sobre como está a saúde da <CRIANÇA>

1D. Em geral, a Sra. considera a saúde de <CRIANÇA >:
01. $\square$ Excelente
02. Muito Boa
03. $\square$ Boa
04. Regular
05. $\square$ Ruim
09. $\square$ Não sabe

2D. CRIANCCA > teve tosse desde < dia da semana > da semana passada?
01. $\square$ Sim
02. $\square$ Não
09. $\square$ Não sabe

3D. <CRIANCCA> teve respiração difícil desde < dia da semana > da semana passada?

01. $\square$ Sim

02. Não

09. $\square$ Não sabe

Passe para a questão $8 \mathrm{D}$ 
9E. A Sra. qastou alqum dinheiro com consultas médicas para <CRIANCQA>?

01. $\square$ Sim

02. $\square$ Não

09. $\square$ Não sabe

10E. A Sra. gastou algum dinheiro com exames complementares ou raio $X$ para $<$ CRIANCุA $>$ ?

01. $\square$ Sim

02. $\square$ Não

09. $\square$ Não sabe

11E. A Sra. gastou algum dinheiro com outras coisas relacionadas à saúde de $<$ CRIANÇA $>$ ?

(enfermeira, óculos, fisioterapia, dentista)

01. $\square$ Sim

02. Não Passe para a questão 1F

09. $\square$ Não sabe

12E. Se sim, qual (is)

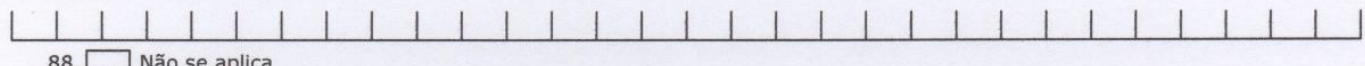

99. Não sabe

BLOCO F - DADOS SOCIOECONÔMICOS E DEMOGRÁFICOS

1F. A família recebe bolsa família ou algum outro benefício de transferência de renda do governo?

01. $\square$ Sim

02. Nã̃o para a questão $3 F$

09. $\square$ Não sabe

2F. Há quanto tempo recebe o benefício do governo? $\lfloor\perp\rfloor$ meses

88. $\square$ Não se aplica

99. $\square$ Não sabe

3F. Sua familia é cadastrada no Programa de Saúde da Família (PSF)?

01. $\square$ Sim

02. $\square$ Não

09. $\square$ Não sabe

Passe para a questão 9F

A Sra. recebeu visita do PSF no último mês pelo:

4F. Agente comunitário

5F. Médico

6F. Enfermeiro

7F. Auxiliar

8F. Dentista ou Auxiliar de dentista

01. $\square$ Sim 02. $\square$ Não $08 . \square$ Não se aplica $09 . \square$ Não sabe

01. $\square \operatorname{Sim}$ 02. $\square$ Não $08 . \square$ Não se aplica $09 . \square$ Não sabe

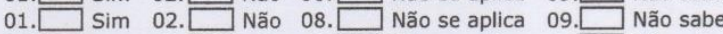

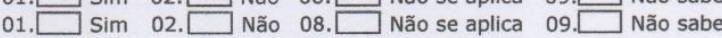

9F. Qual a situação conjugal atual da Sra.?
01. $\square$ Casada
03. Solteira
04. Separada/desquitada/divorciada
05. Viúva
09. $\square$ Não sabe

10F. Quantas pessoas vivem atualmente na casa onde a sra. mora? (Considere apenas as pessoas que estão morando na casa há pelo menos 3 meses, e que não são temporários, como um tio que está temporariamente vivendo com a sra. por menos de 3 meses ou visitantes).

$$
\text { 99. } \square \text { Não sabe }
$$

11F. A Sra. mora atualmente com o marido ou companheiro?
01. $\square \mathrm{Sim}$
02. $\square$ Não
09. $\square$ Não sabe

12F. Sra. exerce alguma atividade remunerada dentro ou fora de casa?
01. $\square \mathrm{Sim}$
02. $\square$ Não
09. $\square$ Não sabe
Passe para a questão $15 \mathrm{~F}$

1714611281

$12 / 17$ 
13F. Qual a sua ocupação (o que faz atualmente no trabalho)?

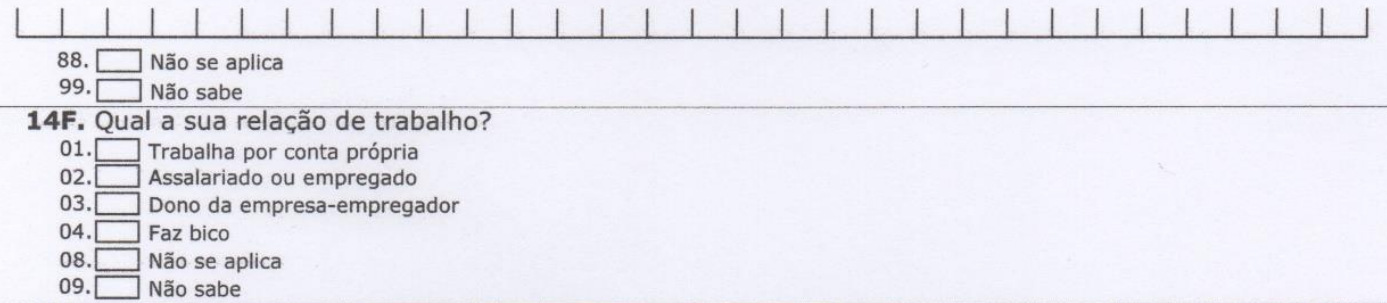

15F. Quem é a pessoa da família com maior renda atualmente? (considerar chefe da família aquele de maior renda). Considerar o parentesco em relação à criança (mãe DA CRIANÇA, pai DA CRIANÇA, etc.)
01. $\square$ Mãe
04. $\square$ Avô
05. Avô
06. Padrasto
07. Tia
08. Tio
09. Irmã
10. Irmão
11. Outro

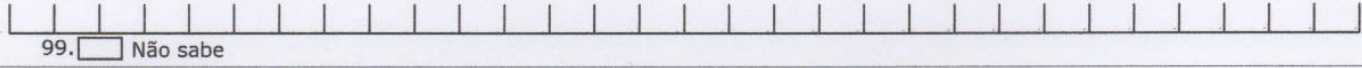

16F. Qual a idade da pessoa da família com maior renda (anos completos)?

$$
1+1 \mid \text { | } 1 \text { Não sabe }
$$

17F. Essa pessoa sabe ler e escrever?

01. $\square$ Sim

02. Não

09. $\square$ Não sabe

18F. Essa pessoa frequenta ou frequentou escola?

02. $\square$ Não

09. $\square$ Não sabe

Passe para a questão 21F

19F. Qual foi o último curso que essa pessoa frequentou ou frequenta?

01. $\square$ Alfabetização de jovens e adultos

02. Ensino fundamental ou $1^{\circ} \mathrm{grau}$

03. Ensino médio ou $2^{\circ} \mathrm{grau}$

04. Superior graduação incompleto Passe para a questão $21 \mathrm{~F}$

05. Superior graduação completo Passe para a questão 21F

08. Não se aplica

09. $\square$ Não sabe

20F. Qual a série que essa pessoa frequenta ou até que série frequentou?
01. $\square$ Primeira
02. Segunda
03. $\square$ Terceira
04. $\square$ Quarta
05. Quinta
06. $\square$ Sexta
07. Sétima
08. $\square$ Oitava
88. $\square$ Não se aplica
99. $\square$ Não sabe

21F. Qual a ocupação atual (ou no que trabalha) a pessoa com a maior renda da família? (Descreva a ocupação. Caso seja aposentado, colocar a última atividade que exerceu).

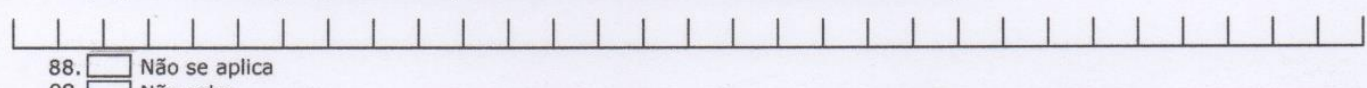
99. $\square$ Não sabe 
22F. Qual a sua relação de trabalho do chefe da família?

01. $\square$ Trabalha por conta própria

02. $\square$ Assalariado ou empregado

03. $\square$ Dono da empresa-emnpregador

04. $\square$ Faz bico

08. $\square$ Não se aplica

09. $\square$ Não sabe

23F. No mês passado quanto qanharam as pessoas da família que trabalham?

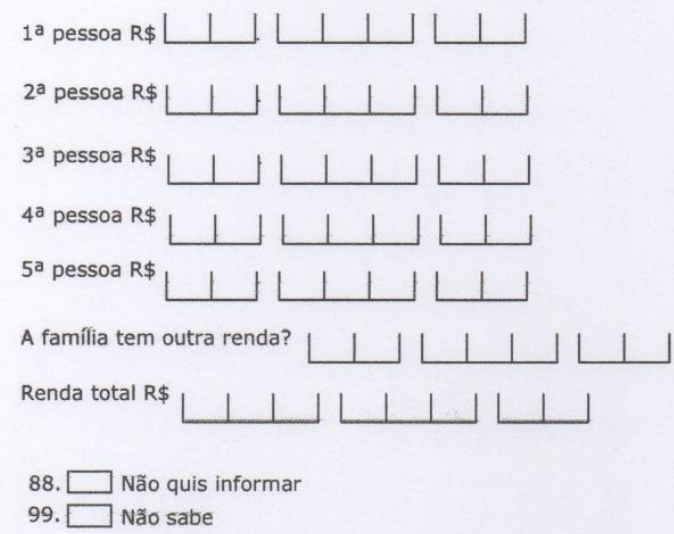

Quantos itens abaixo a família possui? (assinale no quadrado)

24F. Televisão em cores

25F. Rádio

26F. Banheiro

27F. Automóvel

28F. Empregada

29F. Máquina de lavar

30F. Videocassete ou DVD

31F. Geladeira

32F. Freezer (aparelho independente ou parte da geladeira duplex)

\begin{tabular}{|c|c|c|c|c|}
\hline \multicolumn{5}{|c|}{ Ouantidade de itens } \\
\hline 0 & 1 & 2 & 3 & 4 ou mais \\
\hline 0 & 1 & 2 & 3 & 4 \\
\hline 0 & 1 & 2 & 3 & 4 \\
\hline 0 & 4 & 5 & 6 & 7 \\
\hline 0 & 4 & 7 & 9 & 9 \\
\hline 0 & 3 & 4 & 4 & 4 \\
\hline 0 & 2 & 2 & 2 & 2 \\
\hline 0 & 2 & 2 & 2 & 2 \\
\hline 0 & 4 & 4 & 4 & 4 \\
\hline 0 & 2 & 2 & 2 & 2 \\
\hline
\end{tabular}

33F. Grau de Instrução da pessoa com maior renda (circule a resposta)

\begin{tabular}{|l|l|}
\hline Analfabeto/Primário incompleto/ Até 3a Série Fundamental & 0 \\
\hline Primário completo/ Até 4a Série Fundamental/Ginasial incompleto & 1 \\
\hline Ginasial completo/ Fundamental completo/Coleqial incompleto & 2 \\
\hline Colegial completo/ Médio completo/Superior incompleto & 4 \\
\hline Superior completo & 8 \\
\hline
\end{tabular}


14H. Os dentes de <CRIANÇA > são escovados ou limpos à noite depois do último alimento (ou amamentação no peito ou mamadeira) antes de colocá-lo(a) para dormir?
01. Sim, sempre
02. $\square$ As vezes
03. $\square$ Não
08. $\square$ Não se aplica
09. $\square$ Não sabe

15H. <CRIANÇA> já foi levada para consultar com dentista?

01. $\square \operatorname{sim}$

02. $\square$ Não

09. $\square$ Não sabe

Passe para a questão $17 \mathrm{H}$

16H. Qual o motivo principal de <CRIANCุA > ter sido levado ao dentista?

01. $\square$ Para aplicação de Flúor e orientação sobre prevenção

02. Devido a presença de cárie dentária

03. Para verificar porque os dentes não estavam nascendo

04. Porque bateu a boca e machucou/quebrou dente

05. $\square$ outro motivo

$+1+1+1+1+1+1+1+1+1+1+1+1+1+1$

08. $\square$ Não se aplica

09. $\square$ Não sabe

17H. Como você classificaria hoje a saúde dos dentes de <CRIANÇA >?
01. $\square$ Excelente
02. $\square$ Boa
03. $\square$ Razoáve
04. $\square$ Ruim
05. Péssima
08. Não se aplica
09. $\square$ Não sabe

\section{BLOCO I - EXAME CLÍNICO DA CRIANCA}

1I. Peso

2I. Comprimento

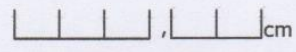

3I. Perímetro cefálico

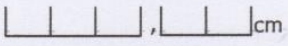

4I. Circunferência da abdominal

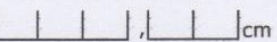

51. Coleta de sanque da críança?

$01 . \square$ Sim
$02 . \square$ Não 


\section{BLOCO M - EXAME CLÍNICO DA MÃE E DADOS DO PAI DA CRIANÇA}

1M. Altura do pai da <CRIANÇA $>$

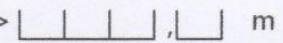

99. $\square$ Não sabe

2M.Peso do Pai da <CRIANÇA $>$

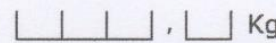

99.

3M. Circunferência đa cintura (mãe)

$\lfloor 1+\mathrm{cm}$

\section{Colocar os dados da Tanita}

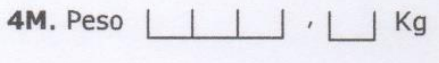

5M. Altura $\downarrow \perp \perp, \downarrow \mid \mathrm{m}$

6M.Gordura Corporal L」 」, 」

7M. Agua $\downarrow \perp \quad \downarrow$ \%

8M. Gordura Viceral $\lfloor\perp\rfloor,\llcorner\quad \%$

9M. Massa muscular $L \perp \perp, L$ Kg

10M. Massa óssea $L \perp \perp, L$ kg

11M. Idade metabólica $\downarrow \perp\rfloor$ anos 